\title{
Modelos de Rede de Filas para Sistemas Computacionais Distribuídos Simulação X Métodos Analíticos
}

\author{
Andrezza Rodrigues Filizzola da Silva
}

Orientador: Prof. Dr. Marcos José Santana

Dissertação apresentada ao Instituto de Ciências Matemáticas e de Computação - ICMC-USP, como parte dos requisitos para obtenção do título de Mestre em Ciências - Área: Ciências de Computação e Matemática Computacional. 
"Não se faz a caminhada sozinho. Há outros caminhantes ao nosso lado. Há cantos de alegria e lamento de dor que chegam aos nossos ouvidos. São os companheiros que se unem ao nosso destino. Juntos nos entre-ajudamos. Enxugamos o suor de muitas frontes e palavras de coragem, de compreensão $e$ de perdão chegam aos nossos ouvidos. E um peregrino misterioso vem se associar ao nosso caminhar. Juntos olhamos para horizontes com gosto de amanhã" (Anônimo) 


\section{Dedicatória}

Ao Wilton, amor da minha vida, por seu amor e compreensão e por ser meu companheiro e amigo incansável. Te amo muito! 


\section{Agradecimentos}

Puxa! Eu tenho tanto e tanta gente a agradecer...Bem, primeiramente, à Deus, por ter me dado força e coragem para seguir em frente sempre.

Ao Wilton, meu amor, que, mesmo estando longe, nunca deixou de me ajudar nesses dois anos de mestrado. Sempre que precisei, lá estava ele, ouvindo-me, aconselhando-me, apoiando-me, chamando-me a atenção, sorrindo e chorando comigo... Adoro a forma como enfrentamos os obstáculos que em nossas vidas aparecem e a forma como resolvemos nossos problemas. Agradeço sempre a Deus por seu amor. A certeza do nosso amor me deu forças para suportar a distância. Mozão, sem você eu não teria conseguido! Te amo!

À minha mãe, por ter me ensinado a enfrentar os momentos dificeis da vida, a agir sempre com muita dignidade e honestidade, por suas palavras sábias, que estavam sempre me encorajando e confortando. Digo isso não só por esses dois últimos anos, mas por toda a minha vida, já que sempre pude contar com o seu "colo". Mãe, tudo que sou hoje devo a senhora, que, com muita sabedoria, sempre fez tudo em meu beneficio. Seu apoio e compreensão foram fundamentais, não só nesses dois anos de mestrado. Te amo!

À minha vó Micas, a matriarca da família, por todo apoio e carinho, que foram essenciais durante dota minha vida, especialmente nesse dois anos de mestrado. Vó, te amo e obrigada por tudo! Sou grata também ao meu avô Eduardo, que deixou à nossa família uma lição de coragem e integridade.

À minha tia Antonieta, outra pessoa sem a qual esse mestrado não teria acontecido, já que sempre me possibilitou estudar em bons colégios e conseqüentemente entrar numa universidade. Ela é o meu anjinho da guarda, pois desde que me entendo, pude contar com seu apoio, compreensão, conselhos, atenção e principalmente com seu amor. Eu a tenho como uma segunda mãe. Tia, também te amo!

Ao meu tio Carlos, que também tem sido um anjinho para mim. Sem ele esses dois anos teriam sido mais dificeis. Tio, também te amo e obrigada por tudo!

Aos meus outros tios, que já devem estar com ciúmes: tia Isabel, tia Eduarda e tio Reinaldo, que sempre estiveram por perto fazendo com que a minha vida estivesse sempre agradável. Nunca canso de agradecer a Deus pela união da nossa família. Amo vocês!

À todos da minha família que torceram e rezaram por mim.

Ao Santana e Regina, por me possibilitarem alcançar um de meus grandes objetivos: o mestrado. Em especial, ao professor Santana, meu grande orientador, que soube me acalmar e fazer com que eu seguisse o caminho correto. Cada dia que passa, fico mais impressionada 
com o seu conhecimento e intuição, que tantas vezes me ajudaram. Professor, fica aqui o meu muito obrigada por tudo! (Acho que ele diria: "Por nada, Aluna!"(-))

À querida professora Creusa, por estar sempre disposta a me ajudar, até mesmo em suas férias, e pelos momentos de descontração. Muito obrigada mesmo!

À Aleteia, minha mais recente amizade, que apesar de ter pouco tempo, já me fez tão bem! Nossa amizade é uma das conquistas que levarei desse mestrado. Sinto muita falta da sua companhia, mas suas orações, incentivos e palavras amigas estavam sempre me confortando, o que foi muito importante para a conclusão do meu mestrado.

Às minhas amigas do peito, Déia e Ionita, pelo carinho e incentivo de todos esses anos de nossa amizade, que foram importantíssimos nesses dois anos. É muito bom poder contar com vocês!

À República Tcheca e Kosovo: Selma, Maju, Flávia e Jorge, por termos formado uma "família", e não uma república simplesmente. Vocês vão sempre estar nas minhas lembranças e no meu coração! Especialmente, ao meu super amigo Jorge, que já é meu amigo há muito tempo e por isso sempre soube como me ajudar, especialmente nesses dois anos de mestrado, período em que suas palavras amigas foram essenciais. Ah! E também aos associados da República: Sílvio e Rudinei.

À Mayb e Camilo, pelos churrascos regados a muito papo e boas gargalhadas, que durante esses dois anos alegraram nossos fins de semana. Especialmente, à Mayb por ter se revelado uma grande amiga.

Ao Jorge e Laura, que me receberam em sua casa, ainda que recém casados e que estavam sempre ao meu lado nos momentos de tensos de final de mestrado. Serei eternamente grata à vocês, meus amigos!

Ao Jorge, Aleteia, Renato, Alex, Alessandro, Thienne, Daniel e Dennys, pelos inesqueciveis momentos de gargalhada e patos no tucupí. É sempre muito bom ter gente da "terrinha" por perto.

A todos os amigos que conviveram comigo na USP: Aleteia, Jorge, Daniel, Renato, Reji, Márcio, Renata, Roberta, Paulo, Simone, Célia, Kalinka, Tatiana, Edmilson, Paulo, Simone, Omar, Adriana, Fernanda, Álvaro, Ricardo, Tomaz, etc.., pelos churrascos e "leitinhos" da vida. Ao William, da matemática. Meu obrigada a todos! Especialmente à Sarita e Célia, que se mostraram sempre prontas a me ajudar.

À Cnpq, pelo auxílio finaceiro, sem o qual esse mestrado seria impraticável. 


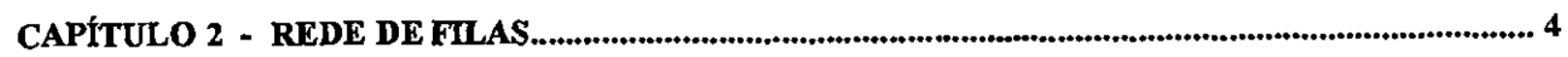

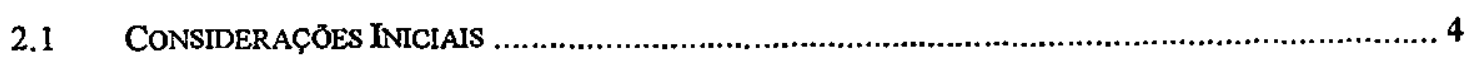

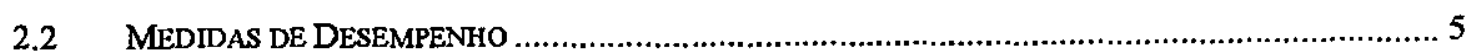

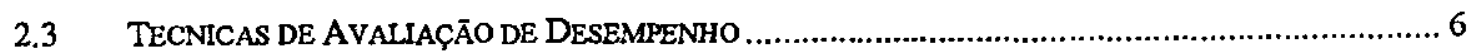

2.4.1 Técnicas de Aferição ............................................................... 6

2.4.2 Técnicas de Modelagem ................................................................ 8

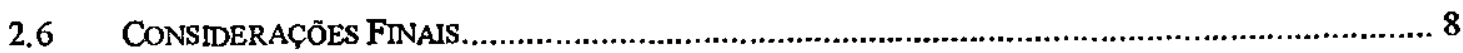

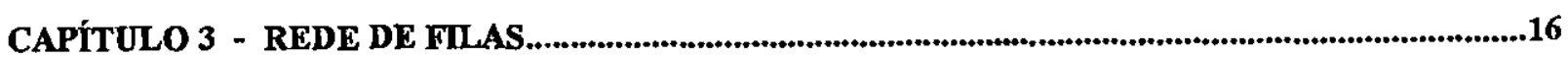

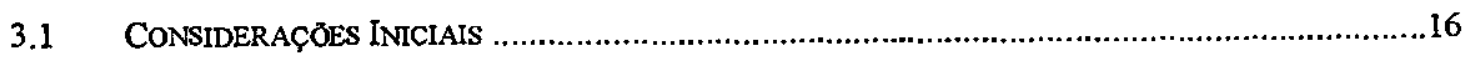

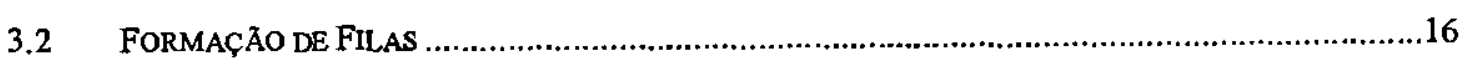

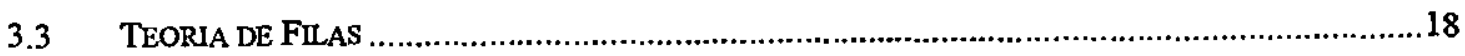

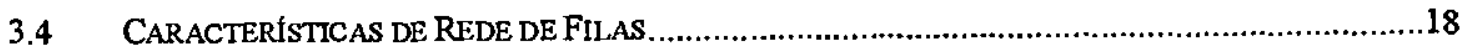

3.4.1 Elementos Básicos de Rede de Filas.................................................18

3.4.2 Notação para Rede de Filas............................................................ 22

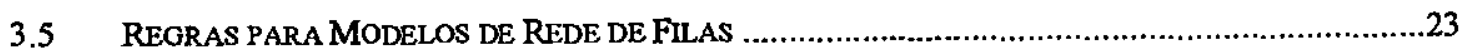

3.5.1 Condição de Estabilidade ................................................................25

3.5.2 Clientes no Sistema versos Clientes na Fila.......................................25

3.5.3 Tempo de Resposta versos Tempo de Fila ..........................................26

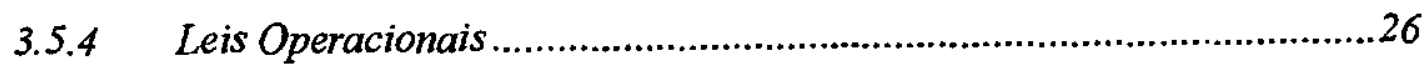

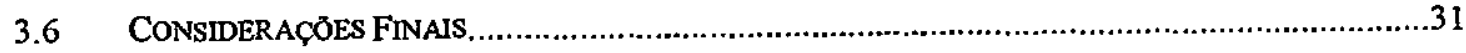

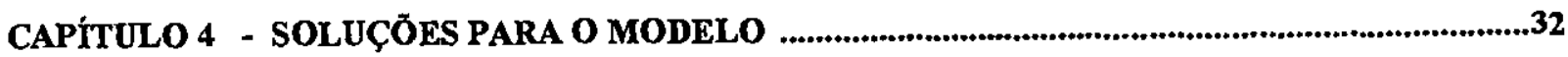

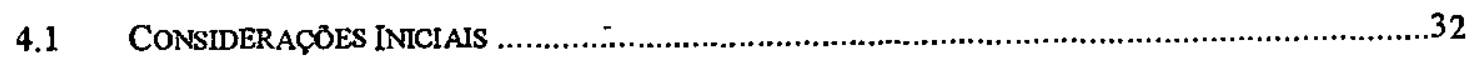

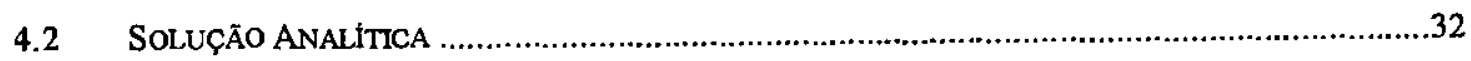

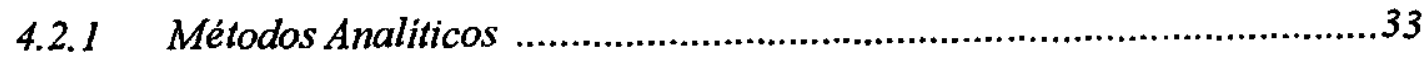

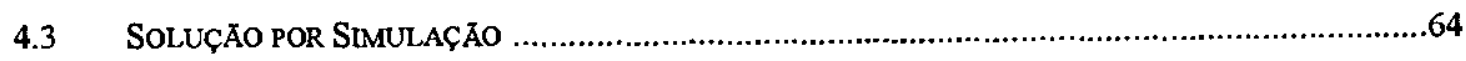

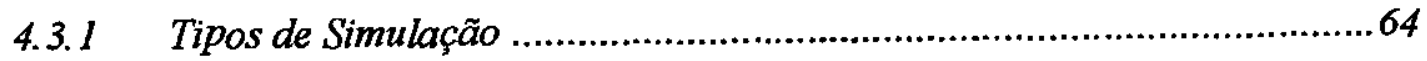

4.3.2 Tipos de Orientação de uma Simulação ................................................66

4.3.3 Etapas de Desenvolvimento da Simulação ..........................................66

4.3.4 Ambientes de Simulação ................................................................ 68 


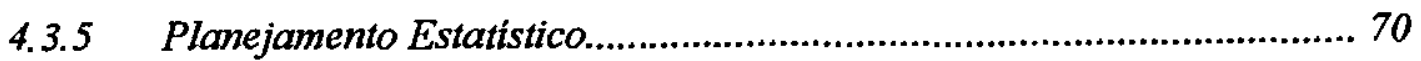

4.4 ANÁlISE DOS RESULTADOS DA SIMULAÇÃo …….............................................................71

4.5 COMPARAÇÃo ENTRE SOLUÇĀo ANALTTTCA E SOLUÇÃo POR SIMULAÇĀo …..........................72

4.6 CONSIDERAÇठ̋ES FINAIS ............................................................................................73

\section{CAPÍTULO 5 - SOLUÇ̃̃o dE MODELOS PRÁTICOS - APLICAÇÃO DOS MÉTODOS} ANALITICOS E SIMULAÇÃO........................................................................................74

5.1 CONSIDERAÇŐES INTCIAIS ...................................................................................74

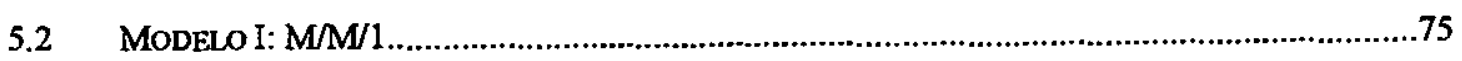

5.2.1 Processo Nascimento-e-Morte ...........................................................76

5.2.2 Limites de Desenpenho ….................................................................77

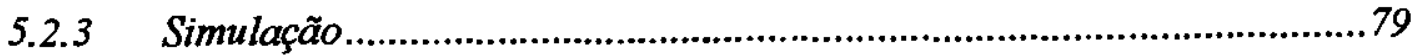

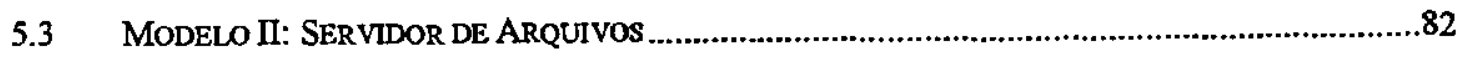

5.3.1 Análise do Valor Médio (AVM) .........................................................83

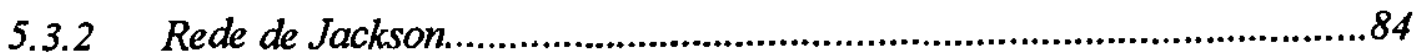

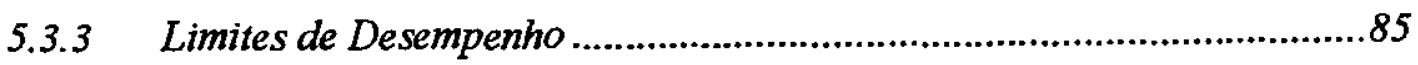

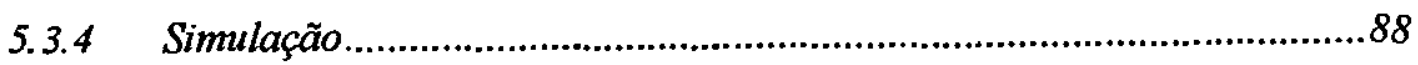

5.4 MODELO III: SERVIDOR ARQUIVOS COM PFE …….....................................................90

5.4.1 Análise do Valor Médio (AVM) .........................................................9l

5.4.2 Rede de Jackson..............................................................................92

5.4.3 Limites de Desempenho .....................................................................95

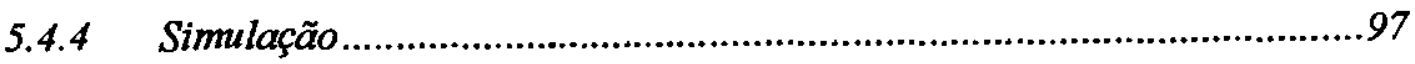

5.5 MODELO IV: AMBIENTE DISTRIBUIDO ......................................................................... 100

5.5.1 Análise do Valor Médio (AVM)..................................................... 101

5.5.2 Decomposição Hierárquica ............................................................. 102

5.5.3 Limites de Desempenho ............................................................... 105

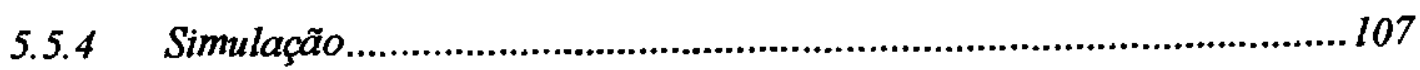

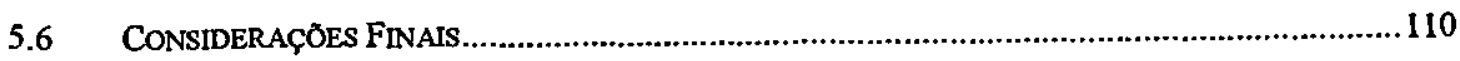

CAPÍTULO 6 - CONCLUSÄO …...........................................................................................111

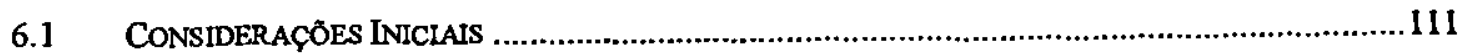

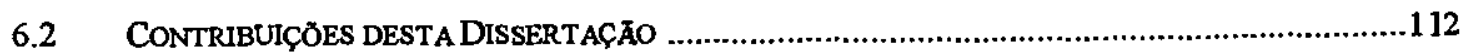

6.3 DIFICULDADES ENCONTRADAS ..............................................................................113

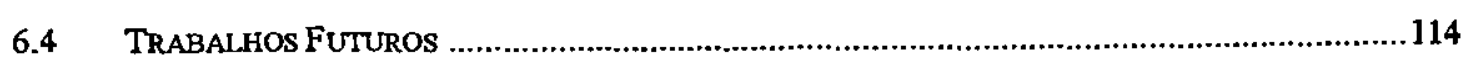

6.5 CONSIDERAÇðES FINAIS ......................................................................................114 


\section{Lista de Figuras}

Figura 2.1 - Hierarquia das Técnicas de Avaliação de Desempenho 6

Figura 2.2 - Redes de Petri - Processos Competindo pelo Processador. 9

Figura 2.3 - Rede Marcada. 10

Figura 2.4 - Rótulos e Condiçōes Externas às Transiçōes. .10

Figura 2.5 - Statechart - Processos competindo pelo Processador. 11

Figura 2.6 - Representação de Estados em Statecharts 12

Figura 2.7 - Estados, Eventos e Transições .13

Figura 2.8 - Rede de Filas - Processos Competindo pelo Processador .13

Figura 2.9 - Técnica de Aferição mais adequada para Um Sistema. 14

Figura 3.1 - Gráfico relacionando o escoamento e o tempo de resposta. 17

Figura 3.2 - Curva genérica de filas

Figura 3.3 - Centro de Serviço com apenas um Servidor.

Figura 3.4 - Centro de Serviço com múltiplos Servidores

Figura 3.5 - tipos de centros de serviço

Figura 3.6 - Sistema de tempo compartilhado.

Figura 3.7 - Modelo Aberto, Fechado e Misto.

Figura 3.8 - Variáveis aleatórias. .24

Figura 3.9 - Links In e Out para Modelo Fechados.

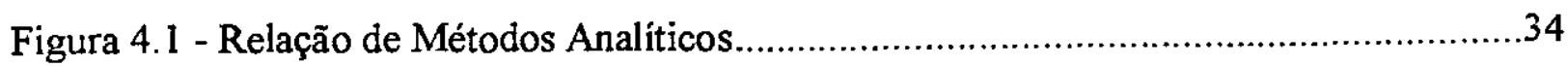

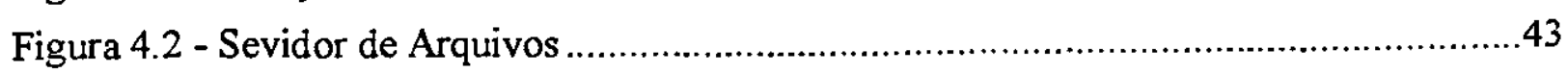

Figura 4.3 - Agregado e Complemento .................................................................53

Figura 4.4 - Niveis da Decomposição Hierárquica .......................................................54

Figura 4.5 - Diagrama de estado do processo nascimento-e-morte ...................................62

Figura 4.6 - Diagrama do processo nascimento-e-morte para o modelo $\mathrm{M} / \mathrm{M} / 1$...............63

Figura 4.7 - Etapas de Desenvolvimento da Simulação.................................................66

Figura 4.8 - Solução mais adequada para um modelo...............................................73

Figura 5.1 - M/M/1 representando um Servidor de Arquivos......................................75

Figura 5.2 - Modelo I: M/M/1 ..................................................................... 76

Figura 5.3 - Relatório de Simulação do Modelo I para a semente 0 ..................................80 
Figura 5.4 - Medidas de desempenho adicionais para o Moddelo I - semente 0 . 80

Figura 5.5 - Modelo II: Servidor de Arquivos .82

Figura 5.6 - Relatório de Simulação do Modelo II para a semente 0 .88

Figura 5.7 - Medidas de desempenho adicionais para o Modelo II - semente 0 .89

Figura 5.8 - Modelo III: Servidor de Arquivos com PFE. .90

Figura 5.9 - Relatório de Simulação do Modelo III para a semente 0 97

Figura 5.10 - Medidas de desempenho adicionais para o Modelo III - semente 0. 98

Figura 5.11 - Modelo IV: Ambiente Distribuído 100

Figura 5.12 - Passo 1 da Decomposição Hierárquica do modelo IV 103

Figura 5.13 - Passo 2 da Decomposição Hierárquica do Modelo IV 103

Figura 5.14 - Passo 4 da Decomposição Hierárquica do Modelo IV - Modelo do Nível 0 ...104

Figura 5.15 - Relatório de Simulação do Modelo IV para a semente 0 108

Figura 5.16 - Medidas de desempenho adicionais para o Modelo IV - semente 0 109 


\section{Lista de Tabelas}

Tabela 2.1 - Classificação de Índices de Desempenho ............................................... 6

Tabela 4.1 - Possíveis Situações.........................................................................4

Tabela 4.2 - Limites Assintóticos do throughput e tempo de resposta .........................60

Tabela 5.1 - Comparação entre os resultados das soluções do Modelo I ............................81

Tabela 5.2 - Comparação entre os resultados das soluções do Modelo II.........................89

Tabela .5.3 - Comparação entre os resultados das soluções do Modelo III.........................99

Tabela 5.4 - Comparação entre os resultados das soluções do Modelo IV .........................109 


\section{Lista de Gráficos}

Gráfico 4.1 - Limites Assintóticos do Throughput .................................................60

Gráfico 4.2 - Limites Assintóticos do Tempo de Resposta .........................................61

Gráfico 5.1 - Limite Otimista do Throughput do Modelo I.............................................79

Gráfico 5.2 - Limites do Tempo de Resposta do Modelo I ..........................................79

Gráfico 5.3- Limite Otimista do Throughput do Modelo II ..........................................8

Gráfico 5.4- Limites do Tempo de Resposta do Modelo II ............................................87

Gráfico 5.5 - Limite Otimista do Throughput do Modelo III ..........................................96

Gráfico 5.6 - Limites do Tempo de Resposta do Modelo III......................................... 97

Gráfico 5.7 - Limite Otimista do Throughput do Modelo IV ...................................... 107

Gráfico 5.8 - Limites do Tempo de Resposta do Modelo IV ..................................... 107 


\section{Lista de Algoritmos}

Algoritmo 4.1 - AVM para modelos Abertos .36

Algoritmo 4.2 - Algoritmo AVM Exato para Modelos Fechados 39

Algoritmo 4.3 - Algoritmo AVM Aproximado para Modelos Fechados 40

Algoritmo 4.4 - Algoritmo AVM Exato para Centros Dependentes de Carga .43

Algoritmo 4.5 - Algoritmo de Convolução 50

Algoritmo 4.6 - Algoritmo para Decomposição Hierárquica .55

Algoritmo 4.7 - Algoritmo para cálculo de limites assintóticos 62 
Esta dissertação aborda a solução de modelos de rede de filas para sistemas computacionais distribuídos, através de métodos analíticos e por simulação.

Dessa forma, são discutidos detalhadamente os seguintes métodos analíticos: Análise de Valor Médio (AVM), Rede de Jackson, Método de Gordon e Newell, Redes BCMP, Decomposição Hierárquica, Limites de Desempenho e Processo Nascimento-e-Morte. Esses métodos são aplicados em diversos modelos que representam elementos fundamentais de um sistema computacional distribuído.

Os modelos considerados abrangem elementos de um sistema computacional distribuido, incluindo servidores de arquivos, rede de comunicação e estações de trabalho.

Além dos métodos analíticos, considera-se também a simulação, implementados no Ambiente ASiA, que gera programas de simulação orientados a evento.

Os resultados obtidos tanto analiticamente, como por simulação, são apresentados, discutidos e comparados, constatando-se uma equivalência. Esses resultados mostram que os diversos métodos analíticos estudados podem ser empregados com êxito na solução de modelos práticos da área de sistemas computacionais distribuídos. 


\section{Abstract}

This MSc dissertation approaches the solution of queuing network models applied to distributed computing systems by means of analytical methods and simulation.

The following analytical methods are detailed discussed: Mean-Value Analysis (MVA), Jackson's Networks, Gordon and Newell's Method, BCMP Networks, Hierarchical Decomposition, Asymptotic Bounds, e Birth-Death Processes. These methods are applied to several models representing fundamental elements of a distributed computing system.

The models considered comprise elements of a distributed computing system including file servers, communication network and workstations.

Besides analytical methods, simulation is also considered by means of the ASiA, that is an environment generating event-oriented simulation programs.

The results obtained both analytically and from simulation are presented, discussed and compared, showing to be equivalent. These results show that the several analytical methods studied can be successfully used to solve practical models in the distributed computing systems area. 


\section{Capitulo 1}

\section{Introdução}

No início da era da informática, em 1945, os computadores eram grandes, caros e operavam isoladamente. Essa situação começou a ser modificada em meados da década de 80, com o surgimento dos microprocessadores e o aprimoramento das redes de interconexão (Tanenbaum,1995). Tais modificações revolucionaram a informática, permitindo que microprocessadores com um alto poder computacional pudessem, através de redes de alta velocidade, trabalhar em conjunto, viabilizando o desenvolvimento dos sistemas computacionais distribuídos.

Os sistemas computacionais distribuídos possuem características essenciais, tais como transparência, confiabilidade, escalabilidade, concorrência e tolerância à falhas, que devem ser mantidas sem prejudicar o desempenho (Tanenbaum,1995).

Desempenho é sempre um ponto fundamental em qualquer sistema computacional, seja ele distribuído ou não, sendo importante avaliá-lo com o objetivo de se ter tanto uma quantificação quanto uma qualificação do resultado observado.

Para avaliar o desempenho de um sistema computacional é necessária utilizar uma técnica de Avaliação de Desempenho apropriada, selecionada dentre as inúmeras disponiveis e que podem ser agrupadas em: Técnicas de Aferição e Técnicas de Modelagem. A escolha da técnica a ser utilizada é um fator relevante, uma vez que o emprego de técnicas inadequadas pode levar ao fracasso da avaliação de desempenho do sistema computacional em estudo (Francês,1998).

Para que não aconteça a seleção de uma técnica inadequada, deve-se ter 0 conhecimento pleno e prévio do sistema a ser avaliado (Soares,1990) podendo, então, estabelecer o objetivo da avaliação.

O objetivo da avaliação é definido, também, a partir do estado de desenvolvimento do sistema, que pode estar em fase final de desenvolvimento, já existir ou ainda ser inexistente, estando, portanto, em fase de projeto. Tendo a informação de estado do desenvolvimento do 
sistema, pode-se então determinar a técnica mais adequada ao estudo. Observa-se então que a avaliação de desempenho desempenha um papel importante em todas as fases de desenvolvimento de um sistema computacional.

As diversas técnicas de modelagem disponíveis, fornecem um modelo representativo do sistema em estudo. Esse modelo deve ser solucionado para então gerar informações úteis para o estudo do sistema. A escolha do método a ser empregado na solução do modelo também pode trazer certas dificuldades. Aos modelos podem ser aplicadas técnicas analíticas (Solução Analítica) e/ou técnicas de simulação (Solução por Simulação). Geralmente, modelos muito complexos e/ou que manipulam um grande número de informações, são solucionados por simulação, enquanto, por outro lado, modelos com um grau de complexidade menor são freqüentemente solucionados analiticamente.

Dentre as vantagens e desvantagens de cada solução de modelos, a solução analítica traz como principal vantagem o fato de fornecer resultados mais precisos, quando sua aplicação é viável, isto é, quando o modelo em estudo pode ser resolvido sem um volume de simplificações que possa comprometer a representação do sistema original. Por outro lado, a solução por simulação é mais simples e flexível, apesar de requerer um processamento computacional que pode ser longo, dependendo do modelo e da precisão requerida para os resultados. Assim, observa-se que para cada solução existe um domínio de aplicação, onde deve ser considerada, principalmente, a complexidade do modelo representativo do sistema.

Assim, este trabalho tem por objetivo estudar diversos métodos analíticos visando a aplicação na solução de modelos de rede de filas que representem elementos de um sistema computacional distribuído. Os métodos analíticos abordados por este trabalho são: Análise de Valor Médio (AVM), Rede de Jackson, Método de Gordon e Newell, Redes BCMP, Decomposição Hierárquica, Limites de Desempenho e Processo Nascimento-e-Morte. Os resultados obtidos através dos métodos analíticos serão, também, comparados com resultados produzidos através do uso de simulação.

Este trabalho visa também, através do estudo desenvolvido, servir como base para o emprego dos métodos analíticos investigados em outros modelos, que representem sistemas computacionais distribuídos ou elementos desses sistemas.

Esta dissertação está organizada em seis capítulos, sendo que o capítulo 2 apresenta as técnicas de avaliação de desempenho que podem ser utilizadas nos sistemas computacionais, onde são abordadas: Construção de Protótipos, Benchmarks, Coleta de Dados e três técnicas de modelagem, sendo Rede de Filas, Rede de Petri e Statecharts. 
O capítulo 3 é dedicado ao estudo da técnica de Rede de Filas, por seu alto grau de importância dentro do trabalho, trazendo suas principais características, elementos básicos, notação, leis operacionais, etc.

O capítulo 4 discute os métodos de solução de um modelo, apresentando um estudo comparativo entre a solução analítica e a solução por simulação. Esse capítulo descreve alguns métodos analíticos, classificando-os em dois grupos: métodos para modelos abertos rede de filas e métodos para modelos fechados rede de filas.

No capitulo 5, aplicam-se os métodos analíticos abordados pelo capítulo anterior, sendo seus resultados comparados com os obtidos por simulação, onde são solucionados alguns modelos relevantes à área de sistemas computacionais distribuídos.

No capítulo 6, finaliza-se este trabalho apresentando uma análise final a respeito do trabalho realizado, identificando-se suas contribuições, as principais dificuldades encontradas no seu desenrolar e as sugestões para trabalhos futuros. 


\section{Avaliação de Desempenho}

\subsection{Considerações Iniciais}

O processo de avaliação de desempenho pode fornecer diversos resultados, tais como a quantidade de serviços prestados durante um determinado intervalo de tempo, o tempo requerido para a realização de uma dada tarefa, que podem ser analisados, para concluir-se se o desempenho do sistema avaliado precisa ser melhorado ou não.

A métrica utilizada para representar o desempenho de um sistema demonstra quão bem o sistema executa suas tarefas. Sob o ponto de vista do usuário, o desempenho pode ser medido através do tempo que o mesmo leva para responder a uma requisição, o que não é um método suficientemente confiável. Assim, para a avaliação de desempenho de um sistema pode se utilizar uma das técnicas que se encontram distribuídas em dois grandes grupos: Técnicas de Aferição e Técnicas de Modelagem (Santana,1990) (Santana,1990a).

As técnicas de Aferição mais populares são: construção de Protótipos, utilização de Benchmarcks e Coleta de Dados. Quanto a Modelagem, as técnicas de Redes de Petri, Statecharts e Rede de Filas são as mais utilizadas. Todas essas técnicas serão discutidas no decorrer deste capítulo, visando estabelecer quando cada uma delas pode (ou deve) ser aplicada, suas vantagens e suas desvantagens.

Para evitar-se a escolha de uma técnica inadequada, alguns pontos são de fundamental importância, tal como o conhecimento pleno e prévio do sistema (Soares,1990). Além disso, deve-se levar em consideração o estado de desenvolvimento do sistema a ser avaliado, o qual pode já existir, estar em fase final de desenvolvimento ou ainda nem existir, sendo apenas uma especulação ou estar na fase de projeto (Orlandi,1995). Assim, a importância da avaliação de desempenho pode ser notada desde a fase de projeto do sistema até a fase de seu uso efetivo. 


\subsection{Medidas de Desempenho}

Durante a avaliação de desempenho do sistema, devem ser colhidas informações associadas aos parâmetros significativos à análise (Fernandes,1992). Diante disto, diz-se que as técnicas de avaliação (Aferição e Modelagem) são os métodos pelos quais tais informaçóes podem ser obtidas. Essas informações podem ser chamadas de medidas de desempenho (Orlandi, 1995).

Para avaliar o desempenho de um sistema deve-se determinar um conjunto de medidas de desempenho a serem colhidas, que são normalmente o escoamento (thoughput), tempo de resposta e utilização. No processo de avaliação de desempenho são obtidas essas medidas do sistema. Então, uma análise é feita sobre essas medidas, fornecendo informações que mostram o que está acontecendo com o sistema, possibilitando, caso necessário, que problemas sejam solucionados através da adequação dos requisitos de desempenho. Assim, o objetivo de um estudo sobre um sistema existente é aperfeiçoar tais medidas (Westphall,1987) (Orlandi, 1995).

As medidas de desempenho podem ser classificadas em: medidas orientadas ao usuário e medidas orientadas ao sistema. $O$ tempo de resposta, por exemplo, encontra-se caracterizado como uma medida de desempenho orientada ao usuário. $\mathrm{O}$ tempo de resposta corresponde ao intervalo de tempo decorrido para que um pedido seja atendido, considerando desde a sua chegada na fila até que seja completado. Dois exemplos típicos de medidas de desempenho orientadas ao sistema são o throughput e a utilização. O throughput é número médio de pedidos atendidos por unidade de tempo. A utilização de um recurso do sistema, por exemplo, é geralmente fornecida pela razão do tempo total em que o recurso se manteve ocupado pelo tempo total de observação (Westphall,1987) (Orlandi,1995).

A seguir, tem-se uma tabela que apresenta as medidas de desempenho mais comuns e suas definições (Westphall, 1987):

\begin{tabular}{|l|l|}
\hline \multicolumn{1}{|c|}{ Exemplos de Medidas } & \multicolumn{1}{|c|}{} \\
\hline - Taxa de Escoamento (throughput) & Volume de informação processada pelo \\
- Taxa de Produção & sistema em uma determinada unidade de \\
- Capacidade (máxima taxa de rendimento) & tempo (geralmente associado ao horário \\
- Taxa de Execução de Instruções & de pico) \\
- Taxa de Processamento de Dados & \\
\hline
\end{tabular}




\begin{tabular}{|c|c|}
\hline $\begin{array}{l}\text { - Tempo de Resposta } \\
\text { - Tempo de Inversão } \\
\text { - Tempo de Reação }\end{array}$ & $\begin{array}{l}\text { Tempo que decorre entre a última ação } \\
\text { associada à entrada da requisição e o } \\
\text { aparecimento do primeiro caracter da } \\
\text { resposta. }\end{array}$ \\
\hline $\begin{array}{l}\text { - Utilização do Módulo de Hardware (CPU, } \\
\text { memória, canal de E/S, dispositivos de E/S) } \\
\text { - Utilização do Módulo de Sistema Operacional } \\
\text { - Utilização de Banco de Dados }\end{array}$ & $\begin{array}{l}\text { Razão entre o tempo que uma } \\
\text { especificada parte do sistema é utilizada, } \\
\text { durante um dado intervalo de tempo e a } \\
\text { duração deste intervalo }\end{array}$ \\
\hline
\end{tabular}

Tabela 2 - 1 - Classificação de Indices de Desempenho

\subsection{Técnicas de Avaliação de Desempenho}

As técnicas de avaliação de desempenho, que são utilizadas para tentar responder questões relacionadas ao desempenho de um sistema, encontram-se agrupadas segundo a hierarquia mostrada na Figura 2 - 1 (Orlandi, 1995) e (Santana,1997).

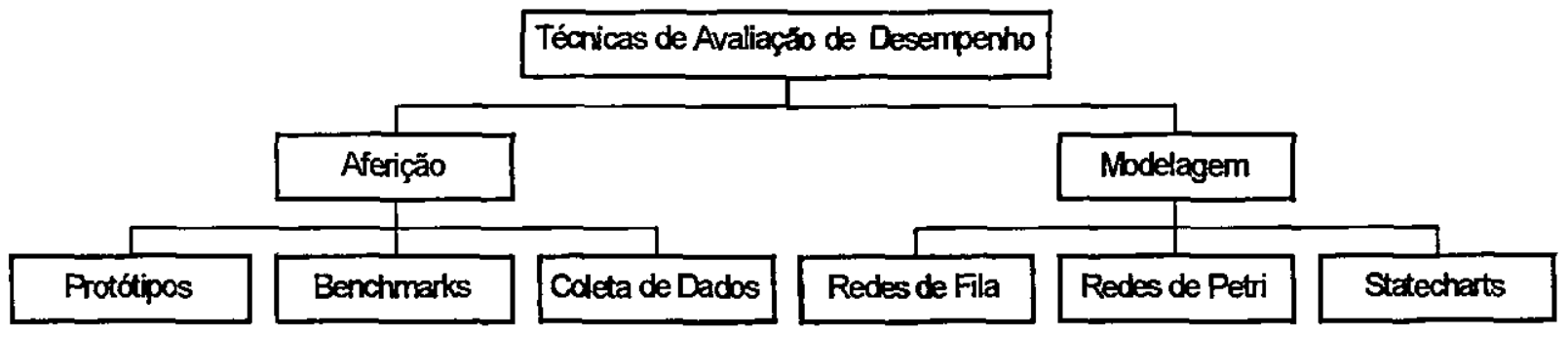

Figura 2 - 1 - Hierarquia das Técnicas de Avaliação de Desempenho

\subsubsection{Técnicas de Aferição}

As técnicas de Aferição são aplicadas principalmente na avaliação de sistemas já existentes ou em fase final de desenvolvimento (Orlandi,1995) e (Santana,1997).

Os resultados dessas técnicas são mais precisos do que os obtidos através de modelagem. No entanto, preocupa-se sempre em não alterar o funcionamento natural do sistema, o que pode ser ocasionado pela experimentação prática aplicada a sistemas existentes ou pela construção de protótipos errados (Orlandi,1995).

As técnicas de aferição a serem estudadas são: Protótipos, Benchmarks e Coleta de Dados. 


\subsubsection{Protótipos}

A construção de protótipos corresponde a uma simplificação de um sistema computacional, mantendo a sua funcionalidade, ou seja, são representadas somente as características essenciais do sistema. A determinação dessas características essenciais acaba se tornando uma dificuldade (Orlandi,1995).

Por possuir um custo menor do que a construção do sistema real (o que não significa necessariamente que seu custo seja baixo), o protótipo é desenvolvido no caso de sistemas ainda não existentes, mas que se encontram em fase final de desenvolvimento, para que seja avaliado se o sistema atenderá às expectativas que se tem a respeito do novo sistema (Francês,1998). No caso de sistemas existentes, a construção de Protótipos tem um custo que a torna inviável (Orlandi, 1995).

\subsubsection{Benchmarks}

Benchmarks são programas usados para testar o desempenho de um software, hardware ou sistema computacional. A mesma tarefa ou programa é submetida a diferentes sistemas, e então seus resultados são comparados entre si (Tanenbaum, 1995).

No caso da aquisição de novos equipamentos, por exemplo, é importante que o desempenho de sistemas distintos sejam comparados. Para isso, o desempenho deve ser obtido com todas as máquinas operando sob as mesmas condições, ou seja, a mesma aplicação deve ser executada em todas elas. Essa aplicação, que pode ser uma aplicação qualquer ou específica para esse fím, é chamada benchmark (Fernandes, 1992).

Para o uso desta técnica, é necessário que se tenha um conhecimento exato da configuração de alguns elementos chaves, como o processador, memória, versões de software, estado do sistema e periféricos (Weicker, 1990). Normalmente, esse tipo de ferramenta não possui um alto custo e encontra-se disponível no mercado. Por outro lado, deve-se ter muito cuidado para que a própria execução do benchmark não venha a influenciar os resultados a obtidos (Orlandi, 1995).

\subsubsection{Coleta de Dados}

As técnicas de aferição são as que oferecem os resultados mais precisos, em particular, a coleta de dados é a mais precisa. Seu objetivo principal é a avaliação de desempenho através da obtenção direta dos dados em um sistema já existente (Francês, 1998). 
Uma coleta de dados é efetuada através da inserção de algum hardware ou software específico para esse fim, sendo por isso utilizada em sistemas computacionais existentes. Semelhante ao Benchmark, essa técnica requer cuidado para que suas instruções não interfiram nos resultados da avaliação (Santana,1990a), (Fernades, 1992).

A coleta de dados pode ser efetuada através de Monitores de Hardware ou Monitores de Software. Os Monitores de Hardware são hardwares especificos usados para coletar e analisar dados pertencentes ao objeto em estudo, devendo limitar-se a obter os sinais sem alterá-los, para que a fidelidade aos valores seja mantida. Os Monitores de Software são utilizados para observar características peculiares ao software que não poderiam ser detectadas pelo monitores de hardware. Os monitores de software podem, por exemplo, ser úteis ao estudo de como algumas características dos sistemas operacionais (políticas de escalonamento de CPU, de alocação de memória, etc.) influenciam no desempenho de um sistema (Orlandi,1998).

\subsubsection{Técnicas de Modelagem}

A modelagem é geralmente utilizada quando se deseja avaliar um sistema ainda inexistente, trazendo como vantagem a possibilidade de antever o desempenho de um sistema computacional.

Para avaliar o desempenho do sistema utilizando a técnica de Modelagem, deve-se primeiramente escolher uma de suas técnicas. Em seguida, é criado um Modelo do sistema a ser avaliado, tendo-se a preocupação de abstrair as características relevantes, o qual deve descrever com fidelidade o sistema (Soares, 1990).

O modelo é a representação do sistema. A confiança num modelo pode vir da certeza de que sua base conceitual está perfeita. Caso não exista nenhum meio para constatar a validade de sua base conceitual, deve-se apelar para a experimentação (levantamento de medidas), que se torna importante na avaliação de desempenho por complementar suas técnicas quando necessário (Westphall,1987).

Todo modelo necessita ser solucionado, o que pode ser feito através de métodos analíticos ou por simulação (Kobayashi,1978) (Orlandi,1995) (Santana,1990) e (Santana,1990a).

Dentre as técnicas para modelar um sistema computacional, Redes de Petri, Statecharts e Rede de Filas serão consideradas neste trabalho por sua adequação ao contexto de sistemas computacionais distribuídos. 


\subsubsection{Redes de Petri}

Podem-se definir Redes de Petri como uma técnica de especificação de sistemas que possibilita uma representação matemática e possui mecanismos de análise poderosos, permitindo a verificação de propriedades e a correção do sistema especificado (Maciel,1996).

Como vantagem, essa técnica traz o fato de permitir a modelagem de sistemas paralelos, concorrentes, assincronos e não-determinísticos (Francês, 1998).

A figura a seguir ilustra a representação de uma rede de Petri básica, mostrando processos disputando pelo processador (Francês, 1998). O modelo possui dois componentes fundamentais: um ativo, denominado transição (representado pelas barras); e outro passivo, denominado lugar (representado pelos círculos). Os lugares equivalem às variáveis de estado e as transições correspondem às açð̃es realizadas pelo sistema (Maciel,1996).

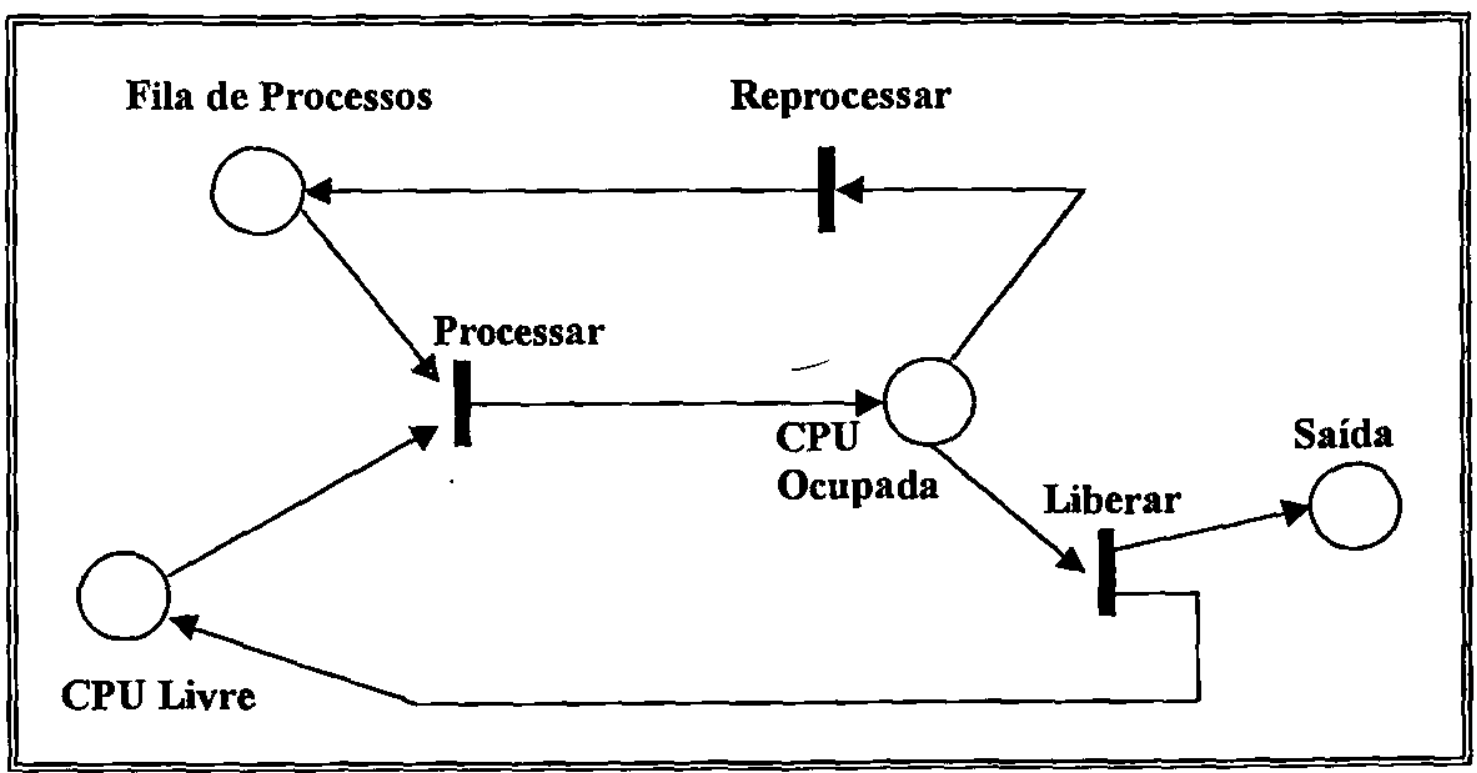

Figura 2 - 2 - Redes de Petri - Processos Competindo pelo Processador

\section{Redes de Petri Marcadas}

Marcas (tokens) são informações atribuídas aos lugares, para representar a situação (estado) da rede em um determinado momento. Assim, para representar o comportamento dinâmico dos sistemas, a marcação da rede de Petri é modificada a cada ação realizada (transição disparada) (Maciel,1996) (Francês, 1998). A Figura 2 - 3 mostra uma rede marcada. 


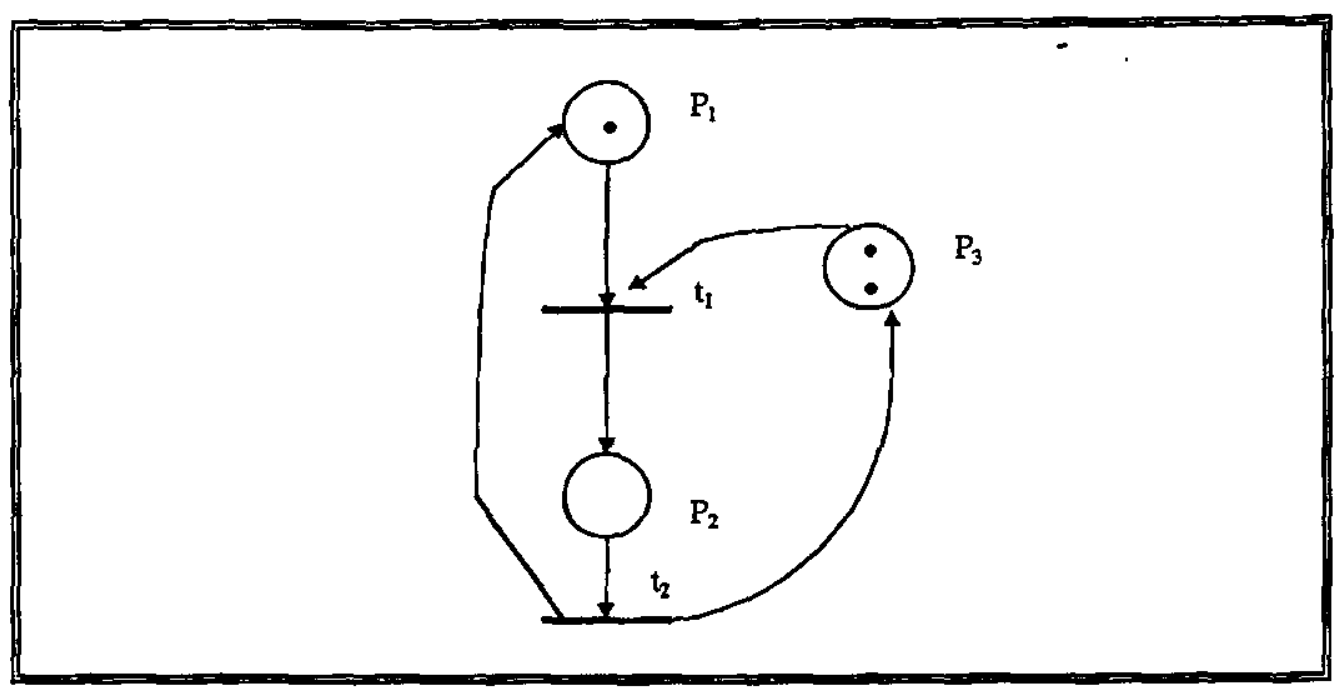

Figura 2 - 3 - Rede Marcada

\section{Notações Particulares das Redes de Petri}

Esse tipo de notação é utilizado quando se deseja representar a diferença entre transições (objetivando um melhor esclarecimento do modelo) e a execução de uma condição externa ao modelo. Assim, para diferenciar as transições são utilizados os chamados rótulos de transições, descritos por meio de um alfabeto qualquer, por exemplo, a,b,c,...,z. Na representação das condições externas, utiliza-se o mesmo esquema de rótulo, entretanto, os símbolos são sempre descritos entre parênteses. A Figura 2 - 4 ilustra ambas situações (Francês, 1998).

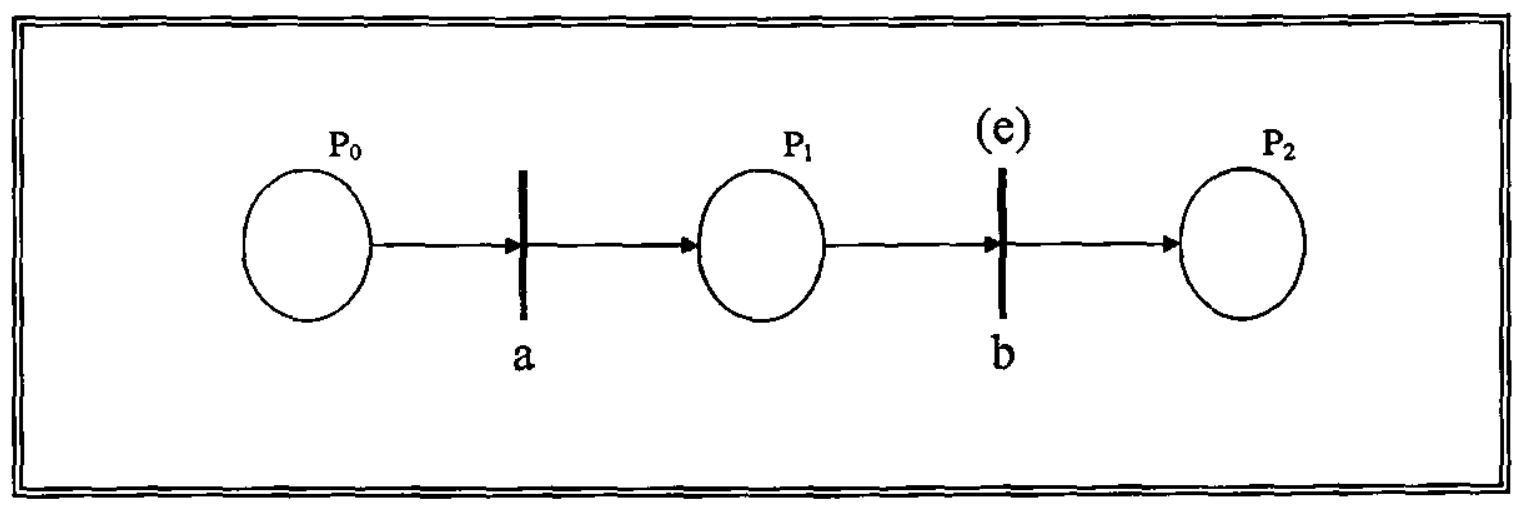

Figura 2 - 4 - Rotulos $\theta$ Condiçōes Externas às Transiçŏes.

\section{Classes das Redes de Petri}

As Redes de Petri podem ser classificadas em Redes Ordinárias e Redes Não-Ordinárias (ou de Alto nível) (Maciel,1996) (Francês,1998). As redes ordinárias se caracterizam por possuirem marcas do tipo inteiro e não negativo. As redes não-ordinárias possuem marcas de tipos particulares, que permitem uma maior clareza e um maior (ou menor) nível de abstração ao modelo (Francês, 1998). 
As redes ordinárias se subdividem em Redes Binárias e Redes Place-Transition. A redes binária é mais simples, permitindo no máximo token em cada lugar e todos os arcos possuem valor unitário. Por outro lado, uma rede place-transition permite que um mesmo lugar possua um acúmulo de marcas e valores não unitários para os arcos (Francês, 1998).

As redes não-ordinárias, por suas marcas não serem do tipo inteiro positivo, permitem a individualização de uma marca (pertencente a um grupo) em um mesmo lugar. A individualização pode ser realizada por meio de vários artificios, tais como cor da marca ou objetos representando os tokens (Francês,1998).

\subsubsection{Statecharts}

Da mesma forma que as Redes de Petri, os Statecharts representam os sistemas através da visão de seus estados, representando também a modificação dos estados diante da ocorrência de uma determinada ação (Francês,1998).

A definição básica de statecharts é fundamentada em conjuntos de estados, transições, eventos primitivos, condições primitivas e variáveis, a partir dos quais o modelador poderá especificar os valores das variáveis do sistema em um certo instante. A idéia central é suprir a deficiência dos diagramas de estado em representar sistemas complexos. Sistemas complexos requerem uma estrutura de representação hierárquica (com agrupamento e refinamento de estados) e de concorrência, de maneira que seja facilmente visível o movimento através dos estados do sistema no decorrer do tempo (Francês,1998). A figura a seguir apresenta o exemplo anteriormente expresso em Redes de Petri, agora ilustrado em statecharts.

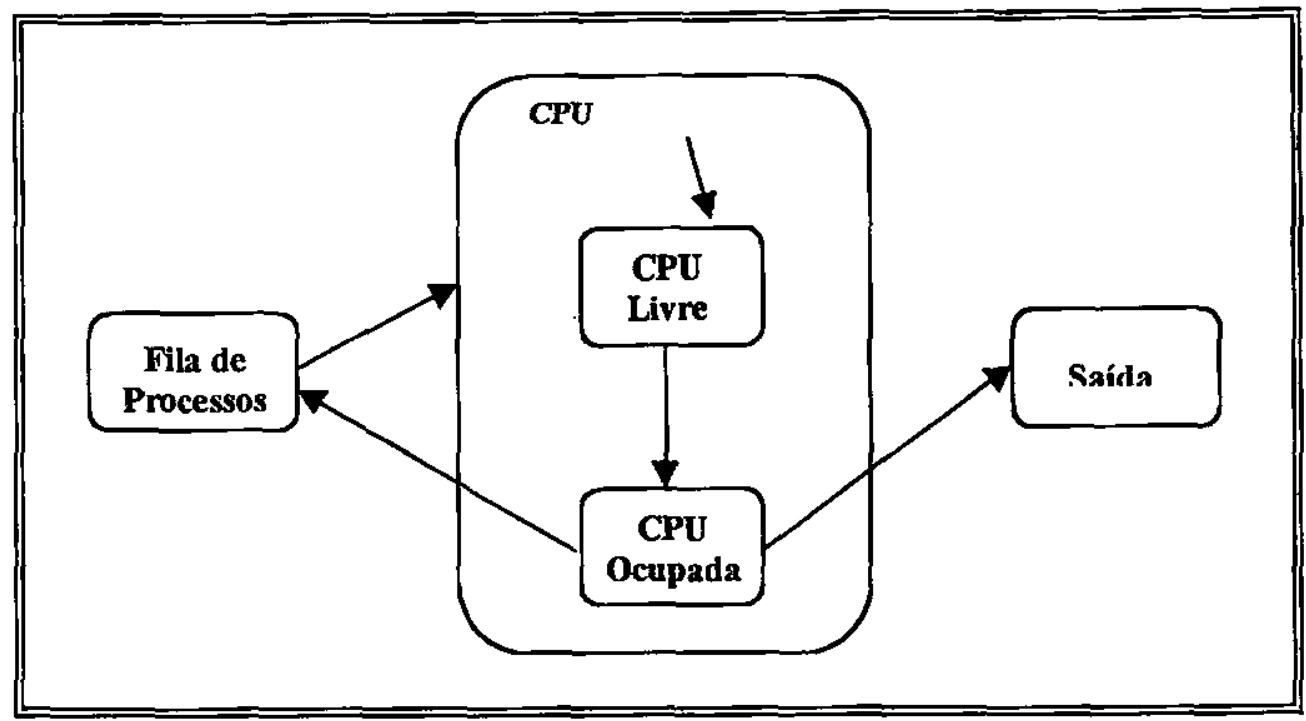

Figura 2 - 5 - Statechart - Processos competindo pelo Processador 
Os estados de um statechart representam os valores das variáveis do sistema em um determinado instante. Esses estados podem ser classificados básicos e não-básicos. Os estados básicos são aqueles que não possuem subestados, enquanto que os não-básicos podem ser decompostos em subestados. Essa decomposição pode ser do tipo OR ou do tipo AND. Uma decomposição do tipo OR indica que o sistema sempre estará em um único subestado em um determinado instante, enquanto que uma decomposição tipo AND indica que o estado poderá estar, simultaneamente, em mais de um subestado (Francês, 1998).

Na Figura 2 - 6, que apresenta as formas de representação de estados em statecharts, têm-se à esquerda, um estado $\mathrm{X}$ do tipo $\mathrm{OR}$ e seus subestados $\mathrm{X}_{1}, \mathrm{X}_{2}$ e $\mathrm{X}_{3}$, o que significa que o sistema não estará em mais de um subestado ao mesmo tempo (subestados disjuntos). $\mathrm{Na}$ mesma figura, à direita, têm-se um estado $Y$ do tipo AND e seus subestados $Y_{1}, Y_{2}$ e $Y_{3}$, que indica que o sistema pode estar em mais de um subestado simultaneamente.

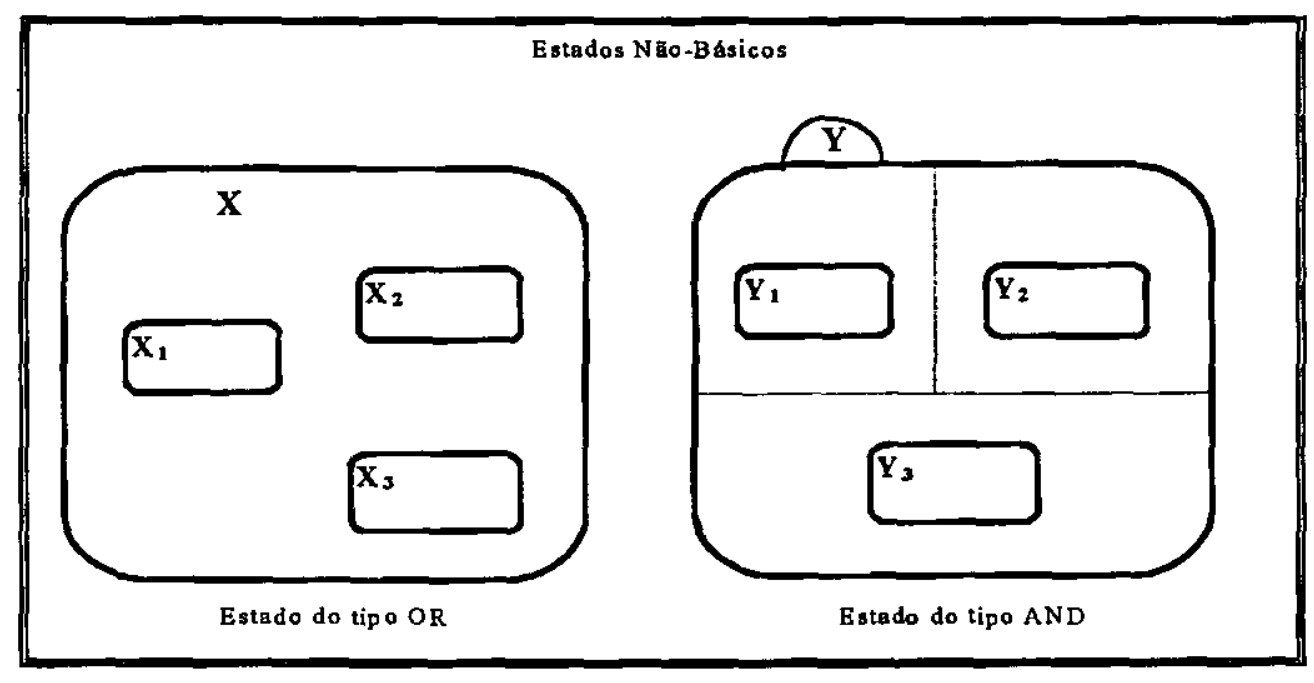

Figura 2 - 6 - Representaçăo de Estados em Statecharts

Na Figura $2-6$, representa-se a concorrência de estados ou subestados por intermédio de linhas tracejadas. Além disso, representa-se a hierarquia entre os estados, isto é, os subestados (estados-filhos) estão contidos em um estado denominado estado-pai (Francês, 1998).

A Figura 2 - 7 reuni eventos, estados e transições, de forma que eventos, representados por letras minúsculas, disparam transições, que são representadas por setas que unem estados. A ocorrência desses eventos pode obedecer a determinadas condições, as quais são representadas por letras minúsculas entre parênteses. Além disso, um superestado pode conter um estado inicial default, de forma que toda vez que o sistema entrará nesse superestado através desse estado default (Fracês, 1998). 


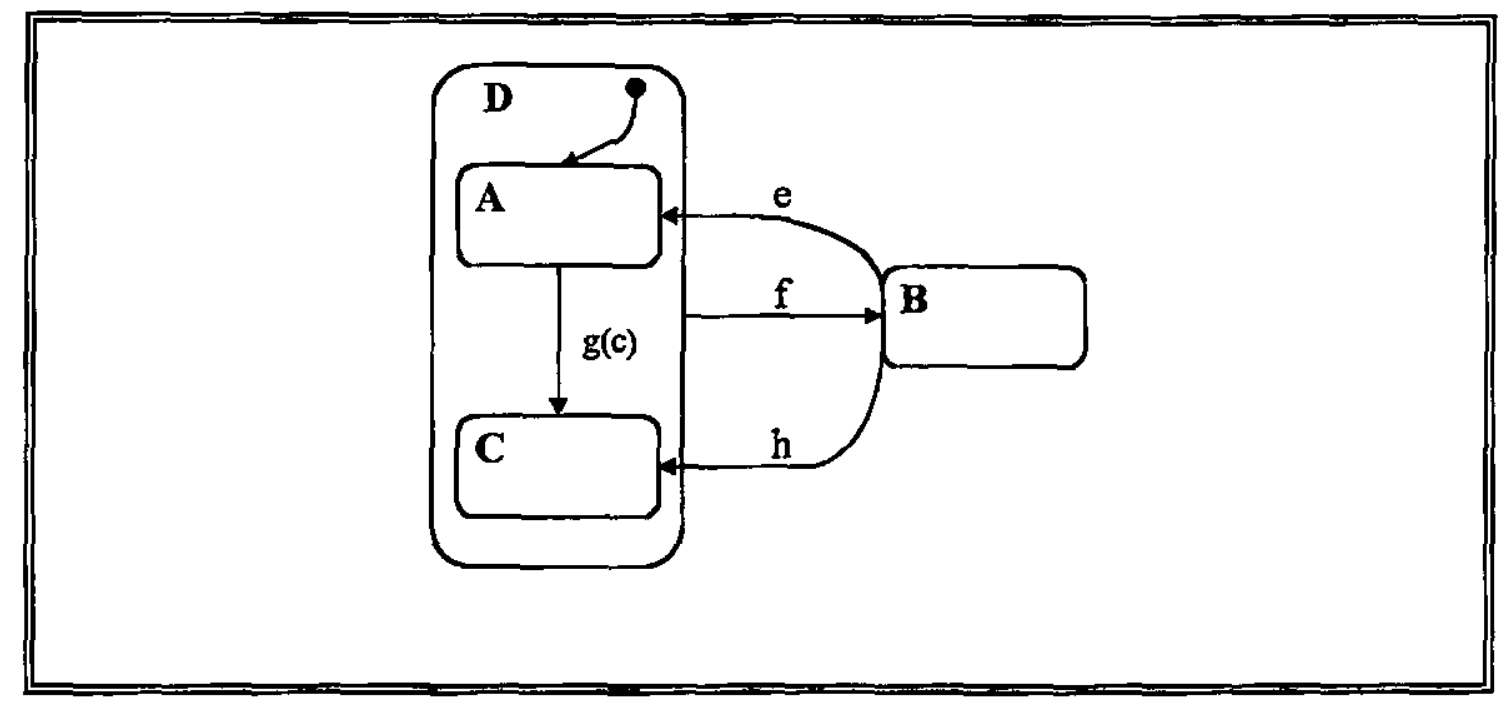

Figura 2 - 7 - Estados, Eventos e Transiçōes

\subsubsection{Rede de Filas}

De modo geral, um modelo de Rede de Filas é uma representação em alto nivel dos recursos de um dado sistema, onde a concorrência de usuários (clientes) para a utilização de um determinado recurso do sistema, certamente, ocasionará a formação de fila (Orlandi,1995).

A figura abaixo apresenta o exemplo anteriormente exposto em Redes de Petri e statecharts, segundo a técnica de Rede de Filas.

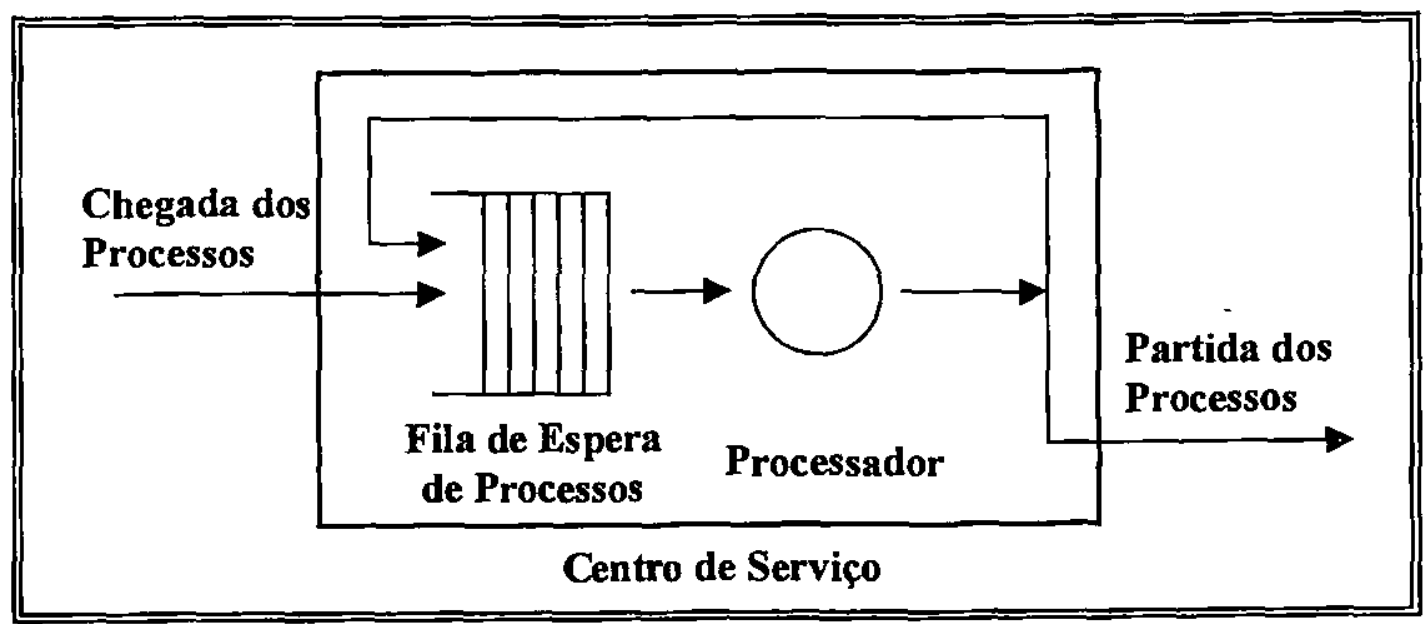

Figura 2 - 8-Rede de Fllas - Processos Competindo pelo Processador

\subsection{Considerações Finais}

A escolha da técnica a ser utilizada na avaliação de desempenho, que pode ser uma técnica de aferição ou de modelagem, corresponde a uma etapa de fundamental importância 
dentro de todo o processo. Nessa etapa, deve-se tomar conhecimento do estado do sistema, possibilitando que seja identificada a técnica e/ou solução mais adequada (Orlandi,1995) e (Santana, 1997).

Quanto as Técnicas de Aferição, conforme ilustrado na Figura 2 - 9, a técnica de Construção de Protótipos é a mais indicada para a avaliação de desempenho de sistemas ainda inexistentes, mas que se encontram em fase final de desenvolvimento (auxiliando no projeto de um novo sistema, podendo antever seu comportamento), nada que a impeça de ser utilizada também para avaliar um sistema existente ou para auxiliar a seleção de um novo sistema. A utilização de Benchmarks é geralmente aplicada a avaliação de desempenho para a seleção de novos sistemas, auxiliando, por exemplo, a aquisição de novos equipamentos ou softwares, secundariamente, essa técnica pode ser empregada na avaliação de um sistema existente ou em fase de projeto. A Coleta de Dados é principalmente utilizada para avaliar o desempenho de sistemas já existentes e, secundariamente, é usada na avaliação de sistemas em fase de projeto ou na avaliação para a escolha de novos sistemas (Orlandi,1995) e (Santana,1997).

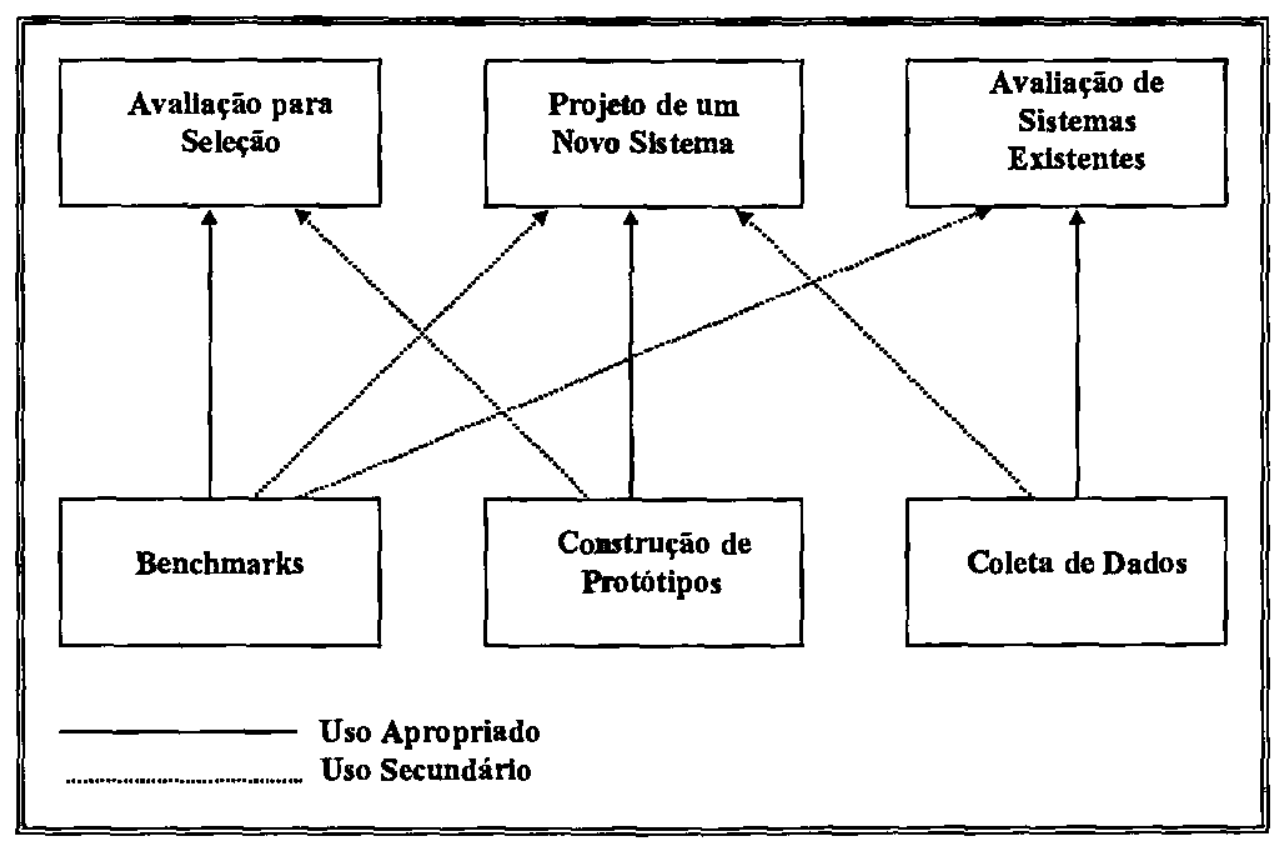

Figura 2 - 9 - Técnica de Aferigăo mais adequada para Um Sistema

No que diz respeito a Modelagem, opta-se por uma de suas técnicas, tais como Redes de Petri, Rede de Filas e Statecharts, prioritariamente para o caso da avaliação de sistemas computacionais já existentes, nada que a impeça de ser aplicada a sistemas que se encontram nos ostros estados de desenvolvimento. Feita a modelagem do sistema a ser avaliado, deve-se selecionar a forma como o modelo do sistema será solucionado, podendo aplicar-se a solução por simulação ou a solução analítica. 
Dentre essas técnicas de Modelagem, a de Rede de Filas é a mais utilizada na avaliação de desempenho de sistemas computacionais, pois estuda o fenômeno de formação de filas, que é muito comum nesse tipo de sistema (Orlandi, 1995). Por isso e por sua importância neste trabalho, tem-se o próximo capítulo dedicado ao estudo dessa técnica. 


\section{Capitulo 3}

\section{Rede de Filas}

\subsection{Considerações Iniciais}

Em computação há várias situações em que usuários concorrem pela utilização de um determinado recurso do sistema computacional. Essa situação ocasionará o enfileiramento das requisições desses clientes à espera de um determinado serviço. Para modelar sistemas nos quais a ocorrência de filas existe, foi criada uma técnica baseada na teoria de filas (um ramo das probabilidades) denominada Rede de Filas (Francês, 1998).

A técnica de rede de filas, , que terá suas características, sua notação e seus elementos, descritos neste capítulo, permite que previsões sobre o comportamento do sistema sejam feitas, viabilizando tomadas de decisões, tendo em vista a melhoria/adequação do sistema em análise.

\subsection{Formação de Filas}

Um sistema, seja ele computacional ou não, geralmente possui mais de um recurso propício à formação de filas (Kleinrock,1975), que são linhas de espera pela utilização de um recurso. Um sistema computacional naturalmente é um exemplo típico de sistemas propícios à formação de filas, pois normalmente existem mais solicitantes do que prestadores de serviço.

À medida que se aumenta a carga de trabalho do sistema, mais clientes (requisições) devem ser completados. Na maioria das vezes, esse acontecimento causa um congestionamento no sistema, caracterizando-se pela formação de filas de clientes esperando por processamento. Isto demonstra que a relação entre o escoamento (throughput) e o tempo de resposta é não-linear (Westphall, 1987), conforme mostra a figura a seguir: 


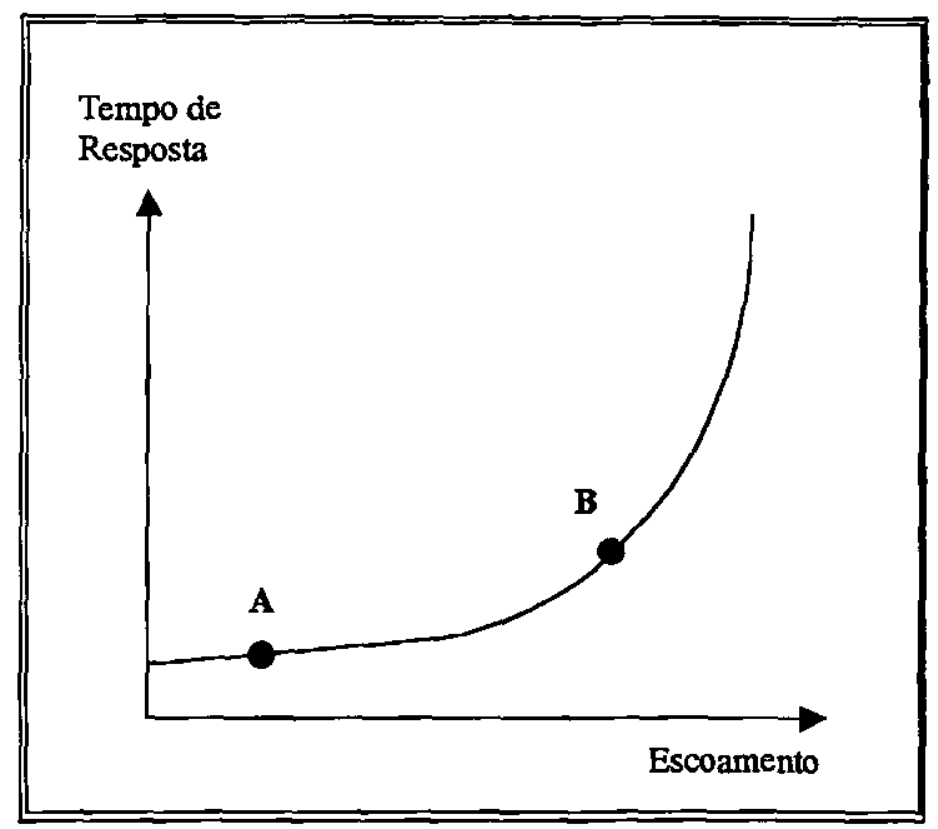

Figura 3.1 - Gráfico relacionando o escoamento $\theta$ o tempo de resposta

Tomando como base a Figura 3.1, quando a carga de sistema é ligeiramente aumentada, o tempo de resposta fica levemente modificado, caso o sistema esteja operando no ponto $B$ da curva. Por outro lado, se o sistema opera no ponto A, pode-se aplicar um grande aumento na carga sem modificar o desempenho, uma vez que o sistema continuará fornecendo um tempo de resposta satisfatório. Sendo assim, um dos objetivos da avaliacão de desempenho é identificar em que ponto da curva o sistema opera (Westphall,1987).

Relacionando-se o tamanho da fila, que cresce com o aumento da carga, com a utilização de um determinado recurso, pode-se obter a curva ilustrada na Figura 3.2 (Westphall,1987).

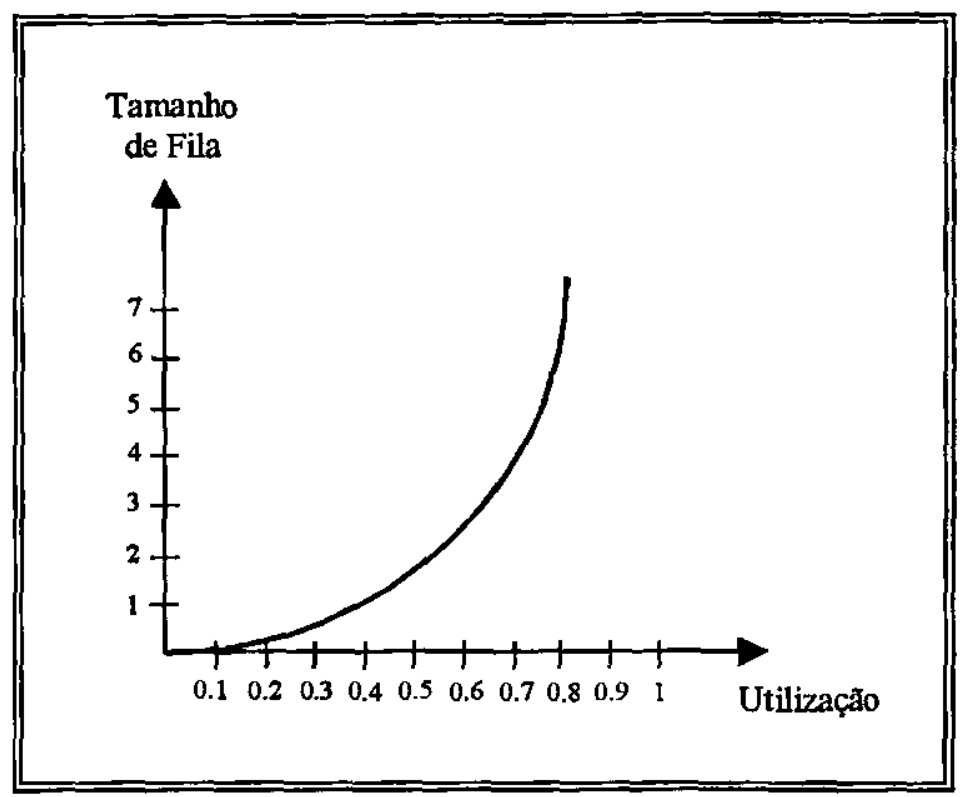

Figura 3.2 - Curva genérica de filas 
Para atingir de forma satisfatória as características de fila, como regra geral, deve-se projetar/construir um sistema de forma que a carga de trabalho não exceda a utilização de aproximadamente 60 a $70 \%$. Na Figura 3.2, observa-se que atingida a utilização de aproximadamente $70 \%$, o tamanho da fila passa a aumentar bruscamente, caracterizando um sistema saturado (Westphall,1987).

\subsection{Teoria de Filas}

A teoria de filas é um ramo da probabilidade que estuda sistemas geradores de espera, chamados de Sistemas de Filas (Allen,1978).

Um dos objetivos principais do estudo de filas é permitir a previsão do que irá acontecer se forem feitas determinadas mudanças. Por intermédio de modelos, que devem representar de forma satisfatória o sistema a ser avaliado, é que é feita essa previsão a respeito do comportamento do sistema, permitindo a tomada de decisões de forma mais consistente (Allen,1978).

A exemplo de algumas mudanças que podem ser feitas no sistema, tem-se: um aumento na taxa de chegada de clientes, uma redução no tempo de serviço; um aumento do número de servidores; uma diminuição no tamanho máximo da fila (fila finita).

Baseado na teoria de filas, foi criada uma técnica, denominada Rede de Filas, para modelar sistemas nos quais a ocorrência de filas existe (Francês, 1998).

\subsection{Caracteristicas de Rede de Filas}

O modelo representativo desse sistema deve ser construído considerando os elementos básicos, além de obedecer algumas regras de notação, de maneira a especificar o comportamento do sistema.

\subsubsection{Elementos Básicos de Rede de Filas}

Um modelo de Rede de Filas é uma coleção de servidores, os quais representam recursos do sistema; e de clientes (jobs ou requisiçōes), dispostos em áreas de espera (filas), que solicitam a prestação de um serviço a um determinado servidor. Um ou mais servidores e uma ou mais áreas de espera formam um Centro de Serviço (Soares, 1990). Desta forma, Rede de Filas possuem como elementos básicos centros de serviço com um ou mais servidores e uma ou mais filas de clientes. Uma fila pode possuir tamanho limitado, denominada fila 
finita, suportando apenas uma quantidade limitada de clientes. Por outro lado, denomina-se de fila infinita aquela que suporta infinitos clientes (Lazowska,1984).

Outros conceito importante é o de sala de espera, aplicado sistemas cujo comprimento da fila, permitindo que os clientes que chegam após o esgotamento da capacidade da fila possam aguardar para entrar no sistema (Jain,1991)

A seguir serão ilustradas duas situaçōes: um centro de serviço com um único servidor (Figura 3.3) e outro com múltiplos servidorés (Figura 3.4).

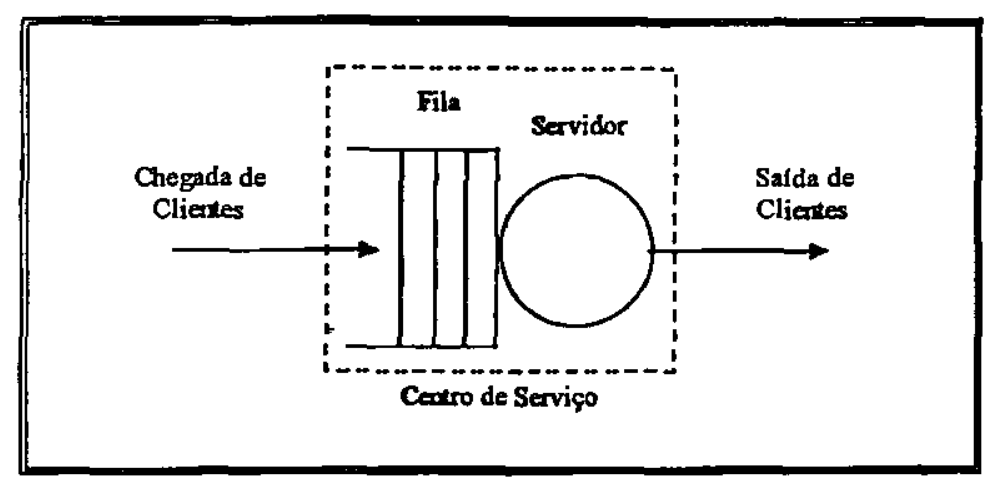

Figura 3.3 - Centro de Serviço com apenas um Servidor

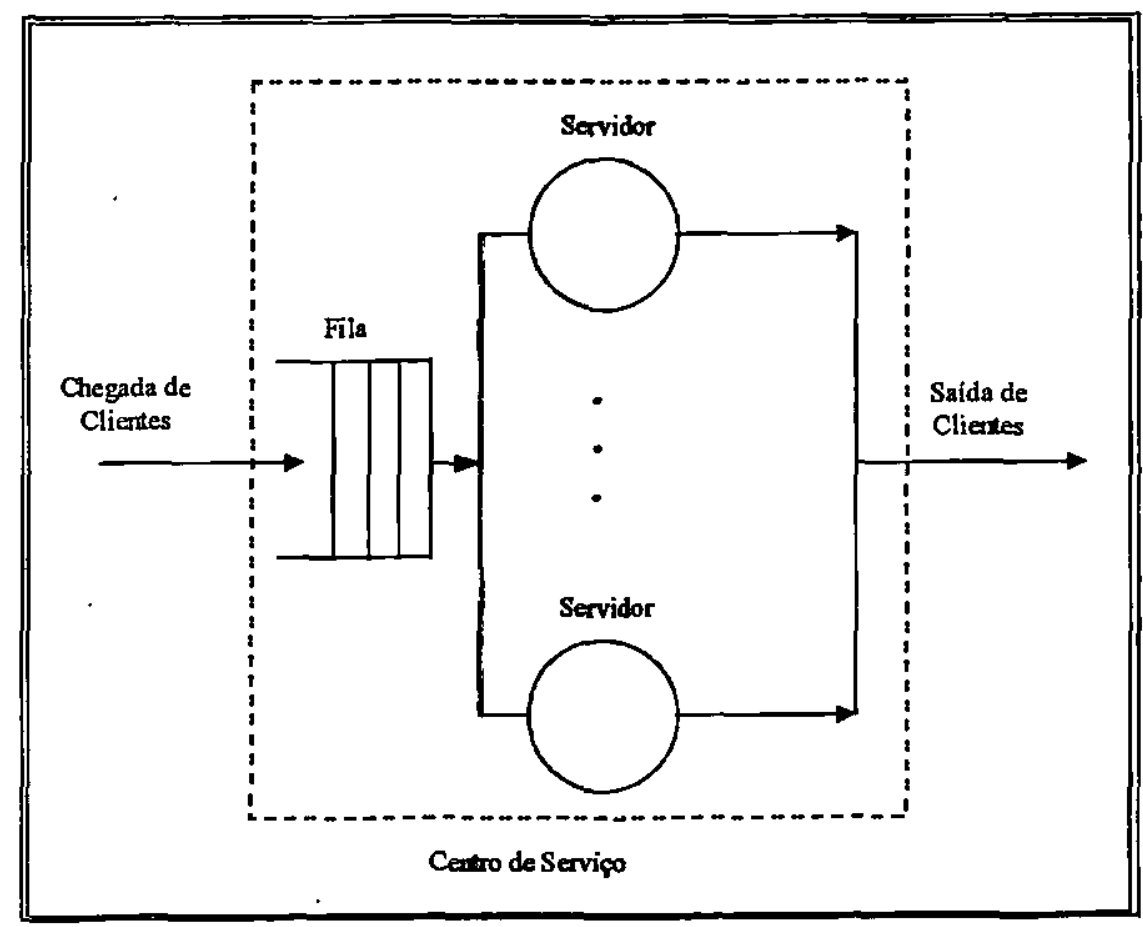

Figura 3.4 - Centro de Serviço com múltiplos Servidores

Os Centros de Serviços, como os representados na Figura 3.3 e na Figura 3.4, também são chamados de Recursos Ativos. Porém, existem também os que são chamados de Recursos Passivos, que são aqueles recursos que não realizam nenhum tipo de "serviço". Centro de serviços passivos são uma extensão às rede de filas convencionais, por exemplo, a memória 
de um computador um recurso que poderia ser representado como um centro de serviço passivo(Soares, 1990).

\section{Tipos de Centros de Serviço}

Os centros de serviço de modelo de rede de filas podem ser de três tipos: centros de capacidade fixa e centros delay. Em um centro de capacidade fixa os clientes competem pelo servidor, sendo representado por uma fila e um ou mais servidores, como mostra a Figura 3.5. Os centros de capacidade fixa possuem um número fixo de servidores. No caso de possuir um único servido, esse tipo de centro é denominado de centro de fila (Figura 3.5).

Por outro lado, em um centro delay não há concorrência entre os clientes, já que consiste não possui fila e o número de servidores não é fixo, sendo então representado apenas por um centros com número infinito de servidores em paralelo, como demonstra também pela Figura 3.5 (Lazowska,1984) (Jain,1991).

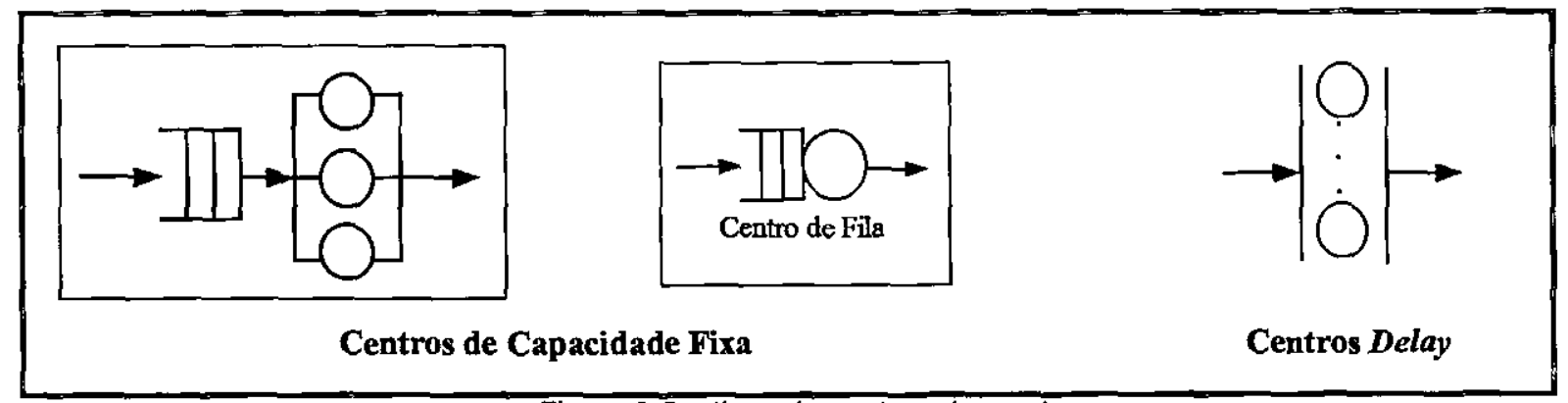

Figura 3.5 - tipos de centros de serviço

Além disso, centros de serviço podem ser dependentes ou independentes de carga. Um centro dependente de carga, é um centro cuja taxa de serviço varia de acordo com o número de clientes presentes no sistema, podendo, por exemplo, aumenta a sua taxa de serviço (ou taxa com que os clientes são atendidos) quando a quantidade de clientes for muito alta. Por outro lado, um centro de serviço independente de carga, mantém sua taxa constante, independentemente do número de clientes (Lazowska,1984).

\section{Classes de Clientes}

Para que possa existir distinção entre os vários clientes que circulam em um modelo, utiliza-se o conceito de Classe de Clientes. Assim, um modelo pode possuir uma ou mais classes de clientes (por exemplo, classe A, B, C, ...).

Quando um modelo possui mais de uma classe de clientes, pode-se estabelecer prioridades entre as mesmas, trajetórias distintas para cada delas, etc. 


\section{Rede Aberta, Fechada e Mista}

Dentre os modelos de Rede de Filas existem as Redes Abertas, as Fechadas e as Mistas. Nas Abertas, os clientes, que correspondem aos $M$ terminais da Figura 3.6, entram no sistema e obrigatoriamente saem. Entretanto, nas Redes Fechadas, o número de clientes que circulam no modelo é fixo, de forma que nem entram e nem saem clientes. Por fim, em uma Rede Mista o modelo se apresenta como uma rede aberta para certas classes de clientes, e fechada para outras (Lazowska,1984).

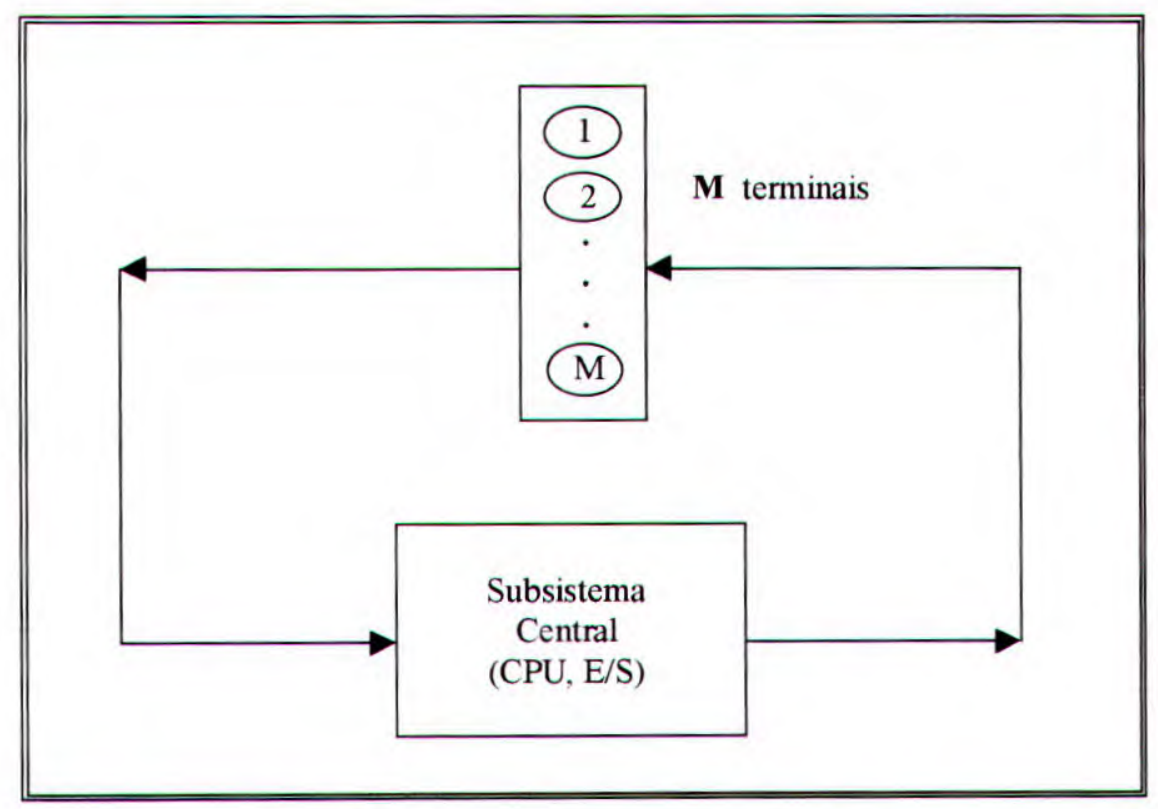

Figura 3.6 - Sistema de tempo compartilhado

Considerando-se o Subsistema Central da Figura 3.6, ilustra-se modelos de Rede Aberta, Fechada e Mista por intermédio da Figura 3.7.

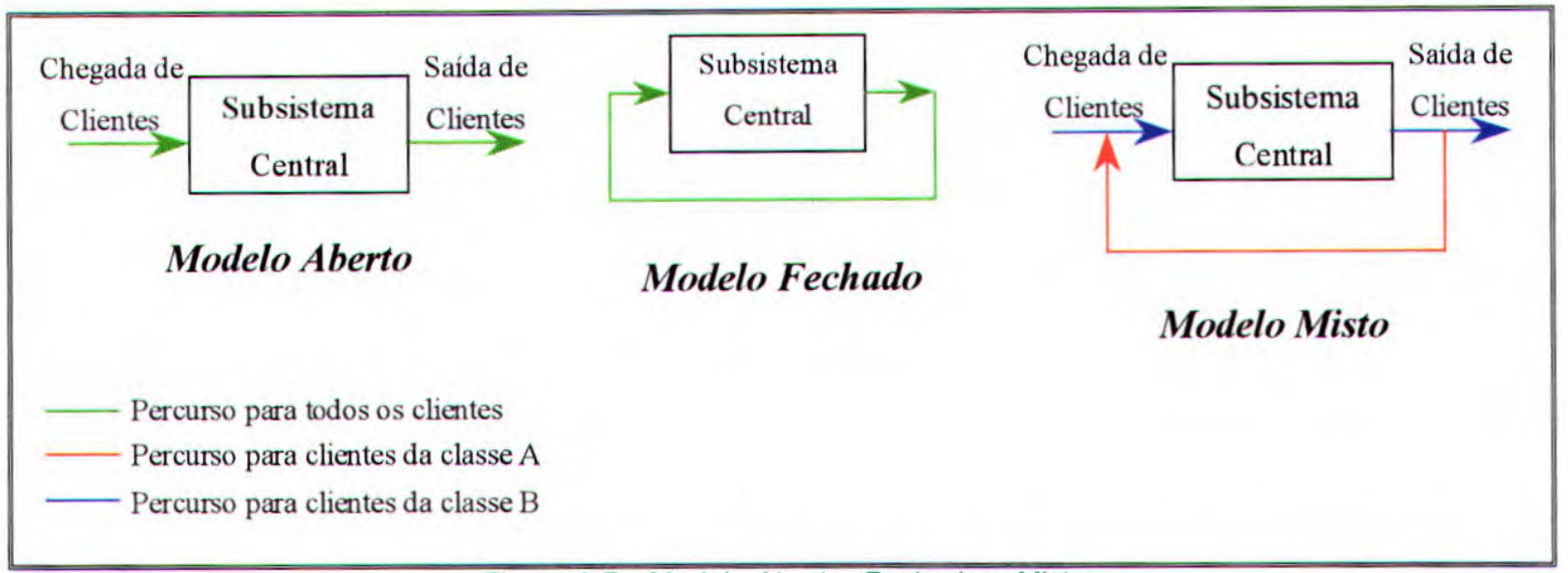

Figura 3.7 - Modelo Aberto, Fechado e Misto 


\subsubsection{Notação para Rede de Filas}

A notação de um sistema de filas é baseada nos parâmetros abaixo (Kleinrock, 1976):

Distribuição dos tempos entre chegadas, simbolizado por A. Refere-se à forma como os clientes entram no sistema, que pode ser, por exemplo, através de uma distribuição exponencial.

Distribuição do tempo de serviço, o B. Descreve a maneira como os clientes são atendidos, que pode, por exemplo, ser descrito pelo tempo médio de serviço (ou tempo de processamento), ou também pelo número médio de clientes atendidos por unidade de tempo.

O número de servidores, o c.

A capacidade do sistema, o K. Refere-se a quantidade de clientes permitida no sistema (tamanho da fila), que pode ser finita ou infinita.

$>\mathbf{O}$ número de clientes na fonte, $\mathbf{~ m}$. A fonte de clientes pode ser finita ou infinita.

$>$ A disciplina de fila, o Z. Especifica a política de atendimento, ou seja, como os clientes vão ser selecionados dentre os que estão esperando. As políticas de atendimento são: FIFO, LIFO, RR e etc.

A junção desses parâmetros resulta na notação $\mathbf{A} / \mathbf{B} / \mathbf{c} / \mathbf{K} / \mathbf{m} / \mathbf{Z}$. Uma notação usualmente empregada é a $\mathbf{A} / \mathbf{B} / \mathbf{c}$ (que é uma simplificaģa da anterior), que assume que o tamanho da fila é infinito, a fonte de clientes também infinita e a disciplina da fila é FIFO (First Im First Out) (Orlandi, 1995). Abaixo serão descritos os valores que A e B podem assumir (Kleinrock,1976) (Allen,1990):

G distribuição geral. Denota a utilização de distribuições arbitrárias, que, por exemplo, pode ser nenhuma das distribuições citadas abaixo ou um conjunto delas;

$\mathbf{H}_{\mathbf{k}}$ distribuição hiperexponencial de estágio k. $\dot{\mathrm{E}}$ um caso particular de distribuição exponencial que admite urna variância muito grande em relação à média;

$\mathbf{E}_{\mathbf{k}}$ distribuição de Erlang de estágio $\mathrm{k}$. É a distribuição derivada da soma de um número inteiro de variáveis aleatórias independentes e exponencialmente distribuídas; 
M distribuição exponencial. É a distribuição cuja probabilidade de acontecer um evento em um pequeno intervalo de tempo é proporcional ao tamanho desse intervalo;

D distribuição determinística, ou seja, tempo de serviço ou de tempo entre chegadas são valores constantes.

A partir da simplificação citada anteriormente, obtêm-se um sistema de fila muito comum, o M/M/1, que se caracteriza por apresentar tempo entre chegadas de clientes e tempo de serviço obedecendo à uma distribuição exponencial, e por possuir um único servidor (Kleinrock, 1976).

Os parâmetros representativos do sistema (A e B) obedecem sempre a uma forma de distribuição de probabilidade. Algumas distribuições utilizadas são: Uniforme, Exponencial e Poisson. Mais detalhes sobre esse assunto podem ser encontrados em (Soares, 1990), (Allen, 1990), (Farias, 1991) e (Jain, 1991).

\subsection{Regras para Modelos de Rede de Filas}

Dois fatores formam a essência da teoria das filas: a chegada de clientes (o padrão e a taxa em que os clientes chegam a uma fila) e o serviço nos centros (o padrão e a taxa de serviço dos servidores). Tais parâmetros influenciam o comportamento do sistema de filas, a partir dos quais é possivel calcular medidas de desempenho, tais como utilização de um centro de serviço, tempo de resposta de um centro serviço e comprimento da fila de um centro de serviço. Essas medidas de desempenho podem ser obtidas por intermédio de algumas relações algébricas, que serão apresentadas nesta seção. Algumas dessas relações, por serem de grande relevância à avaliação de desempenho de modelos de Rede de Filas, são chamadas de Leis Operacionais, também conhecidas como Leis Fundamentais (Lazowska,1984) e (Jain,1991).

Antes de um estudo efetivo a respeito dessas relações algébricas, faz-se necessário conhecer a definição e notação de algumas variáveis (Lazowska,1984), (Menascé,1985) e (Jain, 1991):

\footnotetext{
$>\tau=$ tempo entre chegadas, isto é, o tempo entre duas chegadas sucessivas.

$>\lambda=$ taxa média de chegada $=1 / E[\tau]$, onde $E[\tau]$ é o tempo médio entre chegadas.

$>s=$ tempo de serviço por cliente.
} 
$>\mu=$ taxa média de serviço por servidor $=1 / E[s]$, onde $E[s]$ é o tempo médio de serviço. A taxa de serviço total para $c$ servidores é $c \mu$.

$n=$ número de clientes no sistema, também chamada de comprimento da fila.

Essa variável inclui tanto os clientes que estão recebendo serviço quanto os clientes que estão esperando na fila.

$n_{q}=$ número de clientes esperando para receber serviço, ou seja, esperando na fila para serem atendidos pelo servidor. Sempre, $n_{q}$ é menor que $n$.

$n_{s}=$ número de clientes recebendo serviço.

$>r=$ tempo de resposta ou tempo no sistema. Inclui tanto o tempo de espera como o tempo de recebimento de serviço (ou de atendimento).

$w$ = tempo de espera ou tempo de fila, isto é, o intervalo de tempo entre a chegada $\mathrm{e} o$ instante em que inicia o serviço.

Com exceção de $\lambda$ e $\mu$ (que são valores médios), todas são variáveis aleatórias. As equações que serão apresentadas nesta seção são resultados de relações algébricas existentes entre essas variáveis (Jain,1991). A Figura 3.8 traz as variáveis aleatórias freqüentemente usadas no estudo de sistemas de filas (Allen,1978).

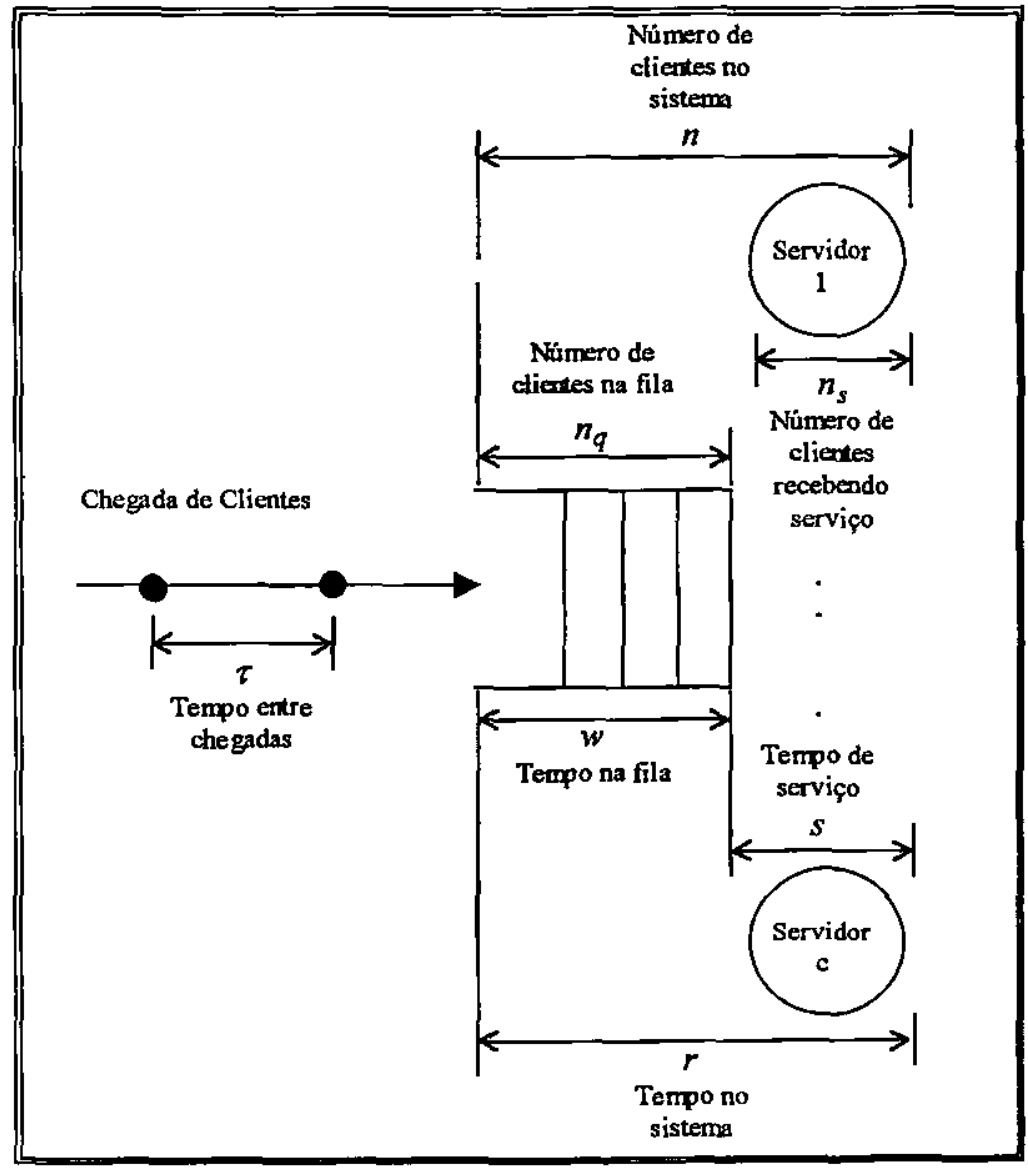

Figura 3.8 - Variáveis aleatónias 
É importante citar que os próximos quatro itens apresentam equações válidas somente para sistemas de fila única. Posteriormente, na secão referente às Leis Operacionais, encontram-se as relações algébricas aplicáveis tanto a sistemas de fila única quanto a sistemas com uma rede de várias filas (Jain, 1991).

\subsubsection{Condição de Estabilidade}

Um sistema é dito instável quando a quantidade de clientes aumenta de forma contínua, tendendo ao infinito. Para que um sistema seja considerado estável, a taxa média de chegada deve ser menor que a taxa média de serviço (Jain,1991).

$$
\lambda<c \mu
$$

Onde, $c$ é número de servidores.

Assim, com a condição de estabilidade satisfeita, consegue-se dar vazão ao sistema, evitando-se que a quantidade de clientes tenda ao infinito, o que impede a formação de filas enormes.

Conclui-se, então, que essa regra de condição de estabilidade não precisa ser aplicada a sistemas com sala de espera e fila finitas, já que o sistema nunca se tornará instável, uma vez que o comprimento da fila é finito e são perdidos todos os clientes que chegam após o esgotamento da capacidade da sala de espera (Jain,1991).

\subsubsection{Clientes no Sistema versos Clientes na Fila}

Uma das regras obtidas dessa relação, conforme a equação abaixo, diz que o número de clientes no sistema é sempre igual à soma da quantidade de clientes na fila e a quantidade de clientes recebendo atendimento (Jain, 1991).

$$
n=n_{q}+n_{s}
$$

Sendo a equação acima composta por variáveis aleatórias, essa igualdade é válida também quando a relação algébrica envolve suas médias. Assim, o número médio de clientes no sistema é igual a soma do número médio de clientes na fila $\mathrm{e}$ o número médio de clientes recebendo serviço, como mostra a equação a seguir (Jain,1991).

$$
E[n]=E\left[n_{q}\right]+E\left[n_{s}\right]
$$




\subsubsection{Tempo de Resposta versos Tempo de Fila}

O tempo de resposta é o tempo gasto pelo cliente no șistema, incluindo o seu tempo de espera na fila e o tempo que passou recebendo serviço (ou sendo atendido) (Jain, 1991), conforme a seguinte relação:

$$
r=w+s
$$

Novamente, por se tratar de variáveis aleatórias, essa igualdade é válida para relacionar suas médias e também suas variâncias (Jain,1991):

$$
E[r]=E[w]+E[s]
$$

\subsubsection{Leis Operacionais}

Aṣ Leis Operacionais descrevem relações algébricas simples, porém de grande relevância à Teoria de Filas, permitindo que modelos de rede de filas tenham os seus desempenhos avaliados, sem que seja necessária a utilização de hipóteses sobre a distribuição dos tempos de serviço ou tempos entre chegadas (Jain, 1991).

Paro o estudo das Leis Operacionais é importante o conceito de amostras operacionais, que correspondem à valores que podem ser medidos durante um período de observação finito. $\mathrm{Na}$ observação de um dispositivo i (servidor) qualquer, durante um tempo $\mathrm{T}$ finito, obtêm-se, por exemplo, as seguintes variáveis operacionais (Jain,1991):

$>A_{i}=$ número de chegadas de clientes

$>C_{1}=$ número de serviço (clientes) completado

$>B_{t}=$ tempo em que o servidor permaneceu ocupado

A partir dessas variáveis, podem-se obter outras variáveis operacionais, que são chamada de amostras operacionais derivadas.

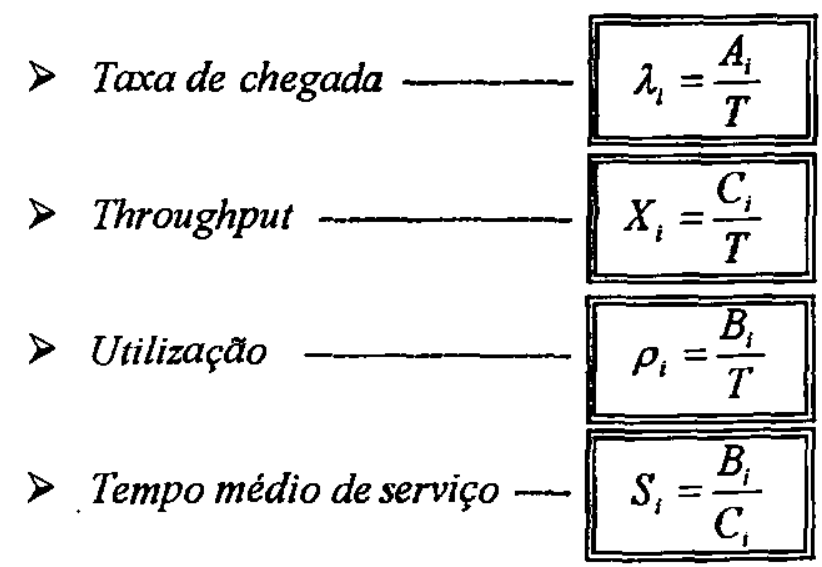


As amostras operacionais podem mudar de um periodo de observaça para outro, mas, existem certas relações algébricas que se mantêm em todo o periodo de observação. Essas relações são denominadas Leis Operacionais (Jain,1991), que podem ser encontradas na literatura inerente, como (Menascé,1985), (Jain,1991), (Lazowska,1984), (Allen,1978).

$\mathrm{Na}$ medição de um sistema real ou simulado, existem clientes na fila ou recebendo atendimento, durante o período de observação. No entanto, se o período é suficientemente longo, o número de chegadas deve ser aproximadamente igual ao número de clientes que são completados $(\mathrm{C} \approx \mathrm{A}$ ), sendo assim, pode-se assumir que $\lambda \approx \mathrm{X}$ (isto é, taxa de chegada do sistema é igual ao throughput do sistema). Isto é chamado de Balanceamento de Fluxo, onde o fluxo de trabalho que sai do sistema é balanceado com o fluxo de trabalho que entra nele (MacDougall, 1989). Durante a descrição das Leis Operacionais, será considerado o Balanceamento de Fluxo (Jain,1991) e (Allen,1978).

\subsubsection{Lei de Little}

A Lei de Little, que corresponde à lei de maior importância, expressa que sistemas cheios (um valor de $n$ grande) estão associados a longos atrasos' de clientes (grande valor de $T$ ), e vice-versa (Lazowska,1984). Onde $n$ é número médio de clientes observados no sistema durante o período de tempo de observação $T$.

Considerando $n$ como sendo o número médio de clientes no sistema durante o periodo de observação, e o $r$ como o tempo médio gasto pelos clientes no sistema (também chamado de tempo de permanência) e definindo-se $r_{n}$ como o tempo gasto no sistema pelo $n$-ésimo cliente, então $r=\sum r_{n}$. O número médio de clientes no sistema é, então, $n=r \frac{C}{T}$. Assim, sabendo-se que o troughput é dado por $X=\frac{C}{T}$, expressa-se a Lei de Little por (MacDougall, 1989):

$$
n=X \cdot r
$$

Considerando o Balanceamento de Fluxo:

$$
n=\lambda \cdot r
$$

A Lei de Little pode ser aplicada em vários níveis do sistema. Por exemplo, considerando-se $n_{l}$ como o número médio de clientes no dispositivo $i$ e $r_{i}$ o tempo médio de resposta do dispositivo $i$, tem-se que:

$$
n_{i}=X_{i} \cdot r_{i} \text { ou } n_{i}=\lambda \cdot r_{i}
$$




\subsubsection{Lei do Fluxo Forçado}

A Lei do Fluxo Forçado relata o throughput do sistema em relação ao throughput individual dos dispositivos. Para isso, deve-se considerar que:

- Em um modelo aberto, o número de clientes que chegam ao sistema por unidade de tempo representa o throughput do sistema.

- Em um modelo fechado, no entanto, não há clientes chegando ao sistema. Assim, considera-se o esquema da Figura 3.9, que mostra que um modelo fechado pode ser visto como um modelo aberto com realimentação (todos clientes que saem voltam imediatamente para o sistema), onde a saída é representada pelo link OUT e a entrada, pelo link IN.

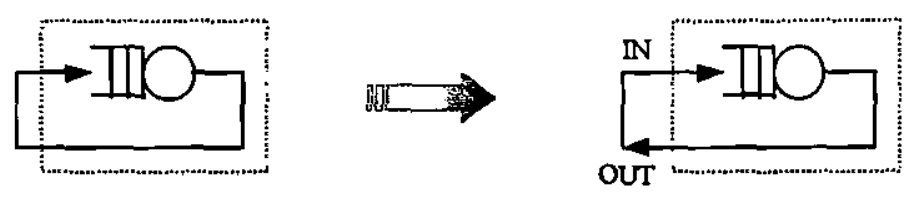

Figura 3.9-Links in $\theta$ Out para Modelo Fөchados

Diante dessas considerações, se no periodo de observação $T$, o número de clientes que chega em cada dispositivo é igual ao número de clientes que saem, ou seja, $A_{i}=C_{i}$, diz-se que os dispositivos satisfazem a hipótese de Fluxo Balanceado.

Tendo um fluxo de clientes balanceado, supondo-se que cada cliente faça $V_{i}$ requisições ao $i$-ésimo dispositivo do sistema, o mimero de clientes que saem do sistema (ou que são completados) $\left(C_{0}\right)$ e o número de clientes que visitam o $i$-ésimo dispositivo $\left(C_{i}\right)$ são descritos por:

$$
C_{i}=C_{0} \cdot V_{i} \quad \text { ou } \quad V_{i}=\frac{C_{i}}{C_{0}}
$$

Sendo assim, A variável $V_{i}$ é a taxa de visitas ao $i$-ésimo dispositivo e ao lado de fora do modelo. Assim, durante o tempo de observação, o throughput do sistema é dado por:

$$
X=\frac{C_{0}}{T}
$$

Por outro lado, o throughput para cada dispositivo $i$ é: $X_{i}=\frac{C_{i}}{T}=\frac{C_{i}}{C_{0}} \cdot \frac{C_{0}}{T}$

Isto é, a Lei do Fluxo Forçado é dada por $X_{i}=X \cdot V_{i}$ 


\subsubsection{Lei de Utilização}

Sabe-se que a Utilização é dada por $\rho_{i}=\frac{B_{i}}{T}$. Algebricamente, $\frac{B_{i}}{T}=\frac{C_{i}}{T} \cdot \frac{B_{i}}{C_{i}}$. Sabendo que $\frac{C_{i}}{T}=X_{i}$ e $\frac{B_{i}}{C_{i}}=S_{i}$, expressa-se a Lei de Utilização como:

$$
\rho_{i}=X_{i} S_{i}
$$

Considerando a hipótese operacionalmente comprovável de Balanceamento de Fluxo, tem-se:

$$
\rho_{i}=S_{i} \lambda
$$

É importante lembrar que a utilização de um dispositivo não pode ser maior do que $100 \%$, ou seja, $U_{\leq} 1$ (MacDougall,1989).

Combinando a Lei de Utilização com a Lei do Fluxo Forçado, tem-se:

$$
\rho_{i}=X_{i} S_{i}=X V_{i} S_{i}
$$

\subsubsection{Lei Geral do Tempo de Resposta}

Considerando-se a Figura 3.6, onde há um terminal por usuário e o resto do sistema é compartilhado por todos, pode-se dividir o sistema em duas partes: os terminais e o subsistema central.

Segundo a Lei de Little, pode-se aplicar a sistema em referência a seguinte equação:

$$
n=X \cdot r \text {, }
$$

onde $n$ é número de clientes no sistema, $r$ é o tempo de resposta do sistema,

$$
\text { e } X \text { é o throughput do sistema. }
$$

Sabendo-se que $n_{i}$ é número de clientes que estão apenas no dispositivo $i, n$ pode ser calculado por:

$$
n=n_{1}+n_{2}+\cdots+n_{M},
$$

onde $M$ é a quantidade de dispositivos do sistema.

Substituindo-se a variável $n_{i}$ pela equação $n_{i}=X_{i} \cdot r_{i}$ (Lei de Little), obtêm-se:

$$
X r=X_{1} r_{1}+X_{2} r_{2}+\cdots+X_{M} r_{M}
$$


Dividindo-se ambos os lados dessa equação por $X$, obtêm-se, por intermédio da Lei do Fluxo Forçado, a Lei Geral do Tempo de Resposta:

$$
r=V_{1} r_{1}+V_{2} r_{2}+\cdots+V_{M} r_{M} \text { ou } r=\sum_{i=1}^{M} V_{i} r_{i}
$$

\subsubsection{Lei do Tempo de Resposta Interativo}

Considerando-se o sistema computacional da Figura 3.6, para a obtenção da expressão que representa a Lei do Tempo de Resposta, será necessário definir o seguinte:

$>\mathbf{Z}$ é a representação do tempo médio de pensar. "Uma transação está no terminal quando o usuánio está pensando elou digitando a próxima requisição após recebida a respasta da requisição anterior. Este tempo é denominado tempo de pensar" (Manascé,1985);

$\mathbf{X}$ transações/seg é a taxa de processamento do sistema;

$\mathbf{R}$ é o tempo médio de resposta do sistema.

Diante do exposto, têm-se:

$>$ o tempo médio que uma transação leva para completar um ciclo completo, incluindo uma passagem pelo Subsistema Central e uma pelos terminais, é $(\mathrm{R}+\mathrm{Z})$;

assumindo que o número de transaçסes (clientes) que saem do subsistema central é igual ao número de transações que nele chegam, tem-se que a taxa de processamento $\mathrm{X}_{0}$ pode ser interpretada como sendo a taxa média na qual ciclos são completados. Assim, pela Lei de Little $(n=r X),(Z+R) X$ deve ser o número médio de pedidos (clientes) em um ciclo, que é igual ao número de terminais ativos. Logo, $M=(Z+R) X$.

Desta forma, com o auxilio da Lei de Little pode-se obter a Lei do Tempo de Resposta, definida pela seguinte expressão:

$$
R=\frac{M}{X}-Z
$$

Esta Lei é comumente utilizada no contexto de um sistema de tempo compartilhado (timesharing).

O tempo de pensar, representado pelo $Z$, valerá 0 (zero) quando o sistema computacional se tratar de uma rede aberta. 


\subsection{Considerações Finais}

A construção de um modelo de Rede de Filas deve seguir algumas regras, para que suas características possam representar com fidelidade o sistema a ser avaliado. Na avaliação de desempenho, modelos corretos proporcionam resultados válidos. Tais resultados podem ser obtidos por meio de relações algébricas existentes entre as variáveis utilizadas no estudo de sistemas de filas. As relações algébricas mais importantes são denominadas de Leis Operacionais. As soluções de modelos encontram-se fundamentadas nessas relações (Jain, 1991).

Soluções de modelos de Rede de Filas é o tema do capítulo seguinte, onde serão abordados métodos de solução analítica e de Simulação, possibilitando a análise e comparação dos mesmos. 


\section{Capítulo 4}

\section{Soluções para o Modelo}

\subsection{Considerações Iniciais}

Toda técnica de Modelagem gera um modelo que exige uma solução, de forma que solucionar um modelo significa obter as informações necessárias à avaliação do sistema, isto é, obter as medidas de desempenho desejadas. Essa Solução pode ser Analítica ou por Simulação (Jain,1991) (Santana, 1997).

A solução Analitica, requer expressões matemáticas para solucionar o modelo. Por outro lado, no caso de uma Simulação, é necessário um programa computacional para implementar o modelo, o qual deve ser executado para gerar os dados necessários à avaliação desejada (Orlandi, 1995) (Santana, 1997).

Em ambas soluções é preciso escolher de que forma será conduzida a solução de um. modelo. No caso de solução analítica, isso significa selecionar a forma pela qual serão obtidas as medidas de desempenho. Considerando-se a Simulação, essa escolha representa optar por um ambiente computacional (programação em linguagens convencionais, utilização de ambientes de simulação existentes, etc.) (Orlandi,1995).

Este capitulo estará voltado para o caso da modelagem utilizando-se Redes de Fila, onde, além da solução por simulação, são expostas algumas formas de se obter analiticamente o desempenho do modelo, tais como Limites de Desempenho (limites assintóticos), Decomposição Hierárquica, Rede de Jackson, Rede BCMP, etc.

\subsection{Solução Analitica}

Em se tratando de solução analítica, não se pode deixar de falar de equilíbrio, já que o modelo só poderá ser solucionado analiticamente se o mesmo estiver em equilibrio. $O$ 
equilibrio é definido pela expressão $(\rho<1)$, onde $\rho$ representa a utilização do sistema em avaliação, que pode ser definida por $\rho=\frac{\lambda}{c \mu}$. Dessa forma, um modelo se encontra em equilíbrio quando a taxa com que os clientes chegam ao sistema $(\lambda)$ é menor do que a taxa com que os mesmos são atendidos pelo sistema $(c \mu)$, onde $c$ é o número de servidores.

Existem várias formas de se obter analiticamente o desempenho de um sistema, mas todas elas consideram que o sistema está em equilibrio. Algumas dessas formas, que, para simplificar, serão chamadas de formas ou métodos analíticos, serão expostas ainda neste capítulo.

Dependendo do grau de complexidade do modelo, que é determinado pela quantidade de detalhes extraídos do sistema real, há situações cuja aplicação dessas formas analíticas é extremamente simples e outras cuja aplicação se torna inviável, podendo acontecer de não existir solução analítica para o modelo (Orlandi,1995) (Soares, 1990).

No caso de um modelo muito complexo, pode-se submetê-lo a algumas simplificações até que ele se adeqüe às restrições do método analítico a ser aplicado, tornando assim viável a sua solução analítica. Essas restrições impostas ao modelo de Redes de Fila podem fazer com que o mesmo passe a ser uma representação inconsistente do sistema real (Orlandi,1995) (Soares,1990). Segundo (Soares, 1990), as restrições sāo as seguintes:

A posse simultânea dè recursos não é permitida;

Somente recursos ativos são permitidos;

Para a disciplina FIFO, a distribuição do tempo de serviço deve ser exponencial.

\subsubsection{Métodos Analiticos}

Para solucionar analiticamente um modelo, um método analítico deve ser selecionado, através do qual serão obtidas as medidas de desempenho desejadas. Os métodos analíticos se encontram distribuídos em dois grupos: métodos para modelos abertos e métodos para modelos fechados (Lazowska,1984) (Jain, 1991). A Figura 4.1 traz alguns desses métodos. 


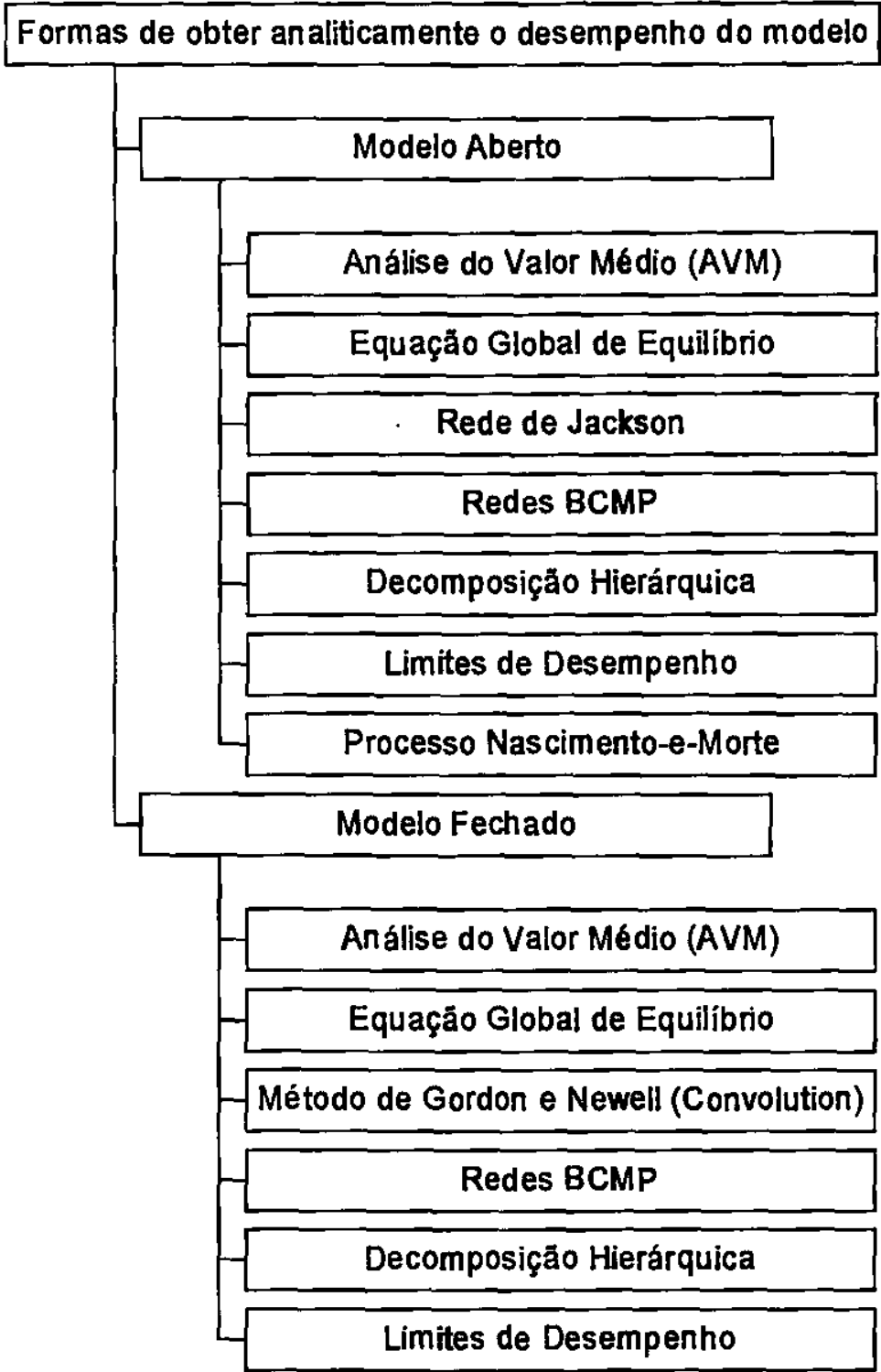

Figura 4.1 - Relaçāo de Métodos Analiticos

Cada um desses métodos, que se referem a modelos de rede de filas, serão abordados nos próximos itens deste capítulo e, no capítulo seguinte, encontram-se aplicados a modelos de sistemas computacionais distribuídos.

\subsubsection{Análise do Valor Médio}

A Análise do Valor Médio (AVM) é um método simples, que permite solucionar tanto modelos abertos, como fechados, onde os parâmetros de entrada e saída assumem apenas valores médios. Por esse motivo, deve-se aplicar esse método a modelos que possuam parâmetros com variância pequena (Lazowska, 1984) (Orlandi,1995).

Por outro lado, com esse método é possivel avaliar o desempenho de modelos com uma variedade de disciplinas de atendimento e distribuições de tempo de serviço, além do fato de 
poder ser aplicado tanto a modelos de única ou múltipla classe de clientes. Além disso, no caso de modelos fechados, pode-se aplicar o método AVM também para modelos que possuem centros de serviço dependentes de carga, como mostra o Algoritmo 4.4 (Lazowska, 1984) (Allen, 1990).

\section{AVM para Modelos Abertos}

O método aqui apresentado se refere a modelos abertos com centros independentes de carga, ou seja, o número de clientes em suas filas não altera a taxa de com que os clientes são atendidos (Lazowska, 1984) (Allen, 1990) (Jain, 1991).

A Análise do Valor Médio (AVM) para modelos abertos consiste na aplicação de uma sequuência de fórmulas. Para obtenção dessa seqüência, mostrada no Algoritmo 4.1, necessitase apenas combinar algumas das Leis Operacionais, discutidas no capítulo anterior, com a Equação (4.1) (Lazowska,1984) (Allen, 1990) (Jain,1991).

$$
R_{i}=S_{i} \cdot\left(1+N_{i}\right)
$$

Para entender a Equação (4.1), supõe-se um cliente chegando ao sistema. Ao chegar ao $i$-ésimo centro, esse cliente vê $N_{i}$ clientes, que denota o número médio de clientes na fila mais o que está sendo servido, e fica sabendo que terá que esperar $N_{t} S_{t}$ unidades de tempo para ser atendido. Sendo assim, incluindo o atendimento desse cliente, estima-se um tempo de resposta de $S_{t}\left(1+N_{i}\right)$ (Jain,1991).

Tendo entendido a Equação (4.1), pode-se, juntamente com as Leis Operacionais, obter algumas equações, que serão posteriormente utilizadas pelo Algoritmo 4.1 (Lazowska,1984) (Jain,1991):

Assume-se a hipótese de fluxo de clientes balanceado: $X=\lambda$

Considerando a lei do fluxo forçado: $X_{i}=X \cdot V_{i}$

Usando a Lei de Utilização: $U_{i}=X_{i} \cdot S_{i}=X \cdot V_{i} \cdot S_{i}=\lambda D_{i}$

Usando a Lei de Little, o número médio de clientes em cada centro é:

$$
\begin{gathered}
N_{i}=X_{i} \cdot R_{i}=X_{i} \cdot S_{i}\left(1+N_{i}\right)=U_{i}\left(1+N_{i}\right) \\
N_{i}=\frac{U_{i}}{1-U_{i}}
\end{gathered}
$$

Substituindo a Equação (4.2) na Equação (4.1), tem-se o tempo de resposta:

$$
R_{t}=\frac{S_{i}}{1-U_{i}}
$$


Para centros delay, que possui infinitos servidores, o tempo de resposta é igual ao tempo de serviço, independente do número de cliente no centro. Nesse caso, já que não há esperas, o número médio de clientes no centro denota o número de clientes recebendo serviço. Com isso, tem-se as seguintes equações para centros delay:

$$
\begin{gathered}
R_{i}=S_{i} \\
N_{i}=R_{i} X_{i}=S_{i} X V_{i}=X \cdot D_{i}=U_{i}
\end{gathered}
$$

Com base nas equações apresentadas anteriormente, define-se a seguir a sequuência de equações (Algoritmo 4.1) para a Análise do Valor Médio de modelos abertos (Lazowska, 1984) (Allen, 1990) (Jain,1991):

Parâmetros de Entrada:

$X=$ taxa de chegada extema ou throughput do sistema

$S_{i}=$ tempo de serviço por visita ao i-ésimo centro

$V_{i}=$ Número de visitas ao i-ésimo centro

\section{Parâmetros de Saída:}

$\mathrm{N}_{\mathrm{i}}=$ número médio de clientes no i-ésimo centro

$R_{1}=$ tempo de resposta do i-ésimo centro

$R=$ tempo de resposta do sistema

Início

Calcular para cada centro do sistema:

Demanda de Serviço do centro: $D_{i}=S_{i} V_{i}$

Utilização do centro: $\rho_{i}=X D_{i}$

Throughput do centro: $X_{i}=X V_{i}$

Tempo de Resposta do centro: $R_{i}= \begin{cases}S_{i} /\left(1-\rho_{i}\right) & (\text { Centros de Fila) } \\ S_{i} & (\text { Centros Delay })\end{cases}$

Número de Clientes no centro: $N_{i}= \begin{cases}\rho_{i} /\left(1-\rho_{i}\right) & (\text { Centros de Fila }) \\ \rho_{i} & (\text { Centros Delay })\end{cases}$

Tendo o desempenho de cada centro, calcular para o sistema:

Tempo de Resposta do sistema: $R=\sum_{i=1}^{M} R_{i} V_{i} \quad$, onde $M$ é número de centros

Número de clientes no sistema: $N=\sum_{i=1}^{M} N_{i} \quad$, onde $M$ é número de centros

Fim

Algaritmo 4.1 - AVM para modelos Abertos 
Aplica-se o Algoritmo 4.1 a modelos abertos de classe única de clientes, de forma que, para múltiplas classes basta utilizar essa mesma seqüência de equações para cada classe de clientes. Por exemplo, o throughput para múltiplas classes seria $X_{c, i}=X_{c} V_{c, i}$ e assim por diante, onde $c$ identifica a classe do cliente (Lazowska, 1984).

\section{AVM para Modelos Fechados}

A Análise do Valor Médio aqui discutida, refere-se a modelos fechados com centros independentes de carga. Posteriormente será discutido o método AVM para modelos fechados com centros dependentes de carga $\mathrm{A}$ versão desse método para centros dependentes de carga será abordada no item seguinte (Lazowska, 1984) (Allen, 1990) (Jain, 1991).

No caso de modelos fechados, o método AVM consiste na aplicação de uma sequêencia de equações, apresentada pelo Algoritmo 4.2, onde os resultados são obtidos através de $N$ iterações, onde $N$ é o número de clientes no sistema (Lazowska,1984) (Allen,1990) (Jain,1991).

Existem duas versões para o Algoritmo AVM para modelos fechados, uma exata e outra aproximada. Ambas são baseadas na Equação (4.4), onde o que difere uma versão da outra é o valor assumido pelo termo $A_{i}(N)$, que representa o número médio de clientes vistos no centro $i$ no instante em que um novo cliente chega (Lazowska, 1984).

Primeiramente, será discutido o Algoritmo AVM exato (Algoritmo 4.2), e com base nessa discussão é que será mostrada a versão aproximada, chamada Algortimo AVM aproximado.

Na obtenção do Algoritmo AVM exato, consideram-se as Leis Operacionais, discutidas no capítulo anterior, juntamente com a Equação (4.4), onde o termo $A_{i}(N)$ é equivalente a $N_{i}(N-1)$ (Lazowska,1984).

$$
R_{i}(N)=S_{i} \cdot\left[1+A_{i}(N)\right]
$$

Rescrevendo a Equação (4.4) para o AVM exato, tem-se:

$$
R_{i}(N)=S_{i} \cdot\left[1+N_{i}(N-1)\right]
$$

Para compreender a Equação (4.5), considera-se a chegada do $N$-ésimo cliente a um sistema com $N-1$ cliente. Ao chegar ao $i$-ésimo centro, esse cliente vê $N_{t}(N-1)$ clientes, que representa o número de cliente no $i$-ésimo centro quando existem $N-1$ clientes no sistema, e sabe-se então que irá esperar $N_{i}(N-1) \cdot S_{i}$ unidades de tempo até que seja atendido. Sendo assim, o tempo de resposta será de $S_{i} \cdot\left[1+N_{i}(N-1)\right]($ Jain, 1991). 
Para modelos fechados, similar a modelos abertos, combinam-se as Leis Operacionais com a equação do tempo de resposta (Equação (4.5)) para a obtenção do Algoritmo AVM Exato(Lazowska, 1984) (Jain, 1991):

Dado o tempo de resposta de cada centro (Equação 4.5), o tempo de resposta do sistema usando a Lei geral do tempo de resposta é:

$$
R(N)=\sum_{i=1}^{M} V_{i} R_{i}(N)
$$

O throughput do sistema usando a Lei do tempo de resposta interativo é:

$$
X(N)=\frac{N}{R(N)+Z}
$$

$>$ O throughput do centro medido em termo de clientes por unidade de tempo é:

$$
X_{1}(N)=X(N) \cdot V_{1}
$$

O número médio de clientes no centro, quando existem $N$ clientes no sistema, usando a Lei de Little é:

$$
N_{i}(N)=X_{i}(N) \cdot R_{i}(N)=X(N) \cdot V_{i} \cdot R_{i}(N)
$$

O tempo de resposta para centros delay é:

$$
R_{i}(N)=S_{i}
$$

Baseando-se nessas equações, desenvolve-se o Algoritmo 4.2 (Lazowska,1984) (Allen,1990) (Jain,1991), que calcula o desempenho médio de modelos fechados de classe única de clientes. No caso de múltiplas classes, para cada iteração, aplicam-se para as equações do algoritmo cada uma das classes.

Parâmetros de Entrada:

$\mathrm{N}=$ número de clientes

$Z=$ tempo de pensar

$M=$ número de centros (sem incluir os terminais)

$S_{i}=$ tempo de serviço por visita ao i-ésimo centro

$V_{i}=$ Número de visitas ao i-ésimo centro

\section{Parâmetros de Saida:}

$X=$ taxa de chegada extema ou throughput do sistema

$\mathrm{N}_{i}=$ número médio de clientes no i-ésimo centro

$R_{i}=$ tempo de resposta do i-ésimo centro

$\mathrm{R}=$ tempo de resposta do sistema

$\rho_{i}=$ utilização do i-ésimo centro

Ininicializacão:

Para $i=1$ a $M$ faça $N_{i}=0$ 
Iteracões:

Início

$$
\begin{aligned}
& \text { Para } i=1 \text { a M faça } R_{i}= \begin{cases}S_{i} \cdot\left(1+N_{i}\right) & (\text { Centros de Fila }) \\
S_{i} & (\text { Centros Delay })\end{cases} \\
& R=\sum_{i=1}^{M} R_{i} V_{i} \\
& X=\frac{N}{R+Z} \\
& \text { Para } i=1 \text { a M faça } N_{i}=X \cdot V_{i} \cdot R_{i}
\end{aligned}
$$

Fim

Throughputs dos centros: $X_{i}=X \cdot V_{i}$

Utilização dos centros: $\rho_{i}=X \cdot S_{i} \cdot V_{i}$

Algoritmo 4.2 - Algoritmo AVM Exato para Modelos Fechados

Para compreender o funcionamento desse algoritmo, deve-se ressaltar que, no caso de modelos fechados, o tempo de resposta do $i$-ésimo centro quando existem $N$ clientes no sistema, representado por $R_{i}(N)$ (Equação 4.4) é computado usando o número médio de clientes no $i$-ésimo centro, quando existiam $N-l$ clientes no sistema, $N_{i}(N-1)$. Dessa forma, para o cálculo do atual (ou real) tempo de resposta de um centro, necessita-se do anterior número médio clientes do mesmo (Lazowska, 1984) (Allen, 1990) (Jain, 1991).

Sendo assim, trabalhando-se com modelos fechados, o desempenho do sistema deve ser obtido por intermédio de iterações entre as medidas de desempenho calculadas no momento em que se tem $N$ e $N-1$ clientes no sistema. Para isso, inicia-se a avaliação do modelo considerando que o número médio de clientes é zero para todos os centros, quando o sistema ainda está vazio $\left(N_{i}(0)=0\right)$, possibilitando calcular o tempo de resposta quando se tem 1 cliente no sistema $\left(R_{i}(1)=S_{i} \cdot\left[1+N_{i}(0)\right]\right)$ e assim por diante, até que o número de clientes no sistema seja igual a $N$ (Lazowska,1984) (Allen,1990) (Jain,1991).

No Algoritmo 4.2, no momento em que se calcula o tempo de resposta do centro usando $R_{i}=S_{i} \cdot\left(1+N_{i}\right)$, apesar de não informar explicitamente que se refere ao número de cliente no $i$-ésimo centro quando ainda existiam $N-1$ clientes, na variável $N_{i}$ está sempre armazenado o número de clientes da iteração anterior, isto é, $N_{i}(N-1)$ (Lazowska, 1984) (Allen, 1990) (Jain, 1991). 
Quanto à versão aproximada do Algoritmo AVM, tem-se que o termo $A_{l}(N)$ é equivalente a $h\left[N_{i}(N)\right]$, onde $h\left[N_{i}(N)\right]$ é uma função que deve depender de $N_{i}(N)$ (Lazowska,1984).

Para o Algoritmo AVM Aproximado (Algoritmo 4.3), onde o número de iterações não irá depender apenas do número de cliente $(N)$, mas também do número de centros de serviço, que podem ser centros de capacidade fixa (incluindo os centros de fila) ou delay, necessita-se da Equação (4.8) (Lazowska, 1984):

$$
R_{1}= \begin{cases}S_{i} \cdot\left[1+A_{i}(N)\right] & (\text { Centros de Capacidade Fixa }) \\ S_{i} & (\text { Centros Delay) }\end{cases}
$$

Com base em (Lazowska,1984), a versão aproximada do algoritmo AVM consta dos seguintes passos:

1) Inicialização: $N_{i}(N)=\frac{N}{M}$ para todos os centros $i$.

2) Aproximação: $A_{i}(N)=h\left[N_{i}(N)\right]$ para todos os centros $i$.

3) Utilizam-se as Equações (4.8), (4.6) e (4.7) sucessivamente para calcular um novo conjunto de $N_{i}(N)$.

4) Se o $N_{i}(N)$ obtido no Passo 3 não estiver dentro de uma determinada tolerância (em geral, $0,1 \%$ ) em relação aos usados como entrada no Passo 2, então retornarse ao Passo 2 usando o novo conjunto de $N_{i}(N)$.

Algoritmo 4.3 - Algoritmo AVM Aproximado para Modelos Fochados

O sucesso do algoritmo aproximado depende da função $h$. Um exemplo simples para a essa função é estimar o número médio de clientes em cada centro no instante de chegada, pela aproximação de seu valor exato, o número de clientes no centro com um cliente a menos no sistema (Lazowska, 1984):

$$
\begin{array}{r}
A_{i}(N)=N_{i}(N-1) \\
A_{i}(N) \approx h\left[N_{i}(N)\right] \\
A_{i}(N) \equiv \frac{N-1}{N} N_{i}(N)
\end{array}
$$

Essa aproximação (Equação 4.9) é baseada na hipótese de que as taxas $N_{i}(N) / N$ e $N_{i}(N-1) / N-1$ são iguais para todos os centros $i$, que é satisfatória para situações extremas, isto é, quando $N$ é muito grande ou muito pequeno (Lazowska, 1984). 


\section{AVM para Centros Dependentes de Carga}

Esse método deve ser aplicado a modelos fechados que possuam 1 ou mais centros de serviços dependentes de carga, ou seja, cuja taxa de serviço varia com o número de clientes neles presentes (Lazowska, 1984) (Jain,1991).

A Análise do Valor Médio para centros dependentes de carga consiste em um algoritmo (Algoritmo 4.4), que é obtido por intermédio de alterações feitas em algumas equações do Algoritmo AVM Exato (Algoritmo 4.2) (Lazowska, 1984) (Jain,1991).

Para centros dependentes de carga, a equação do throughput é idêntica à Equação (4.6), no entanto, são diferentes as do tempo de resposta e do número de clientes no centro, representados respectivamente pelas Equações (4.10) e (4.11). Ambas equações mostram que a distribuição do número de clientes em cada centro é importante para centros dependentes de caga, já que a taxa de serviço é uma função do número de clientes no centro. Por esse motivo, ambas equações utilizam o termo $p_{i}(j \mid n)$, que denota a probabilidade de achar $j$ clientes no $i$-ésimo centro quando há $n$ clientes no sistema, mostrada pela Equação (4.12) (Lazowska, 1984) (Jain,1991). Sendo assim, O tempo médio de resposta por visita é dado por:

$$
R_{i}(n)=\sum_{j=1}^{n} p_{i}(j-1 \mid n-1) \frac{j}{\mu_{i}(j)},
$$

onde $\mu_{i}(j)$ é a taxa de serviço do $i$-ésimo centro quando há $j$ clientes nesse centro, e, dessa forma, tem-se que o tempo de resposta do centro para um cliente que está chegando, quando há $j-1$ clientes no sistema, é $j / \mu_{i}(j)$.

O número médio de clientes no $i$-ésimo centro quando há $n$ clientes no sistema é dado por:

$$
N_{i}(n)=\sum_{j=1}^{n} j p_{i}(j \mid n)
$$

Sendo $p_{i}(j \mid n)$ dada por:

$$
p_{i}(j \mid n)= \begin{cases}\frac{X(n)}{\mu_{i}(j)} p_{i}(j-1 \mid n-1), & j=1,2,3, \ldots, n \\ 1-\sum_{k=1}^{n} p_{i}(k \mid n), & j=0\end{cases}
$$

Considerando as Equações (4.10), (4.11) e (4.12), tem-se o Algoritmo AVM capaz de avaliar centros dependentes de carga resumido no Algoritmo (4.4) (Lazowska, 1984) (Jain, 1991): 


\section{Parâmetros de Entrada:}

$N=$ número de clientes

$Z=$ tempo de pensar

$M=$ número de centros (sem incluir os terminais)

$S_{i}=$ tempo de serviço por visita ao $i$-ésimo centro

$V_{i}=$ Número de visitas ao $i$-ésimo centro

$\mu_{i}(j)=$ taxa de serviço do $i$-ésimo centro quando há $j$ clientes nele

\section{Parâmetros de Saida:}

$X=$ taxa de chegada extema ou throughput do sistema

$N_{i}=$ número médio de clientes no $i$-ésimo centro

$R_{i}=$ tempo de resposta do $i$-ésimo centro

$R=$ tempo de resposta do sistema

$\rho_{i}=$ utiiização do $i$-ésimo centro

$p_{i}(j)=$ probabilidade de ter $j$ clientes no $i$-ésimo centro

Ininicialização:

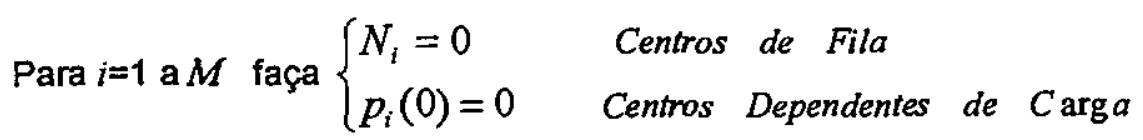

lterações:

Para $n=1$ até $N$ faça

Início

$$
\begin{aligned}
& \text { Para } i=1 \text { até } M \text { faça } R_{i}= \begin{cases}S_{i} \cdot\left(1+N_{i}\right) & (\text { Centros de Capacidade Fixa }) \\
S_{i} & (\text { Centros Delay }) \\
\sum_{j=1}^{n} p_{i}(j-1) \frac{j}{\mu_{i}(j)} & (\text { C.Dependentes C } \arg a)\end{cases} \\
& R=\sum_{i \neq 1}^{M} R_{i} V_{i} \\
& X=\frac{N}{R+Z}
\end{aligned}
$$




$$
\text { Para } i=1 \text { a } M \text { faça }\left\{\begin{array}{l}
N_{i}=X \cdot V_{i} \cdot R_{i} \text { \}Centros Delay ou de Fila } \\
\text { Para } j=n \text { a l faça } p_{i}(j)=\frac{X}{\mu_{i}(j)} p_{i}(j-1) \\
p_{i}(0)=1-\sum_{j=1}^{n} p_{i}(j)
\end{array}\right\} \text { C.Dep.Carga }
$$

Fim

Para $i=1$ a $M$ faça $X_{i}=X \cdot V_{i}$

Para $i=1$ a $M$ faça $\rho_{i}= \begin{cases}X \cdot S_{i} \cdot V_{i} & (\text { Centros Delay ou de Capacidade Fixa }) \\ 1-p_{i}(0) & (\text { Centros Dependente de Carga })\end{cases}$ Algoritmo 4.4 - Algoritmo AVM Exato para Centros Dependentes de Carga

Da mesma forma que o Algoritmo AVM Exato, a versão para centros dependentes de carga aqui apresentada é para modelos fechados de classe única de clientes. No caso de múltiplas classes, para cada iteração, aplicam-se as equações do algoritmo para cada classe (Lazowska, 1984).

\subsubsection{Equação Global de Equilibrio}

Esse método é o mais tradicional, onde para solucionar o modelo, que pode ser aberto chado, monta-se a chamada Equação Global de Equilibrio do sistema, que representa a ibuição de equilíbrio para o número de clientes nos $M$ nós (ou centros) do modelo, otada pela probabilidade conjunta de um sistema estar no estado $n \pi_{n_{1}, n_{2}, \ldots, n_{M}}$, onde $n$ é al ao vetor de estados possíveis $\left\{n_{1}, n_{2}, \cdots, n_{M}\right\}$ e $n_{i}$ é o número de clientes no centro $i$.

Objetivando-se demonstrar como montar a equação global de equilíbrio de um sistema, erá obtida, a título de exemplificação, a equação de equilíbrio do modelo da Figura 4.2, que representa um servidor de arquivos com dois centros, cada um com apenas um servidor.

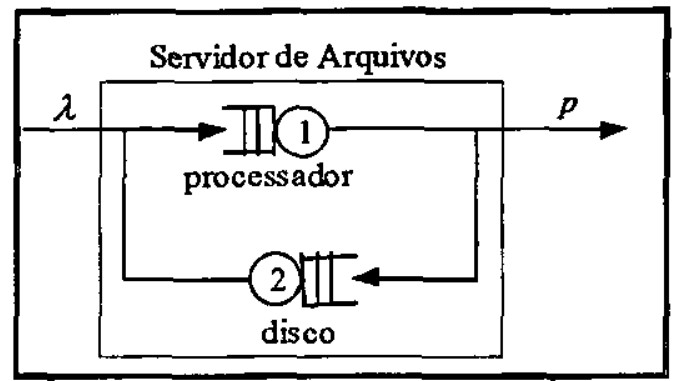

Figura 4.2 - Sevidor do Arquivos 
Em relação ao modelo da Figura 4.2 , onde $M=2$, tem-se que $n=\left\{n_{1}, n_{2}\right\}$, sendo $n_{1}$ e $n_{2}$, o número de clientes nos centros 1 e 2 , respectivamente.

Para obter a equação de equilíbrio do modelo ilustrado pela Figura 4.2, denotada $\pi_{n_{1}, n_{2}}$, atribuem-se valores aleatórios aos estados $n_{1}$ e $n_{2}$, por exemplo $n_{1}=1$ e $n_{2}=1$, e monta-se uma tabela de possíveis situações que podem resultar no estado $n=\{1,1\}$ :

\begin{tabular}{|c|c|c|c|}
\hline \multirow{2}{*}{$\begin{array}{l}\text { Possíveis } \\
\text { situações }\end{array}$} & \multicolumn{2}{|c|}{ Estado atual dos centros 1 e 2} & \multirow{2}{*}{$\begin{array}{c}\text { Evento que impulsionará o } \\
\text { sistema ao estado } n=\{1,1\}\end{array}$} \\
\hline & $n_{1}$ & $n_{2}$ & \\
\hline 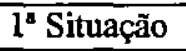 & 0 & 1 & $\lambda$ \\
\hline $2^{2}$ Situaçãa & 2 & 1 & $\mu_{1} p$ \\
\hline $3^{\mathrm{a}}$ Situação & 2 & 0 & $\mu_{1} q$ \\
\hline $4^{\mathrm{a}}$ Situação & 0 & 2 & $\mu_{2}$ \\
\hline
\end{tabular}

Nạ $1^{\text {a }}$ Situação da Tabela 4.1, tem-se 1 cliente no centro 2 e nenhum no centro 1 , instante em que ocorre uma chegada ao sistema, representada por $\lambda$, fazendo com que o centro 1 passe a possuir 1 cliente, o que conduz o sistema ao estado $n=\{1,1\}$. Na $2^{\mathrm{a}}$ Situação, para que $n$ seja igual a $\{1,1\}$, é preciso que um dos clientes que estão no centro 1 saia do sistema, $\mu_{1} p$. Na $3^{a}$ Situação, um cliente deve sair do centro 1 e ir imediatamente para o centro 2 , 0 que é representado por $\mu_{1} q$, para que $n=\{1,1\}$. Similarmente, na $4^{a}$ situação, para que o estado do sistema seja $n=\{1,1\}$, necessita-se que um cliente saia do centro 1 e se conduza imediatamente ao centro 2 , o que é representado por $\mu_{2}$.

Construida a tabela de possíveis situaçōes, pode-se então montar a equação global de equilíbrio do sistema, por intermédio das probabilidades de acontecer cada uma dessas situações juntamente com suas taxas de chegada e de serviço. Por exemplo, para que ocorra a $1^{a}$ situação, necessita-se da probabilidade conjunta de se ter $n_{1}=0$ tal que. $n_{2}=1$, denotada por $\pi_{n_{1}-1, n_{2}}$; e da taxa de chegada $\lambda$. O mesmo deve ser feito para todas as outras situações, resultando na seguinte equação global de equilibrio:

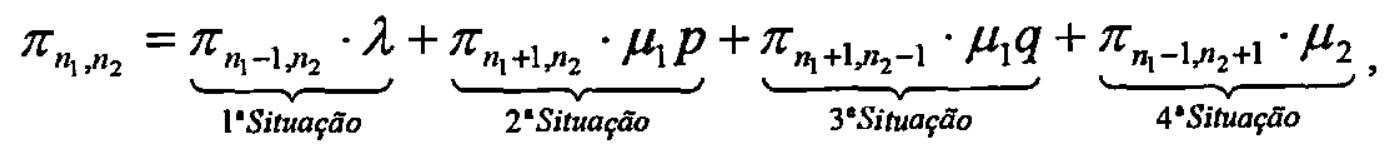

Onde os valores de $\lambda, \mu_{i}$ e $p$ são conhecidos, sendo $q=1-p$, e as probabilidades devem ser calculadas.

A complexidade da equação global de equilibrio aumenta de acordo com o tamanho do modelo, já que quanto maior a quantidade de nós, maior é vetor de estados possiveis 
$\left\{n_{1}, n_{2}, \cdots, n_{M}\right\}$. Assim sendo, para modelos complexos, torna-se mais viável montar a equação de equilibrio usando a Rede de Jackson, para modelos abertos, e o método de Gordon e Newell, para modelo fechados.

Por outro lado, existem modelos cuja equação de equilibrio já é conhecida, podendo ser encontrada em grande parte da literatura inerente ao assunto. Esses modelos são ditos Padrões, cujas distribuições de tempo de chegada e de serviço são conhecidas. A exemplo, tem-se o modelo padrão $\mathrm{M} / \mathrm{M} / 1$, que possui distribuições exponenciais e apenas um servidor, cuja equação de equilibrio é (Allen,1990) (Jain,1991):

$$
\pi_{n_{1}}=\left(1-\rho_{1}\right) \rho_{1}^{n_{1}},
$$

Onde $n_{1}$ é o número de clientes no único servidor (ou estado do servidor) do modelo $\mathrm{M} / \mathrm{M} / 1$ e $\rho_{1}$ é a utilização, dada por $\rho_{1}=\lambda / \mu_{1}$.

\subsubsection{Rede de Jackson}

Dada um modelo de rede de filas com $M$ nós, com características especificadas pelo Teorema de Jackson, Jackson demonstrou que a probabilidade conjunta do número de clientes dos $M$ nós (ou probabilidade do modelo se encontrar no estado $\left\{n_{1}, n_{2}, \cdots, n_{M}\right\}$ ) $p\left(n_{1}, n_{2}, \ldots, n_{M}\right)$ é igual ao produto das probabilidades de cada estado $p_{1}\left(n_{1}\right) \cdot p_{2}\left(n_{2}\right) \cdots p_{M}\left(n_{M}\right)$, onde $p_{i}\left(n_{i}\right)$ é a probabilidade de que há $n_{i}$ clientes no $i$ ésimo nó (Jain, 1991).

Teorema de Jackson: Supondo um modelo de rede de filas $\operatorname{com} M$ nós que satisfaz as seguintes condições (Allen, 1990):

1. Cada nó consiste de $c_{i}$ servidores exponenciais idênticos, cada um com taxa média de serviço $\mu_{i}$, onde $i=1,2, \ldots, M$.

2. Os clientẹs chegam ao no $i$ através do lado de fora do modelo em um padrão Poisson (exponencial) com taxa média de chegada $\lambda_{t}$ (os clientes também podem chegar ao nó $i$ através de outros nós do modelo), para $i=1,2, \ldots, M$.

3. Uma vez atendido no nó $i$, um cliente parte, instantaneamente, para o nó $j$, onde $j=1,2, \ldots M$, com probabilidade $p_{\mathrm{ij}}$; ou deixa o modelo com probabilidade $1-\sum_{j=1}^{\mathrm{M}} p_{\mathrm{ij}}$. 
Os modelos que satisfazem a essas condições são denominados de redes de Jackson.

Para cada nó $i$ de uma rede de Jackson, a taxa média de chegada (ou taxa média de entrada) para o nó, $\Lambda_{i}$, é dada por (Allen,1990):

$$
\Lambda_{i}=\lambda_{i}+\sum_{j=1}^{\mathrm{M}} p_{j i} \cdot \Lambda_{j}
$$

Além disso, se $p\left(n_{1}, n_{2}, \ldots, n_{M}\right)$ denọta a probabilidade conjunta de que há $n_{i}$ clientes no $i$-ésimo nó (ou probabilidade conjunta do número de clientes dos $M$ nós), para $i=1,2, \ldots, M$, que representa a distribuição de equilíbrio para o número de clientes nos $M$ nós $\pi_{n_{1}, n_{2}, \ldots, n_{M}} ;$ e se $\Lambda_{i}<c_{i} \cdot \mu_{i}$ para $i=1,2, \ldots, M$, então o modelo tem uma solução de formaproduto (Allen, 1990) e (Jain, 1991):

$$
\begin{gathered}
p\left(n_{1}, n_{2}, \ldots, n_{M}\right)=p_{1}\left(n_{1}\right) \cdot p_{2}\left(n_{2}\right) \cdots p_{M}\left(n_{M}\right) \\
\text { ou } \\
\pi_{n_{1}, n_{2}, \ldots, n_{M}}=p_{1}\left(n_{1}\right) \cdot p_{2}\left(n_{2}\right) \cdots p_{M}\left(n_{M}\right)
\end{gathered}
$$

Onde, $p_{i}\left(n_{i}\right)$ é a probabilidade de que há $n_{i}$ clientes no i-ésimo nó, se ele é tratado como um modelo $M / M / c_{i}$ com uma taxa média de chegada $\Lambda_{i}$ e tempo médio de serviço $1 / \mu_{i}$ para cada um dos $c_{i}$ servidores. Além disso, cada nó se comporta como se fosse um modelo $M / M / c_{i}$ independente, com taxa média de chegada $\Lambda_{i}$ (Allen,1990).

No caso em que todos os nós do modelo são filas de servidores únicos, cada nó se comporta como se fosse uma fila $\mathrm{M} / \mathrm{M} / 1$ independente, possibilitando que a distribuição do número de clientes seja dada por:

$$
\begin{aligned}
& p\left(n_{1}, n_{2}, \ldots, n_{M}\right)=p_{1}\left(n_{1}\right) \cdot p_{2}\left(n_{2}\right) \cdots p_{M}\left(n_{M}\right) \\
& =\left(1-\rho_{1}\right) \rho_{1}^{n_{1}} \cdot\left(1-\rho_{2}\right) \rho_{2}^{n_{2}} \cdots\left(1-\rho_{\mathrm{M}}\right) \rho_{\mathrm{M}}^{n_{M}} \quad \text {, onde } \rho_{i}=\frac{\Lambda_{i}}{\mu_{i}}
\end{aligned}
$$

\subsubsection{Método de Gordon e Newell}

Com esse método, Gorgon e Newell estenderam o resultado de Jackson para modelos fechados, mostrando que redes fechadas de $M$ nós, com tempos de serviço distribuídos exponencialmente, também possuem solução forma-produto (Algoritmo de Convolução) (Jain, 1991).

O Método de Gorgon e Newell é, geralmente, utilizado quando é necessário obter informações que o Algoritmo AVM Exato não pode fornecer, tais como a distribuição do 
número médio de clientes nos centros de serviço. Sendo assim, deve-se aplicar esse método a modelos fechados, onde centros dependentes de carga e centros delay não são permitidos. No entanto, no decorrer desse item, será discutida a extensão do método de Gordon e Newell que permite que o modelo possua um centro delay representando terminais com tempo de pensar $Z$ (Jain,1991). Extensões para centros de serviço dependentes de carga são apresentadas em (Buzen, 1973).

Esse método possui duas equações básicas, $p\left(n_{1}, n_{2}, \cdots, n_{M}\right)$ e $G(N)$, equações (4.12) e (4.13), respectivamente. A primeira, denota a probabilidade de um sistema estar no estado $n$ (ou probabilidade conjunta de que há $n_{i}$ clientes no $i$-ésimo centro), que é representado pelo vetor de estados possíveis $\left\{n_{1}, n_{2}, \cdots, n_{M}\right\}$, onde $n_{i}$ é o número de clientes no centro $i$ (Jain, 1991).

$$
p\left(n_{1}, n_{2}, \cdots, n_{M}\right)=\frac{D_{1}^{n_{1}} \cdot D_{2}^{n_{2}} \cdots D_{M}^{n_{M}}}{G(N)}
$$

Onde, $D_{i}$ é a demanda de serviço por cliente para o centro $i, N=\sum n_{i}$ é o número total de clientes no sistema, e $G(N)$ é a constante de normalização tal que a soma das probabilidades de todos os estados seja 1 :

$$
G(N)=\sum_{n} D_{1}^{m_{1}} \cdot D_{2}^{m_{2}} \cdots D_{M}^{n_{M}}
$$

Para ambas equações, quanto maior o número de centros de serviço, representados pela letra $i$, mais trabalhoso será o cálculo de $p\left(n_{1}, n_{2}, \cdots, n_{M}\right)$ e $G(N)$, já que maior será a quantidade de possiveis estados do sistema. Para facilitar esse cálculo, utiliza-se de recursos computacionais, computando os valores dessas equações por intermédio de um programa de computador, chamado Algoritmo de Convolução (Jain,1991).

O problema é que o valor de $G(N)$ pode ser muito grande ou muito pequeno e, com isso, pode ser excedido o limite máximo e mínimo do ponto-flutuante de alguns sistemas computacionais, causando erros de overflow e underflow. Para resolver esse problema, multiplicam-se as demandas $D_{i}$ por uma constate apropriada $\alpha$ antes de computar $G(N)$. Denotando-se por $\gamma_{i}$ o valor produto de $D_{i}$ e $\alpha\left(\gamma_{i}=D_{i} \cdot \alpha\right)$, reescrevem-se as equações (4.12) e (4.13) da seguinte forma (Jain,1991):

$$
p\left(n_{1}, n_{2}, \cdots, n_{M}\right)=\frac{\gamma_{1}^{n_{1}} \cdot \gamma_{2}^{n_{2}} \cdots \gamma_{M}^{n_{M}}}{G(N)}
$$




$$
\begin{array}{r}
G(N)=\sum_{n} \gamma_{1}^{n_{1}} \cdot \gamma_{2}^{n_{2}} \cdots \gamma_{M}^{n_{M}} \\
\text { Onde, } \alpha=\frac{1}{(1 / M) \sum_{i=1}^{M} D_{i}}
\end{array}
$$

Assim, uma vez calculado $G(1), \cdots, G(N)$, por intermédio da Equação (4.14), várias medidas de desempenho podem ser obtidas, tais como (Jain,1991):

\section{Distribuição do número de clientes no centro de serviço:}

- A probabilidade de ter $j$ ou mais clientes no $i$-ésimo centro

$$
p\left(n_{i} \geq j\right)=\sum_{n_{i} n_{i} \geq j} \frac{\gamma_{1}^{n_{1}} \cdot \gamma_{2}^{n_{2}} \cdots \gamma_{M}^{n_{M}}}{G(n)}=\gamma_{i}^{j} \frac{G(N-1)}{G(N)}
$$

- A probabilidade de ter exatamente $j$ clientes no $i$-ésimo centro

$$
\begin{aligned}
p\left(n_{i}=j\right) & =p\left(n_{i} \geq j\right)-p\left(n_{i} \geq j+1\right) \\
& =\frac{\gamma_{i}^{j}}{G(N)}\left[G(N-1)-\gamma_{i} G(N-j-1)\right]
\end{aligned}
$$

- O número médio de clientes no $i$-ésimo centro

$$
N_{i}=E\left[n_{i}\right]=\sum_{j=1}^{N} p\left(n_{i} \geq j\right)=\sum_{j=1}^{N} \gamma_{i}^{j} \frac{G(N-j)}{G(N)}
$$

- A probabilidade conjunta de ter $j$ ou mais clientes no $i$-ésimo centro e $l$ ou mais clientes no $k$-ésimo centro

$$
p\left(n_{l} \geq j, n_{k} \geq l\right)=\gamma_{i}^{j} \gamma_{k}^{l} \frac{G(N-j-l)}{G(N)}
$$

\section{Utilização}

- a utilização do centro é igual a probabilidade de ter um ou mais clientes no centro

$$
U_{i}=P\left(n_{i} \geq 1\right)=\gamma_{i} \frac{G(N-1)}{G(N)}
$$

\section{Throughput}

- os throughputs dos centros são dados pela lei de utilização

$$
X_{1}=\frac{U_{t}}{S_{t}}
$$

- o throughput do sistema é dado pela lei do fluxo forçado

$$
X=\frac{X_{i}}{V_{i}}=\frac{U_{i}}{D_{i}}=\alpha \frac{G(N-1)}{G(N)}
$$




\section{Tempo de Resposta}

- o tempo médio de resposta do centro é dado pela lei de Little

$$
R_{i}=\frac{N_{i}}{X_{1}}=\frac{N_{1}}{X \cdot V_{1}}
$$

- o tempo de resposta sistema é dado pela lei de geral do tempo de resposta

$$
R=\sum_{i=1}^{M} R_{i} \cdot V_{i}
$$

\section{Algoritmo de Convolução}

O Algoritmo de Convolução, desenvolvido por Buzen para computar $G(N)$, encontrase fundamentado na seguinte equação (Jain,1991):

$$
\begin{aligned}
\sum_{n} \prod_{i=1}^{k}\left(\gamma_{i}\right)^{n_{i}} & =\sum_{n \mid n_{k}=0} \prod_{i=1}^{k}\left(\gamma_{i}\right)^{n_{i}}+\sum_{n \mid n_{k}>0} \prod_{i=1}^{k}\left(\gamma_{i}\right)^{n_{i}} \\
& =\sum_{n \mid n_{k}=0} \prod_{i=1}^{k}\left(\gamma_{i}\right)^{n_{i}}+\gamma_{k} \sum_{n^{-}} \prod_{i=1}^{k}\left(\gamma_{i}\right)^{n_{i}}
\end{aligned}
$$

Onde, $n$ é o conjunto de todos os vetores estados possíveis $\left\{n_{1}, n_{2}, \cdots, n_{k}\right\}$, tal que $n=\sum_{i=1}^{k} n_{i} ;$ e $n^{-}$é o conjunto de todos os vetores de estados possíveis tal que $\sum_{i} n_{i}=n-1$ (Jain, 1991).

A equação (4.15) revela que, quando $n_{k}>0$, o produtório passa a ter $\gamma_{k}$ como termo constante, permitindo que o problema para computar $G(N)$ seja dividido em dois problemas menores. Dessa forma, pode-se definir uma função auxiliar $g(n, k)$ (Jain, 1991):

$$
g(n, k)=\sum \prod_{i=1}^{k} \gamma_{i}^{n_{i}}
$$

De forma que, a constante de normalização $G(N)=g(N, M)$ pode ser computada através da seguinte seqüência de iterações (Jain, 1991):

$$
g(n, k)=g(n, k-1)+\gamma_{k} \cdot g(n-1, k)
$$

Onde os valores iniciais para a função auxiliar são:

$$
\begin{aligned}
& g(n, 0)=0, \quad n=1,2, \ldots, N \\
& g(n, k)=1, \quad k=1,2, \ldots, M
\end{aligned}
$$


Tem-se então o Algoritmo de Convolução (Jain,1991)

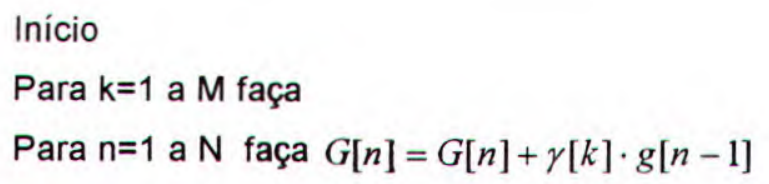

Como já dito anteriormente, o algoritmo (4.6) não abrange modelos que possuam centros delay representando terminais com tempo de pensar $Z$. Para esse tipo de modelo, calcula-se o $G(N)$ assumindo que os terminais (centro delay) correspondem ao centro de índice 0 (zero), de modo que, a equação (4.16) passa a ser iniciada da seguinte forma (Jain, 1991):

$$
g(n, 0)=\frac{\gamma_{0}^{n}}{n !}, \quad n=1,2, \ldots, N
$$

onde, o tempo de pensar $Z$ deve ser multiplicado por $\alpha$, para evitar problemas de underflow ou overflow, sendo o resultado desse produto armazenado em $\gamma_{0}$, ou seja, $\gamma_{0}=\alpha \cdot Z$

Dessa forma, o vetor de estados possíveis do sistema $n$ terá então um componente a mais, sendo equivalente à $\left\{n_{0}, n_{1}, \cdots, n_{M}\right\}$, onde $n_{0}$ é número de clientes nos terminais e $n_{i}$ é numero de clientes no $i$-ésimo centro, de forma que $\sum_{i=0}^{M} n_{i}=N$. As probabilidades de estado são então dadas por (Jain,1991):

$$
p\left(n_{0}, n_{1}, \cdots, n_{M}\right)=\frac{\gamma_{0}^{n_{0}} \cdot \gamma_{1}^{n_{1}} \cdot \gamma_{2}^{n_{2}} \cdots \gamma_{M}^{n_{M}}}{n_{0} ! G(N)}
$$

No caso de ter outros centros delay no modelo, podem-se combiná-los em um único centro de serviço através da soma de suas demandas totais $D_{i}$ com o Z. Assim, o valor de $n_{0}$ passa a representar a soma dos números de clientes de todos os centros (Jain,1991).

O cálculo das medidas de desempenho utilizando $G(N)$, anteriormente mostrado, continua sendo válido para modelos que possuam centros delay. Os números médios de clientes dos centros e as utilizações dos centros para os terminais podem ser computados da seguinte maneira (Jain,1991): 
Número Médio de Clientes :

- O número médio de clientes nos terminais (ou número de usuários pensando), usando a lei de Little

$$
N_{0}=X Z
$$

\section{Utilização}

- a utilização média dos terminais, usando a lei de utilização

$$
\rho_{0}=X Z
$$

- a utilização de cada centro

$$
\rho_{Z}=\frac{\rho_{0}}{N}=\frac{X \cdot Z}{N}=\frac{Z}{R+Z}
$$

\subsubsection{Redes BCMP}

O nome BCMP é a junção das iniciais de Basktt, Chandy, Muntz e Palacios, que generalizaram a Rede de Jackson para que fossem permitidos (Allen, 1990) (Jain, 1991):

$>$ modelos abertos, fechados e mistos.

$>$ distribuições de tempos de serviço diferentes da exponencial;

$>$ diferentes classes de clientes, cada uma com diferentes tempos de serviço, permitindo ainda, que clientes mudem de classe depois de completado o serviço no centro, antes de ir para outro centro de serviço;

$>$ modelos que são abertos para determinadas classes de clientes e fechados para .ọutras.

Para isso, Basktt, Chandy, Muntz e Palacios, tiveram que mostrar que soluções de forma-produto existem para uma classe abrangente de modelos. Essa classe consiste em modelos que satisfazem os seguintes critérios (Allen, 1990) (Jain,1991):

Disciplinas de Fila: Todos os "entros de serviço possuem uma das seguintes disciplinas de fila: First Come First Served (FCFS), também referenciada como First In Firts Out (FIFO); Processor-Sharing (PS), Servidores Infinitos (IS), também chamados de Centros Delay; é Last Come First Served - Premptiva (LCFSP), também conhecida como Last In Firts Out (LIFO).

Classes de Clientes: os clientes permanecem em uma única classe enquanto estão esperando ou recebendo serviço no centro de serviço, mas podem mudar de classe e de centro de acordo com as probabilidades de saída do centro. 
Distribuições de Tempo de Serviço: Em centros de serviço com disciplinas de fila FCFS, as distribuições de tempo de serviço devem ser idênticas e exponenciais para todas as classes de clientes. Em centros de serviço com outra disciplina de fila, diferentes classes de clientes podem possuir distribuiçóes diferentes.

Servico Dependente de Carga: Em um centro de serviço com disciplina de fila FCFS, o tempo de serviço pode depender apenas do total número de clientes do centro. Em centros de serviço com disciplinas de fila PS, LCFS-P e SI, o tempo de serviço para uma classe clientes pode depender do número de clientes no centro pertencentes a essa classe, mas não sofre influência do número de clientes no centro pertencentes a outra classe. Além disso, a taxa de serviço global de um modelo pode depender do número total de clientes nele existente.

Chegada de Clientes: para um modelo aberto, o tempo entre chegadas de uma classe deve ser exponencialmente distribuído. As taxas de chegada podem ser dependentes de carga, de forma que, para modelos abertos existem dois possíveis padrões de chegada Poisson (exponencial). No primeiro, a taxa de chegada do lado de fora do modelo, $\lambda(N)$, tem uma taxa média que depende do número de clientes, $N$, no sistema. No segundo padrão, existe um fluxo de chegada Poisson para cada classe de cliente, onde a taxa de chegada da $i$-ésima classe depende apenas do número de clientes presentes nessa classe.

Os modelos que satisfazem a esses critérios são conhecidos como redes BCMP, que são geralmente solucionados pelo método de Análise do Valor Médio, discutido anteriormente neste capítulo, obedecendo as restrições de cada versão AVM (Allen, 1990).

\subsubsection{Decomposição Hierárquica}

Quanto maior o nivel de detalhamento do modelo, maior é a sua complexidade. Para modelos com um grau de complexidade elevado, os quais podem ser abertos ou fechados, com uma ou múltiplas classes de clientes, utilizam-se, geralmente, o método de aproximação chamado decomposição hierárquica, também conhecida como modelagem hierárquica (Lazowska, 1984) (Jain, 1991).

$\mathrm{Na}$ decomposição hierárquica um modelo grande é dividido em submodelos menores, onde cada um desses submodelos é avaliado separadamente e suas soluções individuais são combinadas para obter a solução do modelo original (Lazowska, 1984) (Jain,1991). 
Considerando o modelo da Figura 4.3, dito modelo original, define-se um ou mais subsistemas arbitrariamente, denominados de agregados, e o que resta do modelo é chamado de complemento. O ponto chave da decomposição hierárquica é rescrever esse agregado através de um único centro de serviço, que imita o comportamento do mesmo, chamado de Centro de Serviço de Fluxo Equivalente (FESC) (Lazowska,1984).

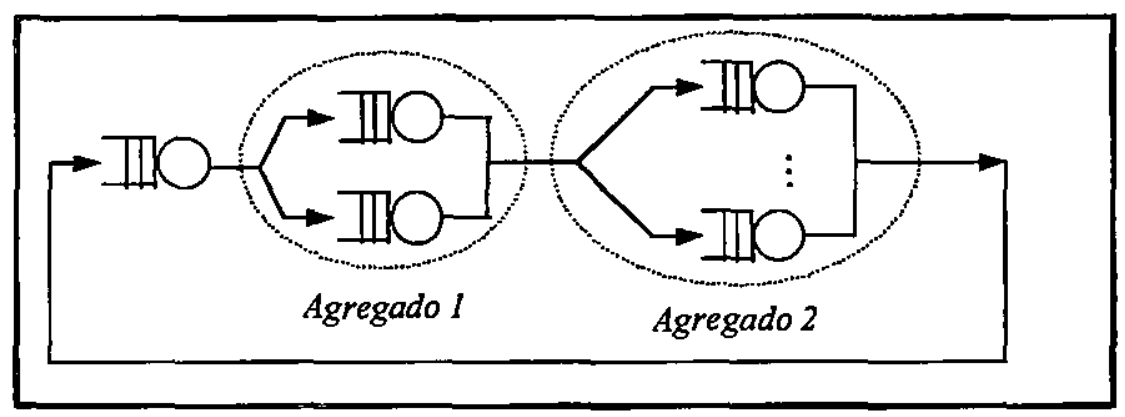

Figura 4.3 - Agragado e Complemento

Caso exista interesse em estudar várias alternativas para o $i$-ésimo centro, pode-se defini-lo como agregado, transformando o resto do sistema em um FESC, de modo que no modelo do nível 0 estejam apenas esse FESC e o $i$-ésimo centro. Dessa forma, podem-se aplicar valores variados de taxa de serviço ao $i$-ésimo centro, possibilitando julgar qual desses valores corresponde à melhor alternativa para o sistema (Jain,1991).

A combinação das soluções dos subsistemas é feita por intermédio de um centro de serviço especial, denominado Centro de Serviço de Fluxo Equivalente (FESC), que reproduz o comportamento dos submodelos considerando que a taxa média de atendimento do FESC varia em função de seu número de clientes, isto é, no caso de um modelo de rede de filas, os FESCs são considerados centros dependentes de carga (Lazowska,1984) (Jain,1991).

O processo de decomposição hierárquica consiste em dividir o modelo em vários níveis, como ilustra Figura 4.4. No nível 0 está o modelo de mais alto nível, onde se encontram os FESCs. Cada FESC representa uma porção do modelo original (o agregado). O nível 1 é formado por um ou mais agregados, que são uma representação mais detalhada dos subsistemas representados pelos FESCs no nível 0, deforma que o modelo original pode ser decomposto em quantos níveis forem necessários, onde as características de um FESC no nível $L$ sāo determinadas pela solução do correspondente agregado no nível $L+1$. Sendo assim, tem-se que a definição do modelo a ser solucionado ocorre do nível 0 ao nível $L$, enquanto que, a solução desse modelo deve ocorrer no sentido contrário, do nivel $L$ ao nível 0 (Lazowska,1984) (Jain,1991). A Figura 4.4 mostra o modelo da Figura 4.3 decomposto em niveis: 


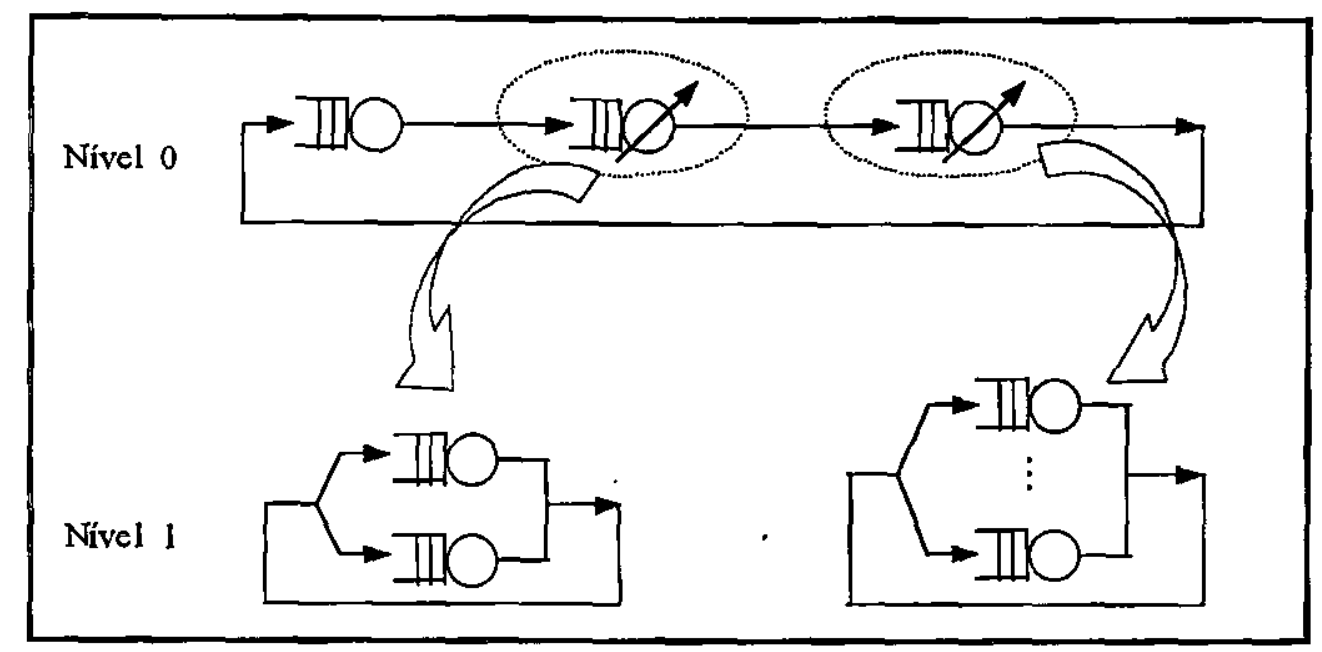

Figura 4.4 - Niveis da Decomposiçåo Hierárquica

As medidas de desempenho obtidas através da decomposição hierárquica são ditas aproximações, pelo fato de um subsistema ser representado como um único centro de serviço, - que ocasiona a perda de informações a respeito da localização dos clientes dentro dos centros que compõem o subsistema. Mas essa perda é perfeitamente aceitável, já que o FESC deve imitar a conduta do agregado, o que significa que ele deve imitar o fluxo de clientes que saem do agregado e entram no complemento, o que é feito através da hipótese de decomposição. Considerando-se essa hipótese, a taxa média com que os clientes partem do agregado depende apenas do estado do agregado, o que é definido pelo número de clientes (população) dentro do mesmo. Sendo assim, como o estado é independente da localização dos clientes dentro dos centros de serviço, as perdas de informações a respeito da localização não afetam a avaliação de desempenho do sistema (Lazowska,1984).

O FESC, para modelos de múltiplas classes de clientes, por ser um centro dependente de carga, possui taxas de serviço $\mu_{c}(n)$ iguais aos throughputs $X_{c}(n)$ do agregado para toda população $n$ e classe $c$. Para um modelo de classe única, forma-se um FESC calculando-se os throughputs $X(n)$ do agregado como uma função apenas do número de clientes $n$ no agregado, o qual terá a sua taxa de serviço $\mu(n)=X(n)$ (Lazowska,1984) (Jain, 1991).

Sendo assim, para especificar um FESC são necessárias as suas taxas de serviço dependente de carga para cada uma de suas classes de clientes. Essas taxas de FESCs do nível $L$ devem ser obtidas através da solução dos modelos do nível $L+1$ (Lazowska,1984) (Jain, 1991).

Para modelos de rede de filas, o FESC do nível $L$ deve ser representado no nível $L+1$ como um modelo constituído de centros de serviço independentes de carga, podendo possuir alguns FESCs com taxas de serviço determinadas através da solução do modelo do 
nivel $L+2$. Para solucionar esse modelo do nível $L+1$ aplicam-se métodos analíticos (Lazowska, 1984). Caso o modelo do nível $L+1$ possua FESCs, deve-se solucioná-lo usando métodos analíticos para modelos de centros dependentes de carga, caso contrário, aplica-se um método para centros independentes de carga. No caso da Análise do Valor Médio ser o método aplicado, consideram-se suas versões exatas, tanto para centros dependentes, como independentes de carga (Lazowska,1984) (Jain, 1991).

No modelo do nível 0 , que é equivalente ao modelo original, cada cliente faz $V_{i}$ visitas ao $i$-ésimo centro a cada visita ao FESC, isto é, $V_{F E S C}=1$ (Jain,1991).

Diante do exposto, dado um modelo aberto ou fechado de uma ou múltiplas classes de clientes, esquematiza-se o método de decomposição hierárquica por intermédio de alguns passos, onde , para simplificar o entendimento, o modelo original é dividido em dois níveis (Lazowska, 1984) (Jain, 1991):

1) Seleciona-se uma porção do sistema para ser o agregado, e o restante do modelo passa a ser chamado de complemento.

2) Cria-se um submodelo (nível 1), atribuindo zero ao tempo de serviço de todos os centros do complemento. Isso é equivalente a criar um modelo com os centros que compōem o agregado.

3) Soluciona-se o submodelo usando AVM, Gordon e Newell, ou outro método para centros independentes de carga. As medidas de desempenho dos centros de serviço desse modelo devem ser obtidas usando probabilidade condicional.

4) Representa-se o agregado por um FESC, construindo assim um modelo equivalente a modelo original (nivel 0). O FESC é um centro de serviço cuja taxa de serviço, para $n$ clientes, é igual ao throughput do submodelo com $n$ clientes nele circulando.

5) Soluciona-se o modelo equivalente usando-se métodos para centros de serviço dependentes de carga. A solução desse modelo inclui a obtenção das medidas de desempenho dos centros que constituem o complemento.

Algoritmo 4.6 - Algoritmo pare Decomposiçăo Hierárquica

Uma vez compreendido o funcionamento do Algoritmo 4.6, consegue-se facilmente estendê-lo a decomposições maiores que 2 niveis, bastando, para isso, que os passos 4 e 5 se repitam até que o nível 0 seja alcançado.

Para obtenção de medidas de desempenho usando probabilidades condicionais, 0 método a ser aplicado ao submodelo deve fazer uso das seguintes equações (Jain, 1991): 
Distribuição do Número de Clientes

- a probabilidade de ter $j$ clientes no $i$-ésimo centro (do agregado)

$$
\begin{aligned}
P\left(n_{i}=j \mid N \text { clientes no sistema }\right)= & \sum_{n=j}^{N}\left[P\left(n_{i}=j \mid n \text { clientes no agregado }\right)\right] \\
& \times P(n \text { clientes no agregado } \mid N \text { clientes no sistema }) \\
= & \sum_{n=j}^{N}\left[P\left(n_{i}=J \mid n \text { clientes no agregado }\right)\right] \\
& \times P(n \text { clientes no } \text { FESC } \mid N \text { clientes no sistema })
\end{aligned}
$$

- o número médio de clientes no $i$-ésimo centro

$$
N_{i}(N)=\sum_{j=1}^{N} j P\left(n_{i}=j \mid N \text { clientes no sistema }\right)
$$

\section{Throughput}

- O throughput do $i$-ésimo centro no agregado e do $j$-ésimo centro do complemento são relacionados da seguinte forma:

$$
\frac{X_{i}}{V_{i}}=X=\frac{X_{j}}{V_{j}}
$$

Tempo de Resposta

- o tempo de resposta usando a lei de little

$$
R_{i}=N_{i} \cdot X_{i}
$$

\section{Utilização}

- a utilização pode ser calculada usando a lei de utilização

$$
U_{i}=X_{i} \cdot S_{i}=X \cdot D_{i}
$$

Algumas dessas equações podem também ser aplicadas aos centros do modelo do nível 0 , como é o caso das equações (4.17) e (4.18), referentes aos throughput e utilização de cada centro de serviço, respectivamente (Jain,1991). No entanto, para o cálculo da utilização do FESC, deve-se fazer uso da seguinte expressão: $\rho_{F E S C}=1-p(0 \mid N)$, onde $p(0 \mid N)$ é a probabilidade do FESC possuir, tal que existem $N$ clientes no sistema.

Caso seja utilizado o método de Gordon e Newell na Decomposição Hierárquica, para o cálculo de medidas de desempenho adicionais, deve-se utilizar as equações expostas anteriormente nesta seção, ao invés das citadas na seção referente ao método de Gorgon e Newell. 


\subsubsection{Limites de Desempenho}

Esse método, que pode ser aplicado a modelos abertos e fechados, consiste em calcular limites inferiores e superiores do througput do sistema e do tempo de resposta, como funções do número ou taxa de chegada dos clientes. Na prática, a grande atração desse método é a simplicidade de suas técnicas. Duas são as técnicas para o cálculo de limites: Limites Assintóticos e Limites de Sistema Balanceado (Lazowska,1984) (Orlandi,1995).

$\mathrm{O}$ cálculo de limites de desempenho, além de simples, é um método rápido, podendo até ser feito manualmente. Sua aplicação provê uma valiosa introspeção a respeito de fatores que afetam o desempenho do sistema, como o "gargalo" do sistema (Lazowska,1984) e (Jain, 1991).

As técnicas de cálculo de limites podem ser usadas para eliminar alternativas inadequadas, fornecendo, por meio de um simples cálculo, informações valiosas sobre todas elas. Outra aplicação é o estudo de dimensionamento do sistema, que envolvem considerações de um grande número de possíveis configurações. No caso de dimensionamento do sistema, geralmente um único recurso é o interesse dominante e o resto do sistema é configurado para acompanhar o poder desse recurso (Lazowska, 1984) e (Orlandi,1995).

O termo limites otimistas é utilizado para referenciar o limite superior do throughput e o limite inferior do tempo de resposta, já que indicam a situação de melhor desempenho. A situação contrária é referenciada como limites pessimistas (Lazowska,1984).

A técnica de cálculo de Limites Assintóticos, por abranger uma classe maior de sistemas, destaca-se mais do que a técnica de cálculo de Limites de Sistemas Balanceados (Orlandi,1995). Seus limites otimistas e pessimistas são derivados de condições extremas de carga: alta e baixa. A validade dos limites é garantida pelo fato que a demanda de serviço independe da quantidade e da localização de clientes no sistema, ou seja, não importa a quantidade de clientes e em que centros de serviço os mesmos estão locados (Lazowska, 1984).

Assim, faz-se necessário saber que a demanda de serviço de cada centro $k$ do modelo, denominada $D_{k}$, é o total de tempo de serviço que um cliente requerer nesse centro. A demanda $D_{k}$ pode ser calculada através do produto de $V_{k}$ (número de visitas que um cliente faz ao centro $k$ ) e $S_{k}$ (tempo de serviço por visita). Para modelo abertos, o valor de $D_{k}$ pode ser também calculado dividindo-se $\rho_{k}$ (utilização do centro $k$ ) por $\lambda$ (taxa de chegada dos 
clientes). Assim, denota-se a demanda total de serviço de um cliente em todos os centros por $D=\sum_{M}^{l} D_{k}$, onde $M$ é quantidade de centros de serviço do modelo (Lazowska,1984).

\section{Limites Assintóticos}

Os limites assintóticos do thoughput $(\mathrm{X})$ e tempo de resposta (R) do sistema, representados no gráfico são dados pelo seguinte (Lazowska, 1984) e (Jain, 1992):

$$
\begin{gathered}
\frac{N}{N D+Z} \leq X(N) \leq \min \left\{\frac{1}{D_{\max }}, \frac{N}{D+Z}\right\} \\
\text { e } \\
\max \left\{D, N D_{\max }-Z\right\} \leq R(N) \leq N D
\end{gathered}
$$

Para derivar os limites das equações (4.19) e (4.20), primeiramente consideram-se os limites do throughput, e depois utiliza-se a Lei de Little para transformá-los nos limites do tempo de resposta (Lazowska, 1984) e (Jain, 1992).

Assim, considera-se inicialmente a situação de carga alta (muito clientes) e a partir da Lei de Utilização para cada centro $k$, tem-se que:

$$
U_{k}(N)=X(N) \cdot D_{k} \leq 1
$$

O centro de maior demanda $\left(D_{\max }\right)$ limita o throughput máximo que o sistema pode atingir. Assim:

$$
X(N) \cdot D_{\max } \leq 1 \quad \text { ou } \quad X(N) \leq \frac{1}{D_{\max }},
$$

onde $D_{\max }$ é igual a máxima demanda dentre todas as demandas $D_{k}$ do modelo, isto é,

$$
D_{\max }=\max _{k} D k
$$

Considerando-se agora a situação de carga baixa (poucos clientes). No extremo dessa situação, um único cliente no sistema proporciona um throughput de $1 / D+Z$, já que cada interação consiste de um tempo de serviço $(D)$ e um tempo de pensar $(Z)$, sendo $D=\sum_{M}^{1} D_{k}$.

No entanto, mais clientes chegarão ao sistema, podendo acontecer duas situações extremas:

- O menor throughput possível ocorre quando cada cliente que chegar ao sistema for adicionado a uma fila. Assim, com $N$ clientes no sistema, o tempo de espera na fila é de $(N-1) D$; o tempo gasto no serviço é igual a $D$; e $Z$ unidades de tempo são 
gastas pensando. Com isso, o throughput de cada clientes é dado por $1 /(N D+Z)$ e o throughput do sistema, por $N /(N D+Z)$.

- O maior throughput possivel ocorre quando cada cliente que chegar ao sistema for imediatamente servido. Assim, com $N$ clientes no sistema, o tempo de espera na fila é nulo; o tempo gasto no serviço é igual a $D$; e $Z$ unidades de tempo são gastas pensando. Com isso, o throughput de cada clientes é dado por $1 /(D+Z)$ e o throughput do sistema, por $N /(D+Z)$.

Combinando-se todas essas informações, resulta-se na equação (4.19), concluindo-se que os limites assintóticos do throughput são dados por:

$$
\frac{N}{N D+Z} \leq X(N) \leq \min \left\{\frac{1}{D_{\max }}, \frac{N}{D+Z}\right\},
$$

onde $N /(N D+Z)$ corresponde ao limite pessimista, e o $\min \left\{\frac{1}{D_{\max }}, \frac{N}{D+Z}\right\}$, ao limite otimista.

Como o limite otimista do throughput consiste de dois componente, referentes as situações de cargas alta e baixa, respectivamente, existe uma determinada população, representada por $N^{*}$, a partir da qual se define quando usar cada um dos componentes. Dessa forma, para todos os $N$ menores que $N^{*}$, aplica-se o primeiro componente, enquanto que, para os $N$ maiores que $N^{*}$, aplica-se o segundo componente. O valor de $N^{*}$ é dado por:

$$
N^{*}=\frac{D+Z}{D_{\max }}
$$

A partir dos limites assintóticos do throughput, por intermédio da Lei de Little, pode-se obter os limites assintóticos do tempo de resposta, $R(N)$, rescrevendo a equação (4.19):

$$
\frac{N}{N D+Z} \leq \frac{N}{R(N)+Z} \leq \min \left\{\frac{1}{D_{\max }}, \frac{N}{D+Z}\right\}
$$

Para expressar os limites do tempo de resposta, inverte-se cada componente da expressão anterior:

$$
\begin{gathered}
\max \left\{D_{\max }, \frac{D+Z}{N}\right\} \leq \frac{R(N)+Z}{N} \leq \frac{N D+Z}{N} \\
\text { ou } \\
\max \left\{D, N D_{\max }-Z\right\} \leq R(N) \leq N D
\end{gathered}
$$


Diante dessas informações, monta-se a seguinte tabela de limites de assintóticos de um sistema:

\begin{tabular}{|l|c|c|}
\cline { 2 - 3 } \multicolumn{1}{c|}{} & \multicolumn{2}{c|}{ Limites Assintóticos } \\
\cline { 2 - 3 } \multicolumn{1}{c|}{} & Limites Otimistas & Limites Pessimistas \\
\hline Throughput: $X(N)$ & $\min \left\{\frac{1}{D_{\max }}, \frac{N}{D+Z}\right\}$ & $\frac{N}{N D+Z}$ \\
\hline Tempo de Resposta: $R(N)$ & $\max \left\{D, N D_{\max }-Z\right\}$ & $N D$ \\
\hline
\end{tabular}

Tabela 4.2-Limites Assintóticos do throughput e tempo de resposta

A partir dos limites da Tabela 4.2, traça-se os gráficos dos limites do throughput e do tempo de resposta, que, em geral, possuem a aparência do Gráfico 4.1 e Gráfico 4.2, respectivamente.

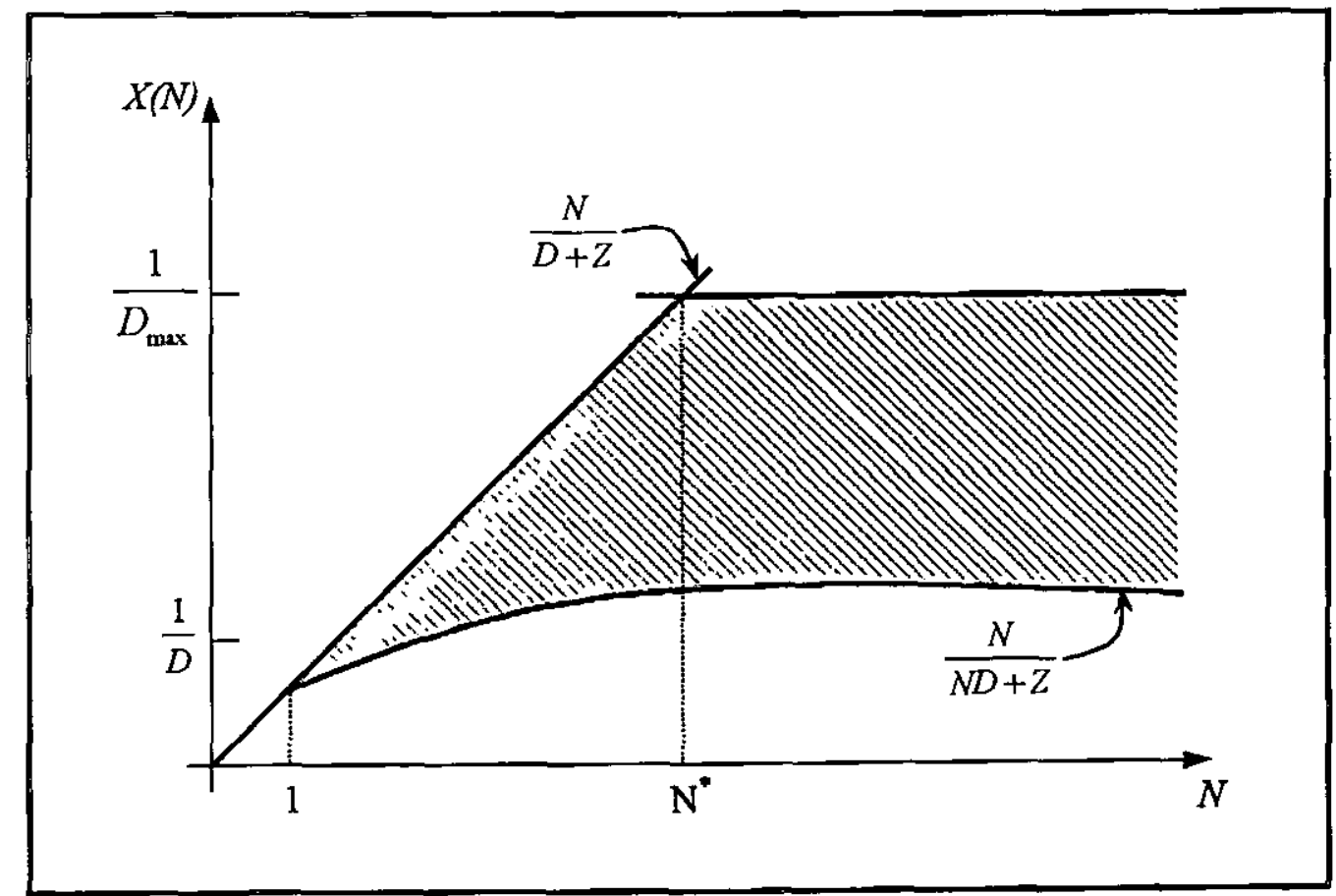

Gráfico 4.1 - Limites Assintóticos do Throughput 


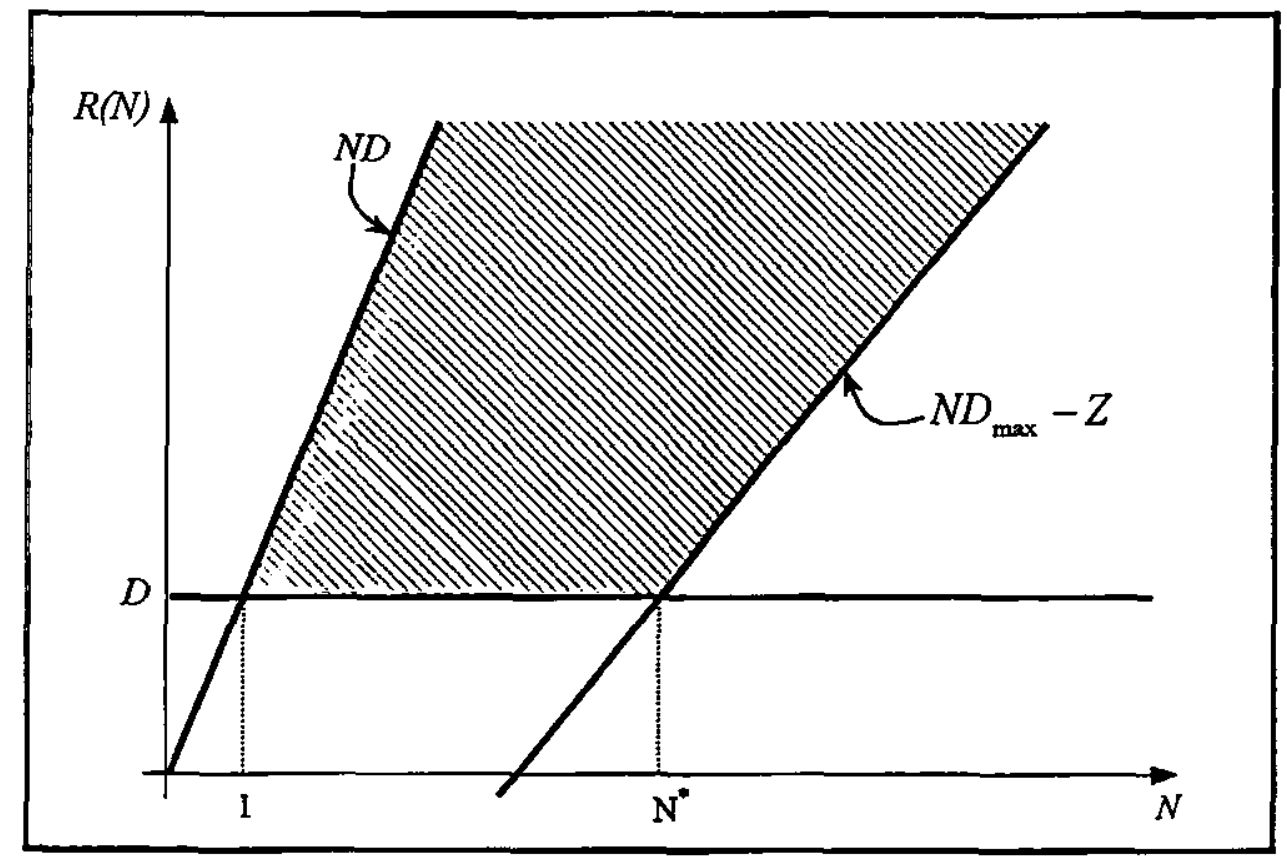

Gráfico 4.2 - Limites Assintóticos do Tempo de Resposta

As áreas detacadas dos gráficos dos limites do throughput e do tempo de resposta, indicam, respectivamente, onde devem se encontrar os valores do throughput e do tempo de resposta do sistema (Lazowska, 1984) e (Jain, 1992).

Esses gráficos de limites assintóticos de um sistema (throughput e tempo de resposta), podem ser obtidos através dos 5 passos do Algoritmo 4.7:

1. Calcule $D_{k}=\frac{U_{k}}{\lambda}$ ou $D_{k}=S_{k} \cdot V_{k}$

2. Calcule $D=\sum_{k=1}^{k} D_{k}$ e $D_{\max }=\max _{k} D_{k}$

3. Calcule o ponto de interseção das componentes de limites otimistas:

$$
N^{*}=\frac{D+Z}{D_{\max }}
$$

4. Os limites do throughput passam pelos seguintes pontos:

Limite Otimista:

$(0,0)$ e $\left(1, \frac{1}{D+Z}\right)$ para $N \leq N^{\star}$

$\left(0, \frac{1}{D_{\max }}\right)$ e $\left(1, \frac{1}{D_{\max }}\right)$ para $N \geq N^{*}$

Limite Pessimista:

Este limite não é linear em $N$. 
5. Limites sobre a média do tempo de resposta passam nos seguintes pontos:

Limite Otimista:

$(0, D)$ e $(1, D)$ para $N \leq N^{*}$

$(0,-Z)$ e $\left(1, D_{\max }-Z\right)$ para $N \geq N^{*}$

Limite Pessimista:

$(0,0)$ e $(1, D)$

Algoritmo 4.7 - Algoritmo para cálculo de limites assintoticos

Quando se tratar de um modelo aberto, ao aplicar-se o Algoritmo 4.7, deve-se considerar um tempo de pensar nulo $(Z=0)$, como já comentado na seção referente a Lei do Tempo de Resposta Interativo.

\section{Processo Nascimento-e-Morte}

Outra forma de solucionar um modelo aberto é modelar o seu comportamento como um processo nascimento-e-morte, que é um processo markoviano ${ }^{1}$ onde as transações estão restritas aos estados vizinhos.

Considerando-se o processo nascimento-e-morte, o estado do modelo é dado pelo número de clientes no sistema (n). Assim, quando o sistema está no estado $n$, estão nele $n$ clientes. A chegada de um novo cliente, representada por $\lambda$, muda o estado do sistema para $n+1$, sendo chamado de nascimento. Da mesma forma, a saida de um cliente, representada por $\mu$, muda o estado para $n-1$, sendo chamado de morte. O diagrama de estados do processo nascimento-e-morte é mostrado na Figura 4.5 (Jain,1991) (Allen, 1978).

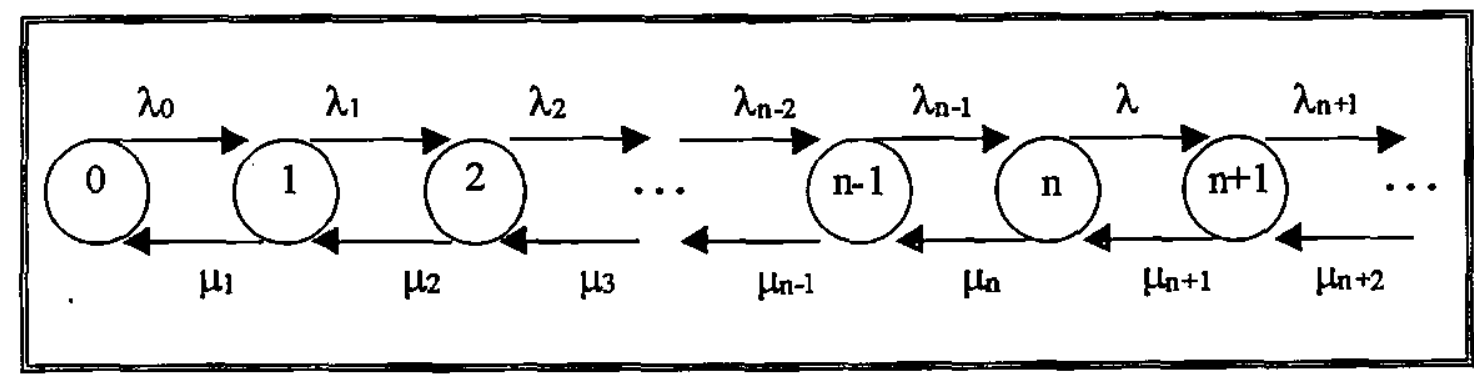

Figura 4.5 - Diagrama de estado do processo nascimento-e-morte

1 processos markoviano - são processos estocásticos em que seus estados futuros são independentes do passado e dependem apenas do presente. 
A Figura 4.6 ilustra o diagrama de estado do processo nascimento-e-morte para um modelo $\mathrm{M} / \mathrm{M} / 1$, onde as taxas de entrada $(\lambda)$ e de saída $(\mu)$ são constantes (Jain,1991) (Allen, 1978).

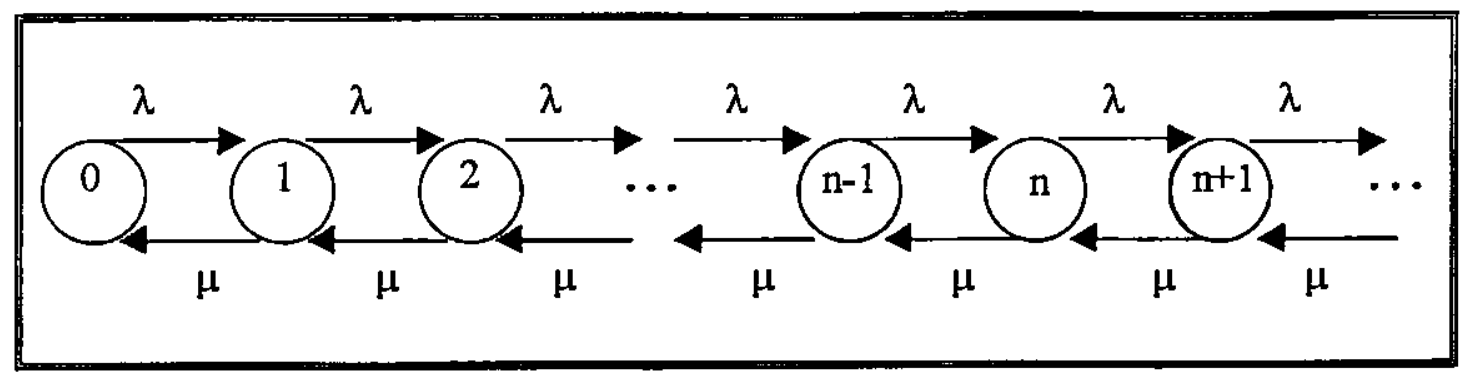

Figura 4.6 - Diagrama do processo nascimento-a-morte para o modelo $M / M / 1$

Considerando-se um processo de nascimento-e-morte, têm-se as seguintes equações para o caso do modelo M/M/1, quando $\rho<1$ (Jain, 1991):

$>$ Intensidade do tráfego $=$ Utilização -

$>$ Número médio de clientes no sistema $E[n]=\frac{\rho}{(1-\rho)}$

$>$ Número médio de clientes na fila - $E\left[n_{q}\right]=\frac{\rho^{2}}{(1-\rho)}$

$>$ Tempo médio de resposta -...-- $E[r]=\frac{1 / \mu}{(1-\rho)}$

Tempo médio de fila

$E[w]=\rho \frac{1 / \mu}{(1-\rho)}$ 


\subsection{Solução por Simulação}

Simulação é um método utilizado para solucionar modelos que tentam imitar o comportamento do sistema, constituindo-se em um experimento estatístico que observa o comportamento do modelo no decorrer do tempo. A partir de um programa computacional, pode-se exercitar o modelo de alguma maneira. Isso pode ser realizado através de dados obtidos de medidas do sistema ou através de valores aleatórios gerados a partir de distribuição (mais usada), com a finalidade de representar as variáveis do sistema (Soares,1990).

\subsubsection{Tipos de Simulação}

O modelo representativo do sistema, a partir do qual é desenvolvido o programa de computador para a simulação, pode ser classificado quanto à natureza do sistema, quanto à forma de organização da simulação, quanto ao o nivel de detalhamento e quanto à geração dos dados de entrada (Orlandi, 1995).

\section{Quanto à Natureza do sistema}

O modelo pode ser do tipo Discreto ou Contínuo. Quando se trata de modelos discretos, as mudanças nos estados do sistema são ocorrem em intervalos de tempo discretos.

No caso de modelos contínuos, as mudanças de estado acontecem continuamente com o tempo, já que os sistemas são representados através de expressões matemáticas que caracterizam a mudança contínua das variáveis de acordo com o tempo.

Quando modelos discretos são usados, a simulação é denominada discreta, empregada no estudo de sistemas computacionais. Assim, este trabalho dará ênfase à simulação discreta no decorrer desta seção.

\section{Quando à Organização da Simulação}

A organização de uma simulação discreta pode ser feita levando-se em consideração as entidades: Atividades, Evento e Processo.

Uma Atividade corresponde a menor unidade do sistema que consome tempo de execução, podendo ser, por exemplo, a execução de um simples passo de uma instrução ou de uma tarefa inteira (dependendo do nível de detalhamento).

Um Evento acontece quando ocorre uma mudança instantânea no estado de uma entidade do sistema, tendo sido essa mudança provoca pela ação de uma atividade. 
Um conjunto de atividades, logicamente relacionadas, corresponde a um Processo. Um sistema corresponde a vários processos que interagem entre si, sendo essas interações controladas pela ocorrência de eventos.

\section{Quanto ao Nível de Detalhamento}

Quanto ao nivel de detalhamento, agrupam-se os modelos em quatro níveis de abstração: nível de circuito, nível de porta, nível de transferência de registradores e nível de sistema. A escolha do nivel de abstração depende do estado de desenvolvimento em que se encontra o sistema a ser avaliado e também do nível de precisão dos resultados que se deseja obter.

O nível de circuito é empregado quando se deseja analisar o comportamento dos componentes físicos do sistema, como resistores e transistores.

Os níveis de porta e de transferência são usados quando se deseja fazer uma análise do ponto de vista funcional.

O nível de sistema é o que possui o maior nível de abstração, não precisando detalhar o sistema ao nivel de elementos fisicos, por exemplo.

\section{Quanto aos Dados de Entrada}

Baseando-se nos dados de entrada e no modelo, classifica-se a simulação em: simulação estocástica e simulação determinística.

Na simulação estocástica os dados de entrada são gerados a partir das médias de distribuições de probabilidades e o modelo representa o sistema levando em consideração o tempo gasto em cada estado desse sistema.

No caso da simulação determinística, descreve-se os dados entrada como uma seqüência de passos, o que requer uma quantidade expressiva de dados (o que não é uma tarefa muito fácil). Por esse motivo, apesar da simulação determinística produzir resultados mais precisos, a simulação estocástica é a mais utilizada.

Em ambos os casos, os dados de entrada são definidos através de informações obtidas a partir do sistema real, o que pode ser feito por intermédio de experimentação de sistemas existentes. 


\subsubsection{Tipos de Orientação de uma Simulaçâo}

Pode-se organizar um modelo de simulação discreta levando-se em consideração três entidades. Dependendo dessa organização, a simulação discreta pode ser orientada a evento, orientada a processo ou orientada a atividade (Orlandi,1995).

Na simulação orientada a evento o programa computacional é organizado como um conjunto de eventos (ou rotinas de eventos).

$\mathrm{Na}$ orientação a processo o programa de simulação é definido por processos que descrevem o sistema.

E, finalmente, em um programa de simulação orientado a atividades é definido por intermédio de atividades que envolvem as entidades do sistema.

\subsubsection{Etapas de Desenvolvimento da Simulação}

O processo de desenvolvimento de uma simulação pode ser dividido em 10 etapas, como mostra a Figura 4.7, que interagem entre si.

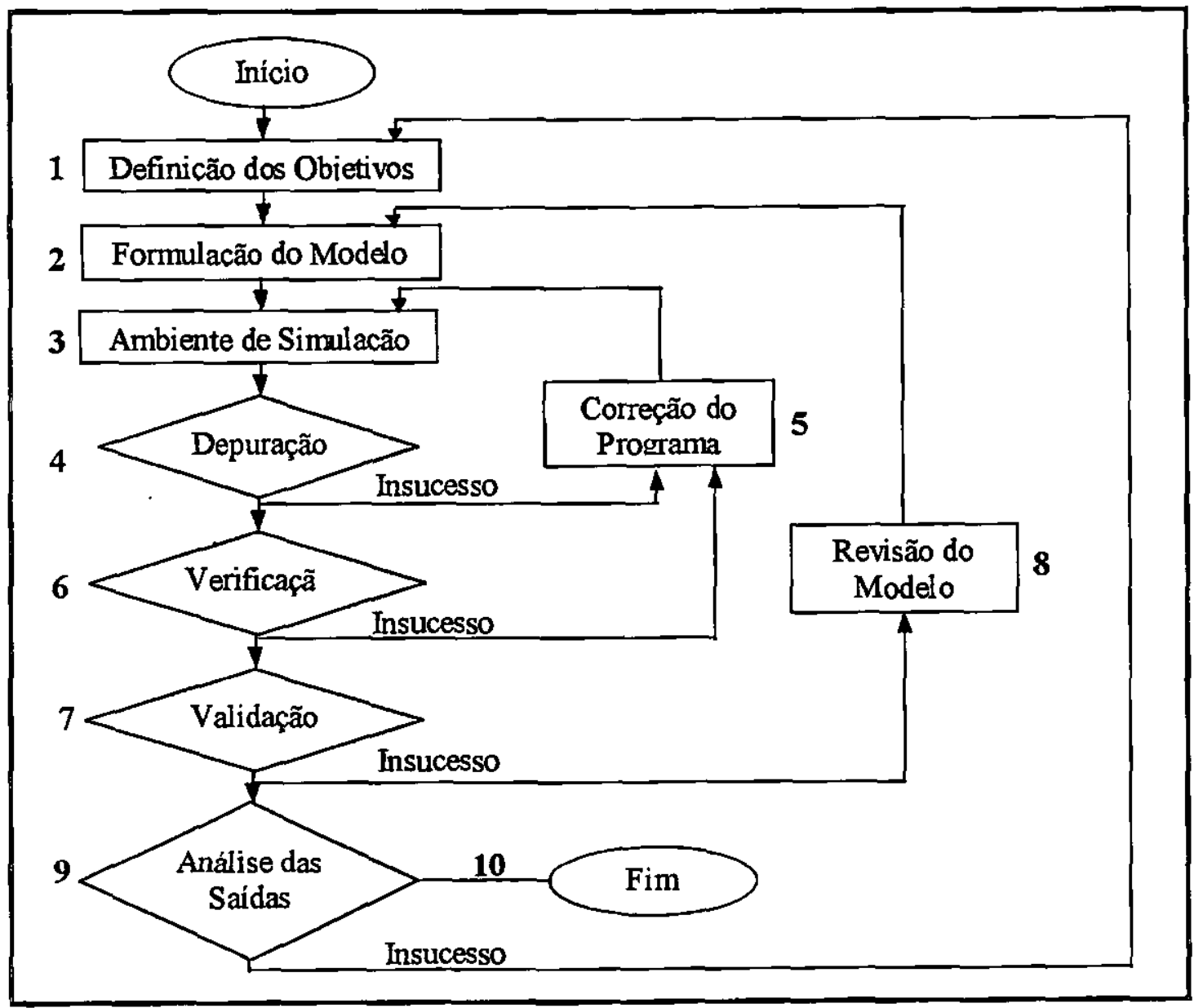

Figura 4.7 - Etapas de Desenvolvimento de Simulaçąa: 
Etapa 1: consiste da definição dos objetivos da avaliação de desempenho, ou melhor, dos objetivos da simulação. Definindo-se os objetivos, pode-se então estabelecer o nível de detalhamento, os tipos de dados de entrada e o tipo de ambiente de simulação. Assim, percebe-se que uma elaboração inadequada dos objetivos pode comprometer a avaliação de desempenho do sistema computacional em questão, já que essa etapa compromete o processo como um todo.

Etapa 2: corresponde à etapa de formulação do modelo, onde devem ser representadas as características essenciais do sistema real. Um modelo pode ser uma representação de alto nível do sistema real, fornecendo uma visão geral do mesmo. Um modelo de alto nível de detalhamento corresponde à uma espécie de síntese do sistema, onde a representação alguns elementos do sistemas podem ser julgadas desnecessárias, o que deve ser feito sem que o modelo passe a ser uma representação inadequada do sistema real. Por outro lado, um modelo pode ser uma representação de baixo nível, podendo ser descrito através de um detalhamento sucessivo, chamado decomposição, onde a descrição do sistema real deve ser feita primeiramente em alto nível, fazendo-se posteriormente os detalhamentos sucessivos, até que seja alcançado o nível de detalhamento desejado. A descrição do modelo fica a critério do usuário (modelador), porém recomenda-se a decomposição para sistema de grande complexidade.

Etapa 3: corresponde à transformação do modelo em um programa de computador, através do uso de um ambiente de simulação. A elaboração desse programa de computador pode ser feita por intermédio de linguagens de programação convencionais, de pacotes de uso específico para criar o programa de simulação, de linguagens de simulação de uso geral ou, ainda, por intermédio de uma extensão funcional de uma linguagem de programação de uso geral. Essas alternativas de ambientes de simulação são melhor explicadas posteriormente, ainda neste seção. Com base no tipo de orientação da simulação, que pode ser a evento, a processo ou a atividade, é deve-se escolher dentre umas dessas alternativas de ferramentas (ambientes computacionais). Além disso, deve-se efetuar tal escolha considerando fatores como complexidade de desenvolvimento, restrições da linguagem, facilidade de programação, flexibilidade e portabilidade.

Etapa 4: corresponde à depuração do programa de computador ou programa de simulação, garantindo que o programa está implementado corretamente e que, consequentemente, produz resultados válidos. 
Etapa 5: corresponde à uma revisão e modificação do programa de simulação. Essa etapa só acontece caso ocorra algum problema de implementação do programa de simulação (etapa 4), como um ou mais erros de compilação do programa, ocasionando uma revisão e correção do mesmo.

Etapa 6: corresponde à uma verificação do programa de simulação, com o intuito de analisar se o mesmo é ou não uma implementação correta do modelo do sistema, o que pode ser feito, por exemplo, comparando-se os resultados da simulação com os obtidos por métodos de solução analitica. Caso ocorra algum problema nessa etapa, deve-se retornar a etapa de número 3, como mostra a Figura 4.7.

Etapa 7: corresponde à validação do modelo, sendo responsável por julgar se o mesmo é ou não uma representação válida do sistema real. No caso do modelo representar um sistema existente, pode-se comparar as mediadas de desempenho do sistema real com os obtidos pela simulação. Por outro lado, o modelo pode ser uma representação de um sistema ainda em fase de projeto, onde a validação é feita através da revisão do modelo.

Etapa 8: corresponde a revisão e correção do modelo. Essa etapa só ocorre quando constata-se algum erro no modelo durante a etapa 7. Nesse caso, devem ser refeitas as etapas 3, 4 e 6, já que são afetadas diretamente caso haja a necessidade de alteração no modelo (Figura 4.7).

Etapa 9: corresponde à fase de verificação da precisão dos resultados da simulação (valores de variáveis de saida da simulação), que são gerados assim que o programa de simulação é executado. Nessa etapa, onde é feita uma análise dos valores das variáveis de saída (resultados da simulação), deve-se considerar efeitos que influenciam esses valores, como o uso de warm-up. Essa análise da precisão é feita normalmente através da utilização de intervalo de confiança.

Etapa 10: representa o fim da solução por simulação, simbolizando validade dos resultados obtidos.

\subsubsection{Ambientes de Simulação}

Diante do exposto, sabe-se para uma simulação é necessário que o usuário saiba uma linguagem de simulação ou que construa seu próprio programa de simulação usando linguagens de programação de propósito geral (tal como a linguagem $\mathrm{C}$ ) ou usar ambientes de simulação já existentes (Santana,1997). Assim, ao contrário da solução analítica, pode-se 
selecionar de que forma o modelo será solucionado, uma vez que a simulação é feita a partir de um ambiente computacional, o qual pode ser selecionado dentre os seguintes (Orlandi,1995):

$>$ desenvolvimento do programa de simulação em uma linguagem convencional, tais como C, Pascal, etc. Nesse caso, o programador é responsável por criar todo o ambiente necessário para a simulação. A vantagem é que o programador tem liberdade para escolher uma linguagem que seja de seu conhecimento, porém tem que desenvolver todas as estruturas exigidas num ambiente de simulação (Orlandi,1995) (Francês, 1998);

$>$ utilização de um pacote de uso específico para criar o programa de simulação. Para tanto, deve existir um pacote que se ajuste às necessidades do sistema a ser modelado. Nesse caso, fica fácil construir o programa, já que normalmente só é necessário parametrizar o modelo pronto. Essa alternativa representa para o programador a aprendizagem de uma nova linguagem, além de oferecer pouca flexibilidade a mudanças, por ser muito específica para um determinado sistema (Orlandi, 1995) (Francês, 1998);

خ utilização de linguagens de simulação de uso geral. Essa alternativa, em comparação com os pacotes especificos, permite que um número maior de sistemas seja modelado. Nesse caso, as linguagens já contêm todas as estruturas necessárias à criação de um ambiente de simulação, livrando o programador da necessidade de executar tal tarefa. Como essas linguagens são menos específicas, elas permitem a simulação de um número maior de sistemas. $\mathrm{O}$ usuário pode ter que aprender uma nova linguagem (Orlandi,1995) (Francês, 1998);

$>$ através de uma extensão funcional de uma linguagem de programação de uso geral. Nesse caso, têm-se os aspectos gerais de uma linguagem de programação unidos ao caráter específico de uma linguagem de simulação. Isso permite ao usuário codificar seu programa utilizando primitivas de uma biblioteca e uma linguagem convencional. Tem-se como exemplo o SMPL (MacDougall,1989) (Orlandi, 1995) (Francês, 1998). 


\subsubsection{Planejamento Estatístico}

Tendo definido o ambiente computacional a ser usado, constrói-se então o programa de simulação, que ao ser executado gera um conjunto de resultados que deve representar corretamente as características do sistema (Orlandi,1995).

Para assegurar a validade desses resultados (variáveis de saída) deve ser aplicado à simulação um planejamento estatístico, onde alguns dos aspectos a serem considerados são:

$>$ A validade estatística dos valores de saída de uma simulação é dependente do grau de aleatoriedade dos números aleatórios gerados. Sendo assim, deve-se usar corretamente os números aleatórios, de forma que sejam independentes, isto é, não deve existir correlação na seqüência de números aleatórios. Além disso, devem ser geradas seqüências diferentes de números aleatórios, a partir da utilização de sementes diferentes (Soares, 1990).

$>0$ uso de warm-up significa que os dados colhidos pelo programa durante $o$ chamado período de aquecimento não são significativos à avaliação. Esse período de aquecimento chega ao final quando o sistema fica em equilibrio (Orlandi,1995). Um sistema fica em equilibrio quando atinge o estado estacionário, que pode ser atingido, por exemplo, se o padrão de chegada não se altera e o sistema tem a capacidade de fornecer o serviço solicitado (Soares, 1990).

Com a questão do warm-up resolvida, efetua-se uma análise dos resultados da simulação (as variáveis de saída), possibilitando verificar a precisão dos mesmos. A precisão dessas variáveis é verificada por intermédio do cálculo de intervalos de confiança, discutido posteriormente (Orlandi,1995).

$>$ pela estimação duvidosa dos parâmetros de entrada do modelo, medidas de desempenho podem ser produzidas contendo erros. Isso acontece, uma vez que essas entradas (distribuições do tempo de serviço, distribuições do tempo de chegada, probabilidades de rotas, disciplinas de filas) correspondem à estimativas dos parâmetros reais, assim pequenos erros cometidos em sua estimativa podem redundar em grandes erros nas medidas de desempenho. (Soares, 1990).

o fim de uma simulação pode ser determinado através de vários modos, denominados métodos de parada. Algumas linguagens de simulação permitem a aplicação de vários métodos, podendo, por exemplo, terminar uma simulação considerando o tempo de execução (determinando o tempo de execução) ou métodos de parada automática (construídos em torno de cálculos sobre intervalos de confiança (Soares, 1990)). 


\subsection{Análise dos Resultados da Simulação}

Para assegurar a validade dos resultados de uma simulação, além dos cuidados que devem ser tomados na fase que antecede a execução do programa de simulação, deve-se fazer uma análise desses resultados (valores das variáveis de saída), para que possa ser verificada a precisão dos mesmos (MacDougall,1989).

A análise dos resultados de uma simulação, que deve ser feita uma vez que se encontra resolvida a questão do warm-up, é normalmente efetuada através da estimativa de um intervalo de confiança (MacDougall,1989).

Várias são as técnicas utilizadas para definir um intervalo de confiança, dentre as quais se destacam as seguintes (Orlandi, 1995):

Técnica de Replicação: o intervalo de confiança é definido através dos dados provenientes de um número específico de execuções do programa de simulação. Assim, são feitas $N$ execuções, denominadas de replicações, usando-se diferentes sementes de números aleatórios em cada uma dessas execuções. Tendo-se os resultados das $N$ execuções (ou replicações), representados por $y_{1}, y_{2}, \cdots, y_{N}$, definese o intervalo de confiança através da média desses resultados, denominada $Y$. Essa é a técnica mais simples de ser aplicada, no entanto, na maioria dos casos, exige um elevado número de replicações.

Técnica de Regeneração: nessa técnica, o modelo de simulação retorna a um ponto previamente determinado, a partir do qual é reiniciada automaticamente a simulação. O intervalo de confiança é construído através dos dados coletados a cada um desses ciclos. A grande dificuldade dessa técnica consiste na definição desses pontos de retorno, denominados de regenerações.

Técnica das Medidas por Lotes: divide-se uma execução longa em um conjunto de $N$ subexecuções, denominadas lotes, cada um determinado comprimento $m$. O intervalo de confiança é calculado ao término de cada lote. Esse valor do intervalo de confiança deve ser comparado com o valor requerido. Caso a precisão requerida já tenha sido alcançada, o processo é encerrado. Caso contrário, determina-se um novo lote e repete-se o processo de comparação até que a precisão requerida tenha sido atingida. Essa técnica é mais complexa que a de replicação, no entanto, mais eficiente, já que o tratamento do warm-up é feito uma única vez, enquanto que na replicação o warm-up é tratado $N$ vezes ( $N$ replicações). 


\subsection{Comparação entre Solução Analitica}

\section{e Solução por Simulação}

O fato de produzir resultados mais exatos do que a simulação, é a grande vantagem da solução analítica, além de ser geralmente o método mais rápido. Portanto, quando aplicável, é o método preferido (Soares,1990) (Kleinrock,1976) (Francês,1998).

Por outro lado, na solução analítica, muitas hipóteses de simplificação devem ser aplicadas ao modelo, o que pode inviabilizar o uso dessa solução em casos mais complexos, situações em que a simulação é mais recomendada. Com essas simplificações, o modelo pode não ser uma representação precisa do sistema real, assim o resultado por mais exato que seja, provavelmente, não terá utilidade (Soares,1990) (Santana,1997) (Francês, 1998). Para resolver esse problema de que muitos modelos não podem ser solucionados analiticamente, foram criadas técnicas especiais denominadas Técnicas de Aproximação (Santana,1997) e como exemplo têm-se modelagem hierárquica e fluxo de equivalência. Nessa técnica, um modelo complexo é decomposto em vários submodelos, os quais são solucionados individualmente e, posteriormente, combinados por intermédio do chamado Centro de Serviço de Fluxo Equivalente (FESC) para obter a solução do modelo original (Soares, 1990) (Orlandi,1995).

No entanto, a simulação não impõe nenhuma restrição, podendo resolver modelos com maior grau de complexidade, permitindo assim a inclusão de muitos detalhes do sistema real no modelo (Santana, 1997) (Francês, 1998).

O problema da simulação de modelos complexos é o tempo necessário para processar o programa de simulação, uma vez que o tempo geralmente aumenta com a complexidade do modelo, podendo tornar a simulação inviável. Técnicas de simulação distribuida podem ser utilizadas para resolver esse problema, pois aceleram potencialmente o tempo de execução da simulação (Santana, 1997)

Outro ponto negativo da simulação, principalmente ao se tratar de modelos complexos, é o fato do usuário precisar saber uma linguagem de simulação ou ter que construir seu próprio programa de simulação usando linguagens de programação de propósito geral, como a linguagem C (Francês,1998). Para evitar que o usuário tenha que aprender uma dessas linguagens é que existem ambientes de simulação automáticos, sendo necessário apenas que se forneça o modelo de Redes de Fila do sistema (através de um desenho), que se informe os parâmetros e que se escolha as op̧̧̃es de saidas (Santana,1997). 
$\mathrm{Na}$ simulação deve ser considerado o custo do planejamento estatístico, que pode proporcionar a inviabilidade dessa técnica de solução de modelos. No planejamento estatístico são considerados os seguintes fatores: usos corretos de números aleatórios, cálculo de intervalos de confiança, uso de warm up, definição do tempo de execução, etc.

De modo geral, percebe-se que as desvantagens de uma solução por simulação correspondem às vantagens de uma solução analítica. Por exemplo, quanto aos resultados, a solução analítica proporciona resultados muito mais exatos, sendo esta uma desvantagem da simulação. Assim, fica claro que cada solução possui o seu domínio de aplicação, o que proporciona a utilização adequada da simulação e da solução analítica.

\subsection{Considerações Finais}

A solução analítica possui suas vantagens em relação à solução por simulação e viceversa, de forma que, as vantagens de uma são as desvantagens da outra. Assim sendo, existem situações que são mais adequadàs a uma solução do que a outra. Conforme a Figura 4.8, a escolha da solução adequada depende do grau de complexidade do modelo. Quando se trata de modelos com um grau de complexidade pequeno, indica-se a solução analítica, podendo, em alguns casos, ser aplicada a modelos que envolvem uma grande quantidade de informações e/ou mais complexos. Ao contrário, a simulação é mais utilizada para solucionar modelos mais complexos (que não se encaixam às restrições exigidas pela solução analítica) e/ou que possuem um grande número de informações, sendo, secundariamente, aplicada à modelos com um baixo grau de complexidade (Orlandi,1995) (Francês,1998).

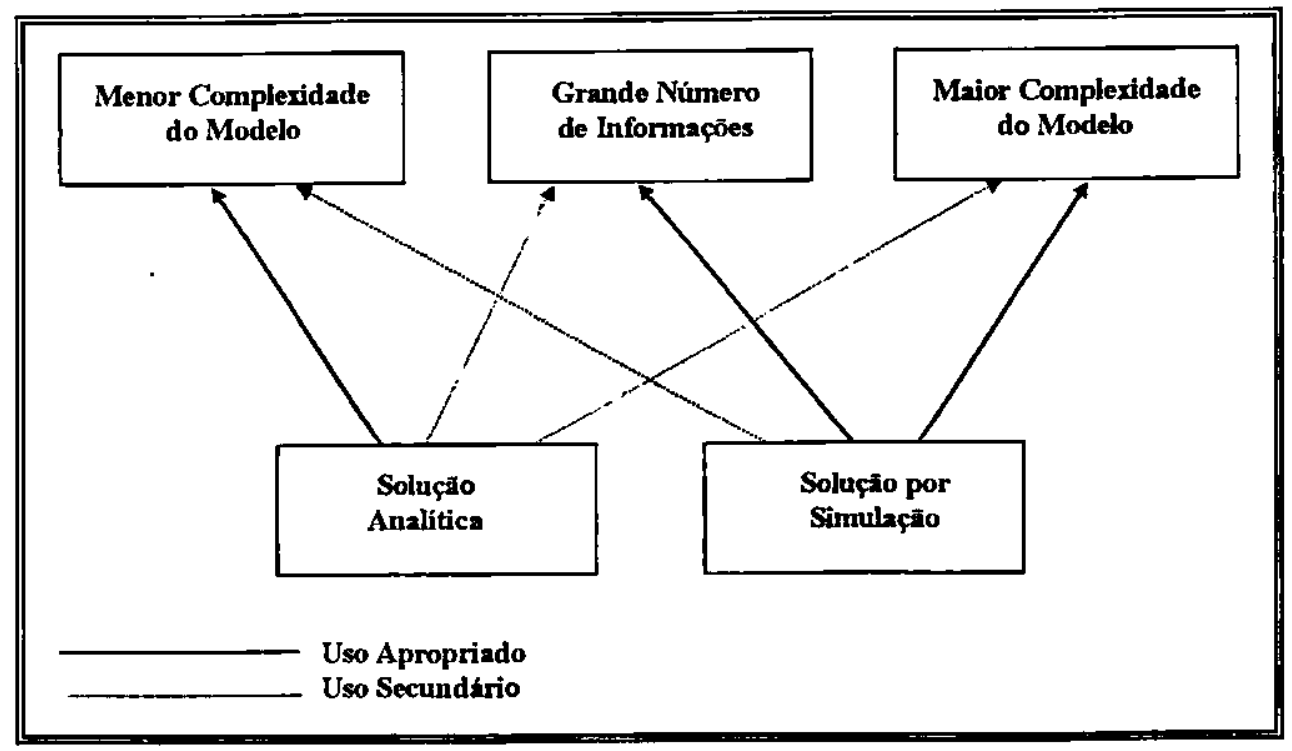

Figura 4.8 - Soluçăo mais adequada para um modelo 


\section{Capítulo 5}

\section{Solução de Modelos Práticos -}

\section{Aplicação dos Métodos Analiticos e Simulação}

\subsection{Considerações Iniciais}

Com o objetivo de maior entendimento dos métodos de solução analítica e por simulação, quatro modelos de rede de filas, representando situações relevantes à área de sistemas distribuídos, são discutidos e solucionados neste capítulo.

Dentre os modelos, três representam um servidor de arquivos de um ambiente distribuído, sendo o primeiro modelo uma representação macroscópica do servidor, enquanto os outros dois o representam de maneira mais detalhada. No primeiro modelo, tem-se o servidor de arquivos denotado por único centro de serviço, composto por um servidor e sua fila, constituindo um modelo padrão $\mathrm{M} / \mathrm{M} / 1$. No segundo, o modelo é composto por dois centros de serviços, cada um com um único servidor e suas filas. No terceiro, adicionam-se dois servidores que representam as funções de um PFE (Processador Front-End).

O quarto modelo é o mais abrangente, pois, além do servidor de arquivos, representa os terminais e a rede de comunicação, denotando assim um ambiente computacional distribuído completo.

$\mathrm{Na}$ avaliação de desempenho desses modelos, utilizam-se métodos de solução analítica e simulação. Os métodos analíticos aplicados ao primeiro modelo do servidor de arquivos, o $\mathrm{M} / \mathrm{M} / 1$, são: Processo Nascimento-e-Morte (solução padrão do modelo $\mathrm{M} / \mathrm{M} / 1$ ), Limites de Desempenho e Simulação. Aos dois outros modelos que representam um Servidor de Arquivos, os métodos de solução analitica aplicados são: AVM para Modelos Abertos, Rede de Jackson, e Limites de Desempenho.

A Decomposição Hierárquica é geralmente aplicada a modelos mais complexos, por isso será usada apenas na solução analítica do quarto e último modelo, sendo necessário 
utilizar nessa solução os seguintes métodos: AVM para centros dependentes de carga e o método de Gordon e Neweel. O quarto modelo também é solucionado analiticamente através dos métodos AVM para Modelos Fechados e Limites de Desempenho. O método de Redes BCMP especifica um grupo de modelos aos quais pode ser aplicado a Análise do Valor Médio e, sendo assim, o método AVM é utilizado na solução de modelos pertencentes a esse grupo.

Para a simulação, utilizada para comparar os resultados obtidos através das soluções analíticas dos quatro modelos, foi usado ASiA - Ambiente de Simulação Automático.

Os modelos abordados neste capítulo representam situações reais dentro da área de sistemas distribuídos, porém os parâmetros adotados nos exemplos apresentados são valores didáticos, escolhidos criteriosamente com o objetivo de tornar mais clara as soluções estudadas.

\subsection{Modelo I: $M / M / 1$}

Um modelo de fila única pode ser usado para avaliar de forma individual cada recurso em um sistema computacional (Jain,1991). Por exemplo, se em um ambiente distribuído, vários terminais solicitam serviços a um servidor de arquivos, suas solicitações serão então enfileiradas até que sejam atendidas pelo servidor. Assim, pode-se modelar o servidor de arquivos (considerando-se uma abstração de nivel bastante elevado) utilizando-se um modelo M/M/1 (Figura 5.1), assumindo-se o tempo entre as chegadas de clientes e os tempos de serviço obedecem a uma distribuição exponencial, que o tamanho da fila e a quantidade de clientes na sala de espera são ambos infinitos, e que a disciplina de fila é do tipo FIFO - First In First Out (isto é, o servidor atende os clientes obedecendo a ordem de chegada) (Jain,1991) (Orlandi, 1995).

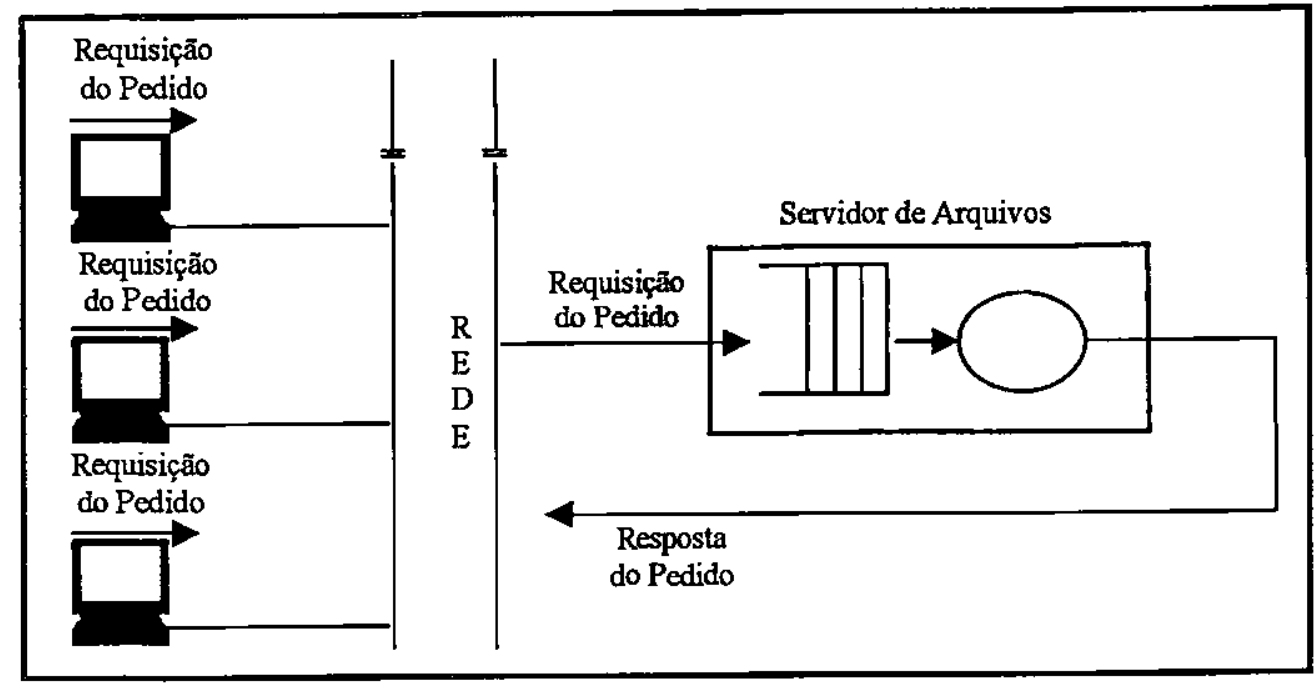

Figura 5.1 - M/M/1 representando um Servidor de Arquivos 


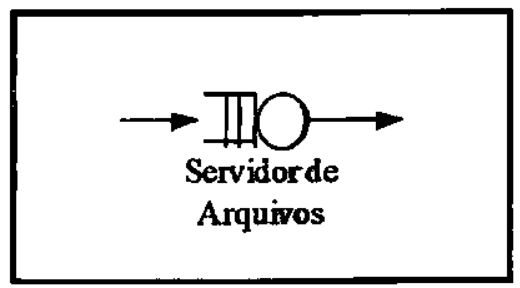

Figura 5.2 - Modelo I: M/M/1

Para avaliar esse modelo (representado simplificadamente na Figura 5.2), que é aberto, alguns métodos de solução analítica são ưilizados, sendo seus resultados validados posteriormente por comparação com os valores obtidos através de simulação. Consideram-se, em ambas soluções, os seguintes parâmetros de entrada:

$$
\lambda=12 \quad \text { e } \quad \mu=20 \rightarrow S=1 / \mu=0,05
$$

Como se trata de um modelo conhecido (padrão), o M/M/1 possui soluções padrões que podem ser encontradas na literatura referente ao assunto, como discutido na seção que segue.

\subsubsection{Processo Nascimento-e-Morte}

A primeira solução analítica considerada neste trabalho aborda o modelo $\mathrm{M} / \mathrm{M} / 1$ como um processo nascimento-e-morte, por possuir os tempos entre chegadas e tempos de serviço exponencialmente distribuidos. Para solucioná-ło é necessário saber apenas a taxa média de chegada $(\lambda)$ e a taxa média de serviço $(\mu)($ Jain,1991) (Alen,1978).

Para o cálculo, necessitam-se dos parâmetros de entrada, que nesse caso são $\lambda=12 \mathrm{e}$ $\mu=20$. Aplicando-se as equações ao modelo $M / M / 1$, obtêm-se as seguintes medidas de desempenho, que representam a solução do mesmo:

$>$ Throughput: $X=\lambda=12$ (Lei do Ftuxo Balanceado)

$>$ Utilização: $\rho=\lambda / \mu=0,60 \rightarrow 60 \%$

$>$ Número médio de clientes no sistema: $E[n]=\frac{\rho}{(1-\rho)}=1,50$

$>$ Número médio de clientes na fila: $E\left[n_{q}\right]=\frac{\rho^{2}}{(1-\rho)}=0,9$

$>$ Tempo médio de resposta: $E[r]=\frac{1 / \mu}{(1-\rho)}=0,125$

$>$ Tempo médio de fila: $E[w]=\rho \frac{1 / \mu}{(1-\rho)}=0,075$ 


\subsubsection{Limites de Desenpenho}

No caso do modelo $\mathrm{M} / \mathrm{M} / 1$, no cálculo dos Limites de Desempenho, mais especificamente; dos Limites Assintóticos, utiliza-se o Algoritmo 4.7, sabendo-se que o número de centros de serviço é igual a $1(k=I), D=D_{k}$ e $D_{m a x}=D$. Entretanto, antes de aplicar - Algoritmo 4.7, para o cálculo dos Limites Assintóticos para o modelo I, necessita-se obter a utilização $(\rho)$, sabendo-se que $\lambda=12$ e $\mu=20$. A utilização pode ser obtida tanto através da Lei de Utilização, dada por $\rho=S \lambda$, quanto por intermédio da equação mostrada na solução anterior, $\rho=\lambda / \mu$. Assim:

$$
\rho=S \lambda=\frac{1}{\mu} \lambda=0,60 \rightarrow 60 \%
$$

Além da utilização, deve-se saber que o valor do tempo de pensar, $Z$, eqüivale a zero quando o modelo é aberto. Assim, para o caso do modelo $\mathrm{M} / \mathrm{M} / 1$ :

$$
Z=0
$$

Por intermédio do Algoritmo 4.7, referente ao cálculo dos limites assintóticos, considerando $k=1$, obtêm-se:

$$
\begin{aligned}
& D_{k}=\frac{\rho_{k}}{\lambda} \rightarrow D_{1}=\frac{\rho_{1}}{\lambda}=\frac{0,6}{12}=0,05 \\
& D=\sum_{k=1}^{k} D_{k}=D_{1}=0,05 \\
& D_{\max }=\max _{k} D_{k}=D_{1}=0,05 \\
& N^{*}=\frac{D+Z}{D_{\max }}=\frac{0,05+0}{0,05}=1
\end{aligned}
$$

Ainda através do Algoritmo 4.7, obtêm-se os pontos que posteriormente constituirão os gráficos dos limites assintóticos do modelo $\mathrm{I}$.

O gráfico dos limites assintóticos do throughput do sistema é dado pelos pontos:

Limite Otimista:

$$
\begin{aligned}
& (0,0) \text { e }\left(1, \frac{1}{D+Z}\right) \text { para } N \leq N^{*} \rightarrow(0 ; 0) \text { e }(1 ; 20) \\
& \left(0, \frac{1}{D_{\max }}\right) \text { e }\left(1, \frac{1}{D_{\max }}\right) \text { para } N \geq N^{*} \rightarrow(0 ; 20) \text { e }(1 ; 20)
\end{aligned}
$$

Limite Pessimista:

Este limite não é linear em $N$. 
O gráfico dos limites assintóticos do tempo de resposta do sistema é dado pelos pontos:

Limite Otimista:

$(0, D)$ e $(1, D)$ para $N \leq N^{*} \rightarrow(0 ; 0,05)$ e $(1 ; 0,05)$

$(0,-Z)$ e $\left(1, D_{\max }-Z\right)$ para $N \geq N^{*} \rightarrow(0,0)$ e $(1,0,05)$

Limite Pessimista:

$(0,0)$ e $(1, D) \rightarrow(0 ; 0)$ e $(1 ; 0,05)$

Assim, possuindo-se os pontos, traçam-se os gráficos para os limites assintóticos do throughput e do tempo de resposta (Gráfico 5.1 e Gráfico 5.2).

Essas retas constituem as assintotas que definem o limite otimista para o throughput do sistema, simbolizando que o throughput deve se apresentar na área localizada abaixo das mesmas. No caso do Modelo I, de acordo com a solução analítica anterior, o valor médio do throughput é 12 quando o sistema possui em média 1,5 clientes. Como mostrado no Gráfico 5.1, esse throughput, representado pelo ponto de cor vermelha no gráfico, encontra-se na área abaixo do limite otimista.

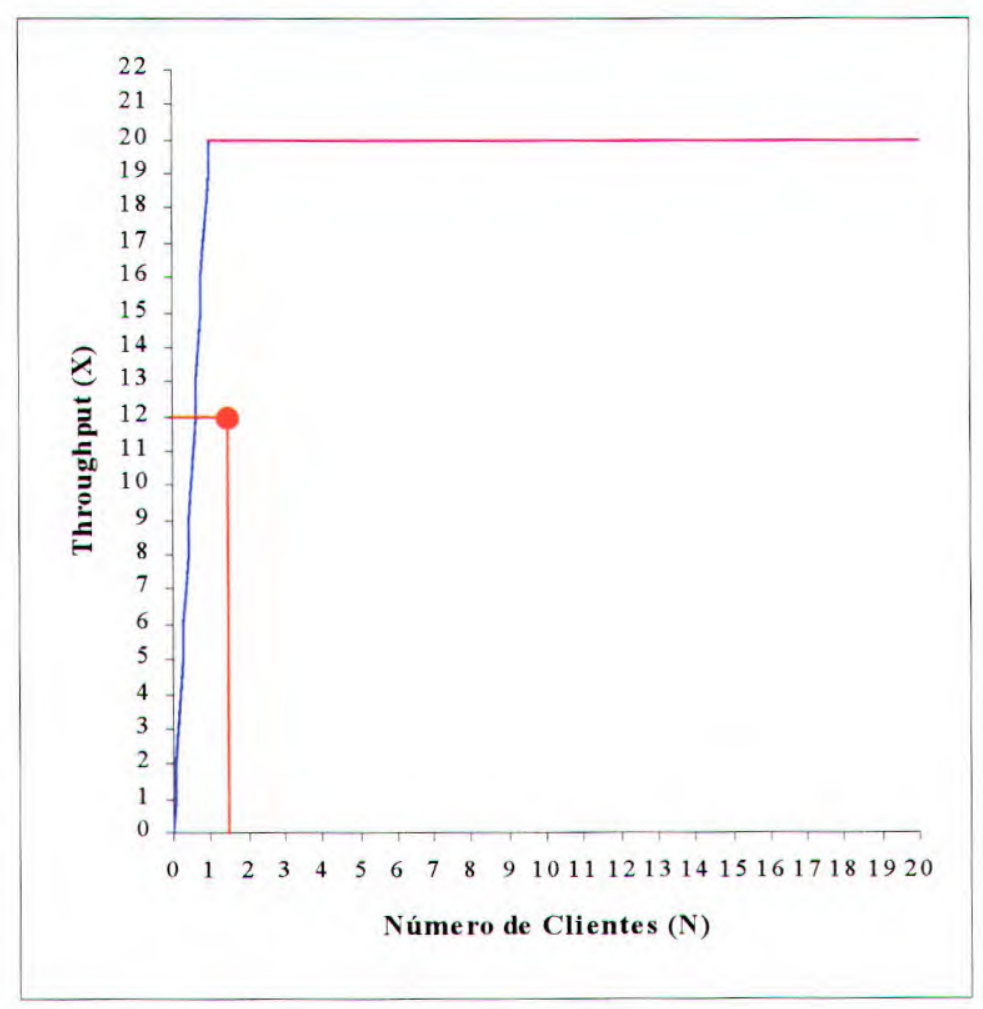

Gráfico 5.1 - Limite Otimista do Throughput do Modelo I

O Gráfico 5.2, que foi construído de forma similar ao do throughput, representa os limites assintóticos para o tempo de resposta do modelo I. Nesse gráfico, além do limite otimista (retas na cor azul e rosa), encontra-se traçado o limite pessimista para o tempo de 
resposta, traçado por intermédio dos pontos $(0 ; 0)$ e $(1 ; 0,05)$, representado pela reta tracejada na cor verde, que é coincidente com a reta na cor rosa.

Diante do gráfico, tem-se que o tempo de resposta deve se apresentar na área que fica acima do limite otimista, tendo tal área delimitada pela reta do limite pessimista. No caso do modelo I, como o limite pessimista coincide com uma das restas componentes do limite otimista, o valor do tempo de resposta deve simplesmente estar acima do limite otimista.

Segundo a solução analítica anterior, o tempo médio de resposta do modelo I vale 0,125 quando o número de clientes do sistema é em média 1,5. Diante desses dados, como mostrado no Gráfico 5.2 (ponto de cor vermelha), constata-se que o tempo de resposta se apresenta dentro da área desejada.

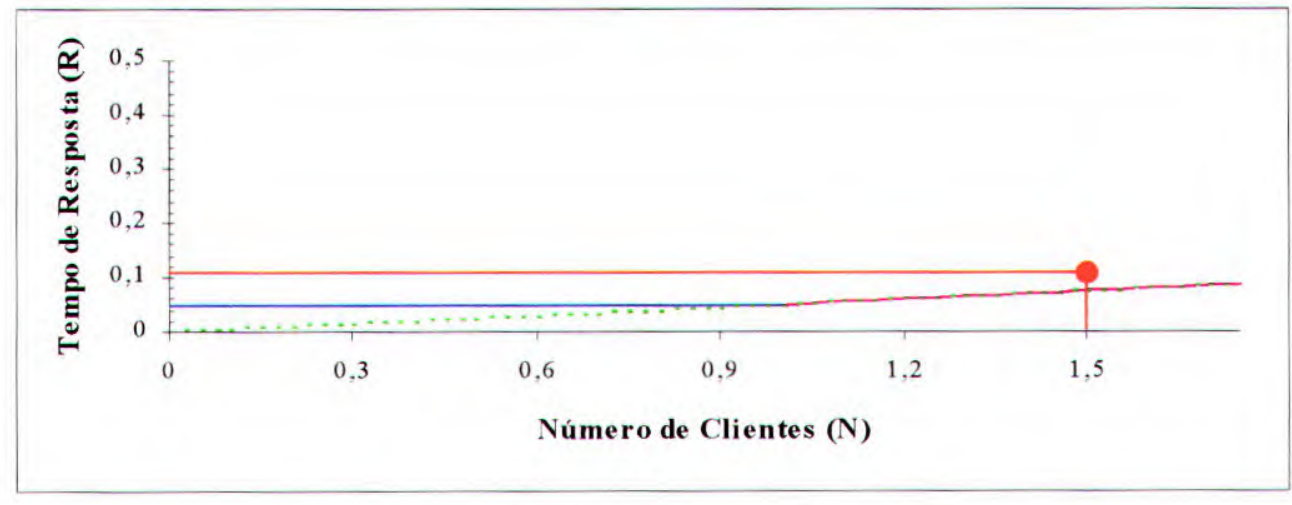

Gráfico 5.2 - Limites do Tempo de Resposta do Modelo I

\subsubsection{Simulação}

Para a simulação do modelo $\mathrm{M} / \mathrm{M} / 1$, assim como para os outros modelos, foi utilizado o Ambiente de Simulação Automático (ASiA). O ASiA gera automaticamente um código (programa computacional) usando uma extensão funcional da linguagem C, o SMPL, para simular os modelos que o usuário constrói por intermédio de uma interface gráfica (Brushi,1997).

Os parâmetros considerados para a simulação no ASiA são: tempo entre chegadas $(\tau=1 / \lambda)$, tempo de serviço de cada servidor $(S=1 / \mu)$, tempo de execução da simulação (te e as distribuições do tempo de serviço e do tempo entre chegadas. No caso do modelo I, tên se os seguintes parâmetros: $\tau=0,0833 ; S=0,05 ; \quad t e=1.000 .000$ u.t. e distribuições exponenciais para o tempo de serviço e para o tempo entre chegadas.

Para a simulação são consideradas 8 execuções (replicações), cada uma com um comprimento equivalente a 1.000 .000 u.t. e os resultados apresentados são valores médios, com o correspondente intervalos de confiança de 95\% (MacDougall,1989). 
Ao simular-se o Modelo I (M/M/1), para cada uma das execuçōes, obtêm-se como saída padrão um relatório contendo os resultados da simulação, dentre os quais destacam-se a utilização e o comprimento médio de fila. A Figura 5.3 apresenta o relatório correspondente à semente 0 (zero), uma das 8 sementes de números aleatórios.

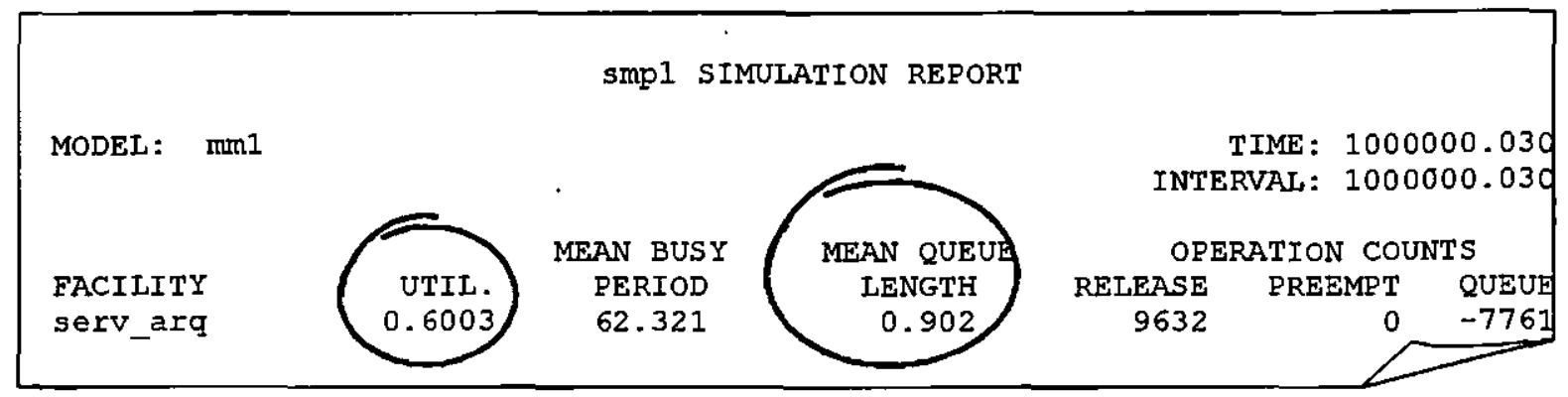

Figura 5.3 - Relatónio de Simulação do Modelo I para a semente 0

Para complementar as informaçōes da simulação, altera-se o código gerado pelo ASiA, fazendo-se com que o mesmo passe a fornecer medidas desempenho adicionais (Brushi,1997). Assim, além dos valores fornecidos pelo relatório da simulação apresentado na Figura 5.3 (utilização e comprimento médio de fila), pode-se também comparar os resultados analíticos a outras medidas de desempenho. A Figura 5.4 apresenta as medidas adicionais obtidas para a execução de semente 0 (zero) (MacDougall,1989):

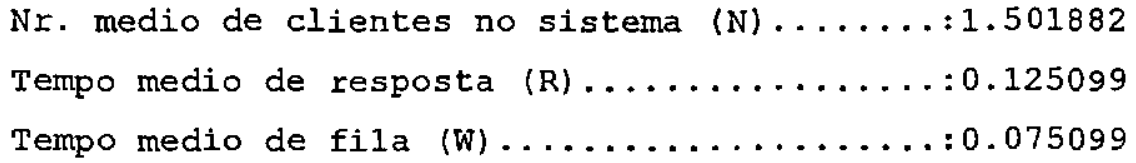

Figura 5.4 - Medidas de desempenho adicionais para o Moddelo I-semente 0

A partir dos resultados da simulação, que correspondem à média das 8 execuções (replicação), compara-se os valores das medidas de desempenho obtidos pelas soluções analíticas do modelo I (Tabela 5.1), observando-se que os resultados da simulação eqüivalem aos obtidos por intermédio dos métodos analíticos. 


\begin{tabular}{|c|c|c|c|}
\cline { 2 - 4 } \multicolumn{1}{c|}{} & \multicolumn{2}{c|}{ Soluçöes Analíticas } & Simulação \\
\cline { 2 - 4 } & $\begin{array}{c}\text { Processo } \\
\text { Nascimento-e-Morte }\end{array}$ & $\begin{array}{c}\text { Limites de } \\
\text { Desempenho }\end{array}$ & AsiA \\
\hline $\begin{array}{c}\boldsymbol{X} \\
\text { (throughput do sistema) }\end{array}$ & 12 & OK & - \\
\hline $\begin{array}{c}\rho \\
\text { (utilização do sistema) }\end{array}$ & $60 \%$ & - & $0,6032463 \pm 0.00003411$ \\
\hline $\begin{array}{c}\boldsymbol{N} \\
\text { (número de clientes no sistema) }\end{array}$ & 1,5 & - & $1,5022275 \pm 0,00024139$ \\
\hline $\begin{array}{c}\boldsymbol{N}_{\boldsymbol{g}} \\
\text { (número de clientes na fila) }\end{array}$ & 0,9 & - & $0,90191675 \pm 0,00021486$ \\
\hline $\begin{array}{c}\boldsymbol{R} \\
\text { (tempo de resposta) }\end{array}$ & 0,125 & OK & $0,125121 \pm 0,00001461$ \\
\hline $\begin{array}{c}W \\
\text { (tempo de fila) }\end{array}$ & 0,075 & - & $0,075121 \pm 0,00001461$ \\
\hline
\end{tabular}

Tabela 5.1 - Comparaçăo entre os resultados das soluçōes do Modelo I 


\subsection{Modelo II: Servidor de Arquivos}

Da mesma forma que no modelo anterior, as solicitações são feitas ao Servidor de Arquivos, podendo ser enfileiras ou atendidas imediatamente. No modelo $I$, entretanto, encontra-se representada a possibilidade de acesso à disco, como mostra a Figura 5.5:

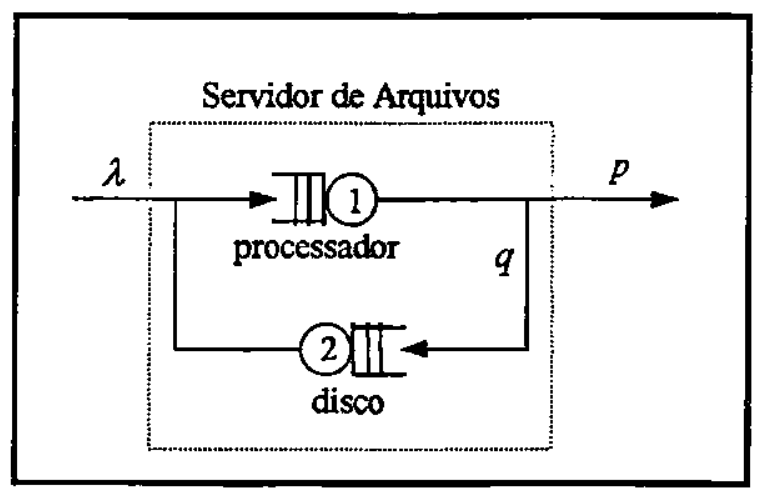

Figura 5.5 - Modelo Il: Servidor de Arquivos

Assim, ao chegar uma solicitação ao servidor de arquivos, o processador inicia sua execução, a qual deve ser interrompida no caso de ser identificada uma operação com disco. Nesse caso, o processador requisita o disco e inicia a execução de uma nova solicitação, mantendo a anterior bloqueada até que o disco envie a resposta da requisição. No momento da requisição, a solicitação pode ser enfileirada ou imediatamente atendida pelo disco, de forma que, assim que a operação é finalizada, uma resposta é enviada ao processador, para que o mesmo possa, caso necessário, concluir o processamento da solicitação bloqueada.

O modelo II, que é aberto e caracteriza-se por uma chegada exponencial, disciplina de fila FIFO, atendimento exponencial e uma única classe de clientes, será solucionado analiticamente por intermédio de três métodos: AVM para modelos abertos, Rede de Jackson e Limites de Desempenho, cujos resultados serão comparados aos da simulação. Para essas soluções, consideram-se os seguintes parâmetros de entrada:

$$
\begin{aligned}
& \lambda=12 \\
& \mu_{1}=25 \rightarrow S_{1}=1 / \mu_{1}=0,04 \\
& \mu_{2}=20 \rightarrow S_{2}=1 / \mu_{2}=0,05 \\
& p=60 \%=0,6
\end{aligned}
$$




\subsubsection{Análise do Valor Médio (AVM)}

Considerando-se o Modelo II, pode-se avaliar seu desempenho por intermédio do Algoritmo 4.1, que aborda a Análise de Valor Médio para modelos abertos.

Antes de se aplicar o algoritmo, necessita-se computar a taxa de visita, $V_{i}$, para cada centro por (Allen,1991):

$$
V_{f}=\sum_{i=0}^{M} V_{i} p_{i j}
$$

Onde $M$ é número de centros e $V_{0}=1$ é a taxa de visita do lado de fora do modelo. Logo:

$$
\begin{aligned}
& V_{1}=\underbrace{V_{0}}_{1} \underbrace{p_{01}}_{1}+V_{1} \underbrace{p_{11}}_{0}+V_{2} \underbrace{p_{21}}_{1} \rightarrow V_{1}=1+V_{2} \\
& V_{2}=V_{0} \underbrace{p_{02}}_{0}+V_{1} \underbrace{p_{12}}_{q}+V_{2} \underbrace{p_{22}}_{0} \rightarrow V_{2}=q V_{1}
\end{aligned}
$$

Assim,

$$
\begin{aligned}
& V_{1}=1+q V_{1}=\frac{1}{1-q}=\frac{1}{p}=\frac{1}{0,6}=1,6667 \\
& V_{2}=q V_{1}=0,4 \times 1,6667=0,6667
\end{aligned}
$$

Considerando-se o Throughput do sistema igual à taxa de chegada de clientes ao sistema $(X=\lambda)$, aplica-se o Algoritmo 4.1, obtendo-se:

- Demanda de Serviço do centro: $D_{i}=S_{i} V_{i}\left\{\begin{array}{l}D_{1}=0,04 \times 1,6667=0,0667 \\ D_{2}=0,05 \times 0,6667=0,0333\end{array}\right.$

- Utilização do centro: $\rho_{i}=X D_{1}\left\{\begin{array}{l}\rho_{1}=12 \times 0,0667=0,8004 \approx 0,80 \\ \rho_{2}=12 \times 0,0333=0,3996 \approx 0,40\end{array}\right.$

- Throughput do centro: $X_{i}=X V_{i}\left\{\begin{array}{l}X_{1}=12 \times 1,6667=20,0004 \\ X_{2}=12 \times 0,6667=8,0004\end{array}\right.$

- Tempo de Resposta do centro:

$$
R_{i}=S_{i} /\left(1-\rho_{i}\right)\left\{\begin{array}{l}
R_{1}=0,04 /(1-0,8004)=0,2004 \\
R_{2}=0,05 /(1-0,3996)=0,0833
\end{array}\right.
$$

- Número de Clientes no centro:

$$
N_{i}=\rho_{i} /\left(1-\rho_{i}\right)\left\{\begin{array}{l}
N_{1}=0,8004 /(1-0,8004)=4,01 \\
N_{2}=0,3996 /(1-0,3996)=0,6656
\end{array}\right.
$$


- Tempo de Resposta do sistema:

$$
R=\sum_{i=1}^{M} R_{i} V_{i}=(0,2004 \times 1,6667)+(0,0833 \times 0,6667)=0,3895
$$

- Número de clientes no sistema: $N=\sum_{i=1}^{M} N_{i}=4,01+0,6656=4,6756$

\subsubsection{Rede de Jackson}

Uma outra forma de solucionar analiticamente o modelo II, que é aberto, é através do método de Rede de Jackson, já que o modelo a ser solucionado possui chegada e atendimento de clientes exponencialmente distribuídos.

Considerando os parâmetros de entrada do modelo, apresentados na solução anterior, aplica-se o método de Rede de Jackson:

$$
\begin{gathered}
\pi_{n_{1}, n_{2}}=p_{1}\left(n_{1}\right) \cdot p_{2}\left(n_{2}\right)=\left(1-\rho_{1}\right) \rho_{1}^{n_{1}} \cdot\left(1-\rho_{2}\right) \rho_{2}^{n_{2}}, \\
\text { onde } \rho_{i}=\frac{\Lambda_{i}}{\mu_{i}} \text { e } \Lambda_{t}=\lambda_{i}+\sum_{j=1}^{\mathrm{M}} p_{j i} \cdot \Lambda_{j}
\end{gathered}
$$

Dessa forma, tem-se um sistema linear:

$$
\begin{aligned}
& \Lambda_{1}=\underbrace{\lambda_{1}}_{\lambda}+\underbrace{p_{11}}_{0} \Lambda_{1}+\underbrace{p_{21}}_{1} \Lambda_{2} \rightarrow \Lambda_{1}=\lambda+\Lambda_{2} \\
& \Lambda_{2}=\underbrace{\lambda_{2}}_{0}+\underbrace{p_{12}}_{q} \Lambda_{1}+\underbrace{p_{22}}_{0} \Lambda_{2} \rightarrow \Lambda_{2}=q \Lambda_{1}
\end{aligned}
$$

Assim, pode-se calcular as taxas de entrada para cada centro de serviço:

$$
\begin{aligned}
& \Lambda_{1}=\lambda+q \Lambda_{1}=\frac{\lambda}{1-q}=\frac{12}{0,6}=20 \\
& \Lambda_{2}=0,4 \times 20=8
\end{aligned}
$$

Tendo-se os valores das taxas de entrada $\Lambda_{1}$ e $\Lambda_{2}$, calcula-se a utilização de cada centro:

$$
\rho_{i}=\frac{\Lambda_{i}}{\mu_{i}}\left\{\begin{array}{l}
\rho_{1}=\frac{20}{25}=0,80 \\
\rho_{2}=\frac{8}{20}=0,40
\end{array}\right.
$$

Dessa foram, tem-se que a distribuição de equilibrio para o número de clientes do modelo II é dada por:

$$
\pi_{n_{1}, n_{2}}=(1-0,80) \cdot 0,80^{n_{1}} \cdot(1-0,40) \cdot 0,40^{n_{2}}
$$


Além disso, como em uma rede de Jackson se considera cada nó do modelo como um modelo $\mathrm{M} / \mathrm{M} / 1$, podem-se calcular outras medidas de desempenho para cada nó por intermédio das equações definidas pela solução de Processo Nascimento-e-Morte do Modelo I, já que o mesmo é um modelo $\mathrm{M} / \mathrm{M} / 1$. Sendo assim, obtêm-se para cada nó do modelo II as seguintes medidas:

- Número médio de clientes

- no nó $1: n_{1}=\frac{\rho_{1}}{\left(1-\rho_{1}\right)}=4,0$

- no nó $2: n_{2}=\frac{\rho_{2}}{\left(1-\rho_{2}\right)}=0,6667$

- Número médio de clientes na fila

- do nó 1: $n q_{1}=\frac{\rho_{1}^{2}}{\left(1-\rho_{1}\right)}=3,2$

- do nó $2: n q_{2}=\frac{\rho_{2}{ }^{2}}{\left(1-\rho_{2}\right)}=0,2667$

- Tempo médio de resposta

- no nó $1: r_{1}=\frac{1 / \mu_{1}}{\left(1-\rho_{1}\right)}=0,20$

- no nó 2: $r_{2}=\frac{1 / \mu_{2}}{\left(1-\rho_{2}\right)}=0,0833$

- Tempo médio de fila

- do nó 1: $w_{1}=\rho_{1} \frac{1 / \mu_{1}}{\left(1-\rho_{1}\right)}=0,16$

- do nó 2: $w_{2}=\rho_{2} \frac{1 / \mu_{2}}{\left(1-\rho_{2}\right)}=0,0333$

\subsubsection{Limites de Desempenho}

Para o cálculo dos Limites Assintóticos referentes ao Modelo II, deve-se utilizar o Algoritmo 4.7, levando-se em consideração que o número de centros de serviço do modelo é igual a $2(k=2)$. Entretanto, antes que o Algoritmo 4.7 seja aplicado ao modelo II, necessita-se da utilização de cada centro de serviço $\left(\rho_{k}\right)$, que corresponde a $\rho_{1}=0,80$ e $\rho_{2}=0,40$, segundo as soluções anteriores do modelo II, que fazem uso da Lei de Utilização. 
Além disso, deve-se saber que o valor do tempo de pensar, $Z$, eqüivale a zero quando o modelo é aberto. Assim, para o Modelo II, tem-se que $Z=0$.

Por intermédio do Algoritmo 4.7 referente ao cálculo de limites assintóticos, considerando $k=2$, obtêm-se:

$$
\begin{aligned}
& D_{k}=\frac{\rho_{k}}{\lambda}\left\{\begin{array}{l}
D_{1}=\frac{0,80}{12}=0,0667 \\
D_{2}=\frac{0,40}{12}=0,0333
\end{array}\right. \\
& D=\sum_{k=1}^{k} D_{k}=D_{1}+D_{2}=0,1 \\
& D_{\max }=\max _{k} D_{k}=0,0667 \\
& N^{*}=\frac{D+Z}{D_{\max }}=\frac{0,1+0}{0,0667}=1,4993
\end{aligned}
$$

Dando seqüência ao Algoritmo 4.7, obtêm-se os pontos que constituem os gráficos dos limites assintóticos do throughput e do tempo de resposta do sistema.

O gráfico dos limites do throughput do sistema é dado pelos pontos:

\section{Limite Otimista:}

$$
\begin{aligned}
& (0,0) \text { e }\left(1, \frac{1}{D+Z}\right) \text { para } N \leq N^{*} \rightarrow(0 ; 0) \text { e }(1 ; 14,99) \\
& \left(0, \frac{1}{D_{\max }}\right) \text { e }\left(1, \frac{1}{D_{\max }}\right) \text { para } N \geq N^{*} \rightarrow(0 ; 14,99) \text { e }(1 ; 14,99)
\end{aligned}
$$

\section{Limite Pessimista:}

Este limite não é linear em $N$.

O gráfico dos limites do tempo de resposta do sistema é dado pelos pontos:

Limite Otimista:

$$
\begin{aligned}
& (0, D) \text { e }(1, D) \text { para } N \leq N^{*} \rightarrow(0 ; 0,1) \text { e }(1 ; 0,1) \\
& (0,-Z) \text { e }\left(1, D_{\max } Z \text { Z) para } N \geq N^{*} \rightarrow(0,0) \text { e }(1 ; 0,0667)\right.
\end{aligned}
$$

Limite Pessimista:

$$
(0,0) \text { e }(1, D) \rightarrow(0 ; 0) \text { e }(1 ; 0,1)
$$

De posse desses pontos, podem-se desenhar os gráficos que definem os limites de assintóticos para o throughput e para o tempo de resposta do Modelo II, similarmente ao Modelo I. O Gráfico 5.3 é referente ao limite otimista do throughput, simbolizando que o throughput do sistema deve estar na área abaixo do gráfico. Segundo a Análise do Valor Médio do Modelo II, o throughput médio do sistema é igual a 12 quando existem em média 
4,68 clientes no sistema, encontrando-se na área abaixo do gráfico, como representado no Gráfico 5.3 (ponto na cor vermelha).

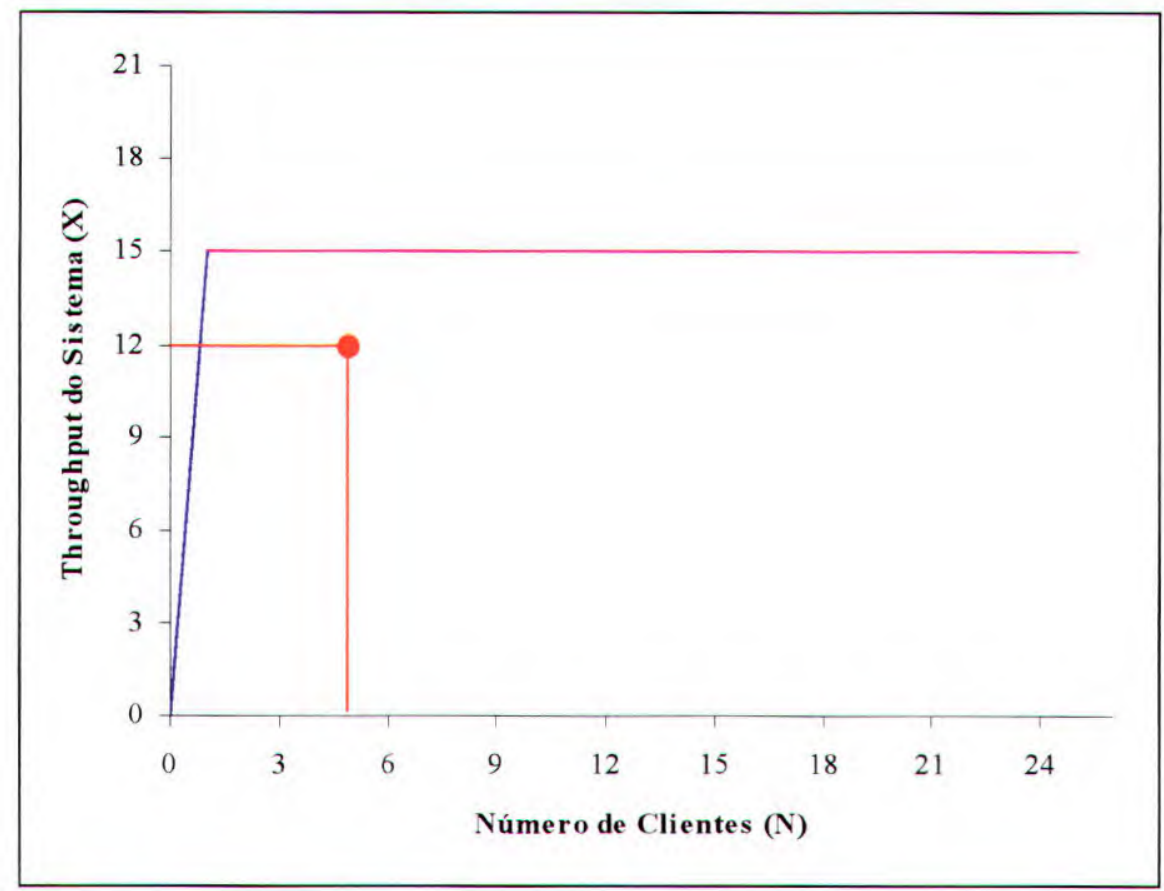

Gráfico 5.3- Limite Otimista do Throughput do Modelo II

O Gráfico 5.4 representa o limite assintótico do tempo de resposta do Modelo II, que foi construído da mesma forma que o anterior, e além da assíntota do limite otimista, possui também a do limite pessimista (reta na cor verde).

De acordo com o método AVM aplicado ao modelo II, o tempo de resposta do sistema é aproximadamente igual a 0,39 quando o sistema possui em média 4,68 clientes. Tal tempo de resposta está representado no Gráfico 5.4 (ponto de cor vermelha), encontrando-se na área delimitada pelas retas dos limites otimistas e pessimista, como esperado, já que nesse caso, ao contrário do Modelo I, o limite pessimista não coincidiu com uma das retas que compõem o limite otimista.

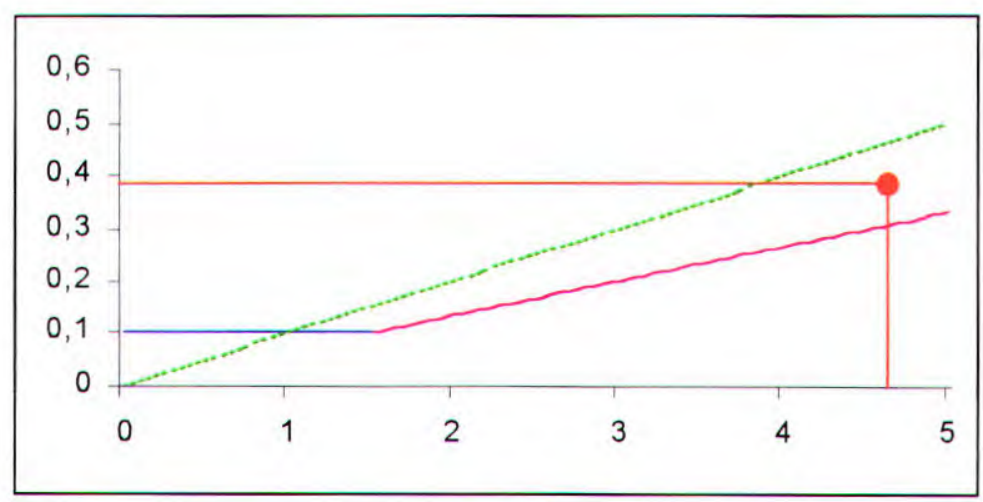

Gráfico 5.4- Limites do Tempo de Resposta do Modelo /I 


\subsubsection{Simulação}

A simulação do modelo II, igualmente ao modelo anterior, foi efetuada por intermédio do ASiA (Brushi, 1997).

Para a simulação, considerou-se os seguintes parâmetros de entrada foram consiterados: $\tau=0,0833$ (tempo entre chegadas de clientes); $S_{1}=0,04$ (tempo de serviço do centro 1) e $S_{2}=0,05$ (tempo de serviço do centro 2); te=1.000.000 (tempo de execução da simulação) e distribuições exponenciais para o tempo de serviço e para o tempo entre chegadas.

Para a simulação são consideradas 8 execuções (replicações), cada uma com um comprimento equivalente a 1.000 .000 ut e os resultados apresentados são valores médios, com o correspondente intervalos de confiança de 95\% (MacDougall, 1989).

Simulando-se o Modelo II, para cada uma das execuçōes, obtêm-se como saída padrão um relatório contendo os resultados da simulação, dentre os quais destacam-se a utilização e o comprimento médio de fila. A Figura 5.6 apresenta o relatório correspondente à semente 0 (zero), uma das 8 sementes de números aleatórios.

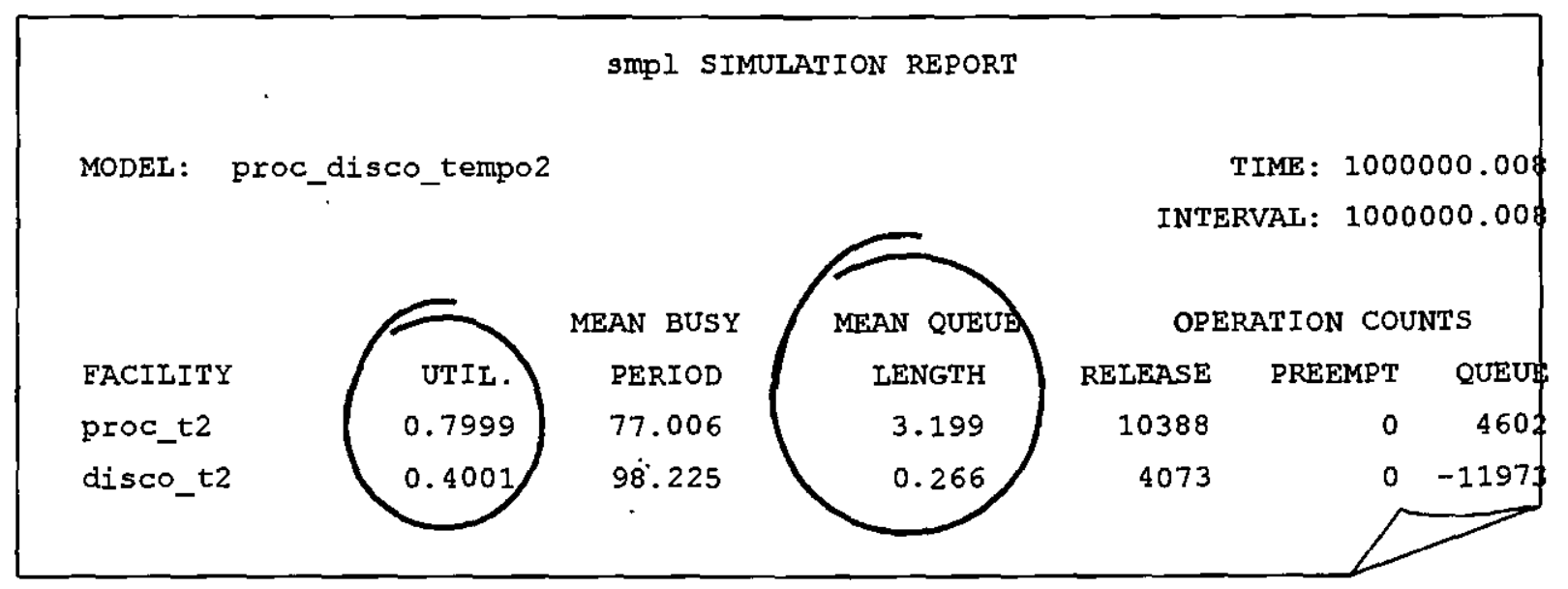

Figura 5.6 - Relatório de Simulação do Modelo ll para a semente 0

Assim como para o Modelo I, algumas medidas adicionais forma obtidas. A Figura 5.7 apresenta as medidas de desempenho adicionais obtidas para a execução de semente 0 (zero) (MacDougall, 1989):

\begin{tabular}{|c|c|}
\hline $\begin{array}{l}\text { Throughput do Sistema } \\
\text { Throughput do sistema } \\
\text { Throughput do Sistema } \\
\text { Nr. medio de clientes } \\
\text { Nr. medio de clientes } \\
\text { Nr. medio de clientes }\end{array}$ & 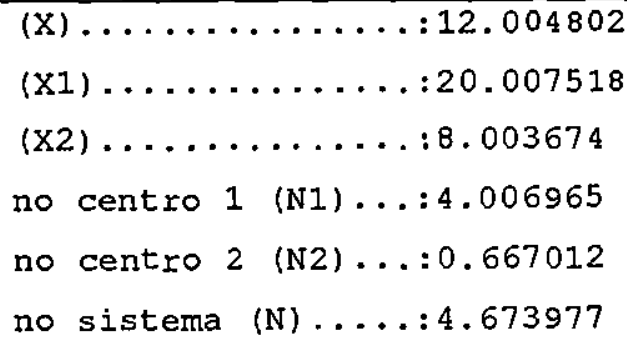 \\
\hline
\end{tabular}




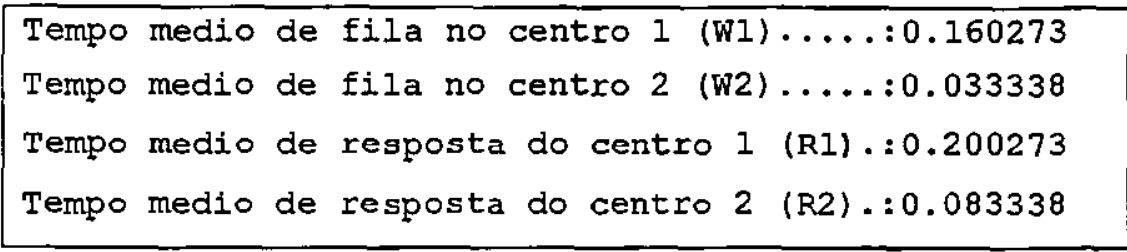

Figura 5.7 - Medidas de desempenho adicionais para o Modelo ll - semente 0

De acordo com os resultados da simulação, que correspondem à média das 8 execuções (replicação), comparam-se os resultados das medidas de desempenho obtidas pelas soluções analíticas do modelo $\Pi$, apresentando-se na Tabela 5.2 que os resultados da simulação eqüivalem aos obtidos por intermédio dos métodos analíticos.

\begin{tabular}{|c|c|c|c|c|c|}
\hline & \multicolumn{3}{|c|}{ Soluçōes Analíticas } & \multirow{2}{*}{\multicolumn{2}{|c|}{$\frac{\text { Simulaçāoo }}{\text { AsiA }}$}} \\
\hline & $\begin{array}{c}\text { Análise do } \\
\text { Valor Médio }\end{array}$ & $\begin{array}{l}\text { Rede de } \\
\text { Jackson }\end{array}$ & $\begin{array}{c}\text { Limites de } \\
\text { Desempenho }\end{array}$ & & \\
\hline $\begin{array}{c}X \\
\text { (throughput do sistema) } \\
\end{array}$ & 12 & 12 & OK & & - \\
\hline $\begin{array}{c}\rho_{1} \\
\text { (utilização do centro 1) } \\
\end{array}$ & $0,8004 \rightarrow 80 \%$ & $0,80 \rightarrow 80 \%$ & - & 0,80019488 & $\pm 0,00023806$ \\
\hline $\begin{array}{c}\boldsymbol{\rho}_{2} \\
\text { (utilização do centro 2) }\end{array}$ & $0,3996 \rightarrow 40 \%$ & $0,40 \rightarrow 40 \%$ & - & 0,40004725 & $\pm 0,00009476$ \\
\hline $\begin{array}{c}\qquad X_{1} \\
\text { (throughput do centro 1) }\end{array}$ & 20,004 & - & - & 20,0048725 & $\stackrel{+}{ \pm} 0,00594603$ \\
\hline $\begin{array}{c}\mathrm{X}_{2} \\
\text { (throughput do centro 2) }\end{array}$ & 8,0004 & - & - & 8,00093475 & $\pm 0,00188877$ \\
\hline $\begin{array}{c}R_{1} \\
\text { (tempo de resposta do centro 1) }\end{array}$ & 0,2004 & 0,20 & - & 0,19999113 & $\pm 0,00004239$ \\
\hline $\begin{array}{c}\boldsymbol{R}_{2} \\
\text { (tempo de resposta do centro 2) }\end{array}$ & 0,0833 & 0,0833 & - & 0,08328775 & ${ }_{-}^{+} 0,00001612$ \\
\hline $\begin{array}{c}N_{1} \\
\text { (número de clientes no centro 1) }\end{array}$ & 4,01 & 4,0 & - & 3,9000896 & $\pm 0,23733445$ \\
\hline $\begin{array}{c}\mathrm{N}_{2} \\
\text { (número de clientes no centro 2) }\end{array}$ & 0,6656 & 0,6667 & - & 0,66638088 & $\stackrel{+}{ \pm} 0,00028174$ \\
\hline $\begin{array}{c}\boldsymbol{R} \\
\text { (tempo de resposta do sistema) }\end{array}$ & 0,3895 & - & OK & & - \\
\hline $\begin{array}{c}N \\
\text { (número de clientes no sistema) }\end{array}$ & 4,6756 & - & - & 4,66717763 & $\begin{array}{l} \pm 0,00141597 \\
\simeq\end{array}$ \\
\hline $\begin{array}{c}N q_{1} \\
\text { (nr. de clientes na fila do centro l) }\end{array}$ & - & 3,2 & - & 3,20060213 & $\pm 0,00125130$ \\
\hline $\begin{array}{l}\quad N q_{2} \\
\text { (nr. de clientes na fila do centro 2) }\end{array}$ & - & 0,2667 & - & 0,26633338 & $\pm 0,00018893$ \\
\hline $\begin{array}{c}W_{1} \\
\text { (tempo de fila do centro 1) }\end{array}$ & - & 0,16 & - & 0,15999113 & $\begin{array}{l}+0,00004239 \\
-\end{array}$ \\
\hline $\begin{array}{c}W_{2} \\
\text { (tempo de fila do centro 2) }\end{array}$ & - & 0,0333 & - & 0,03328775 & $\pm 0,00001612$ \\
\hline
\end{tabular}

Tabela 5.2 - Comparaçăo entre os resultados das soluçōes do Modelo II 


\subsection{Modelo III: Servidor Arquivos com PFE}

Apesar de ser mais completo, no que se refere à carga, esse modelo mantém o mesmo comportamento dos dois modelos anteriores, diferenciando-se apenas pela presença do processador Front-End (PFE), representado pelos dispositivos PFE-In e PFE-Out (Figura 5.8).

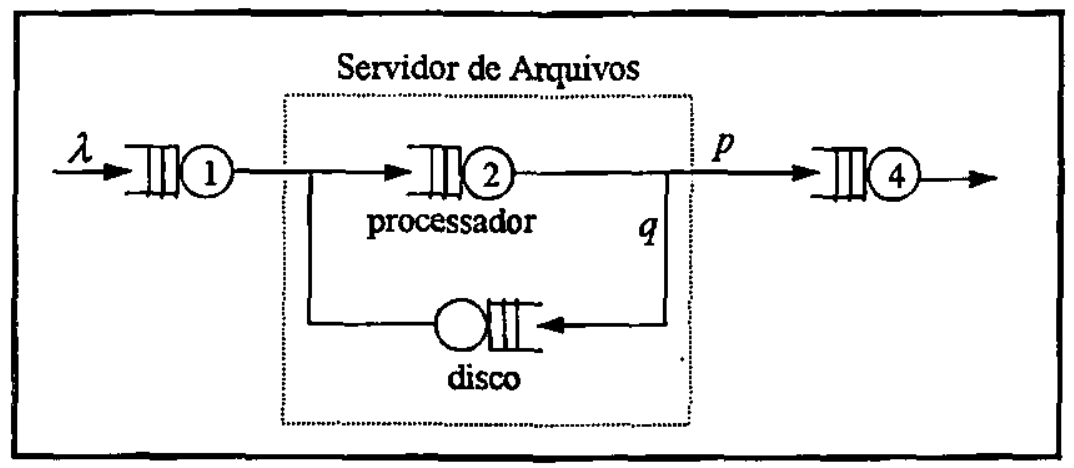

Figura 5.8 - Modelo III: Servidor de Arquivos com PFE

O PFE gerencia a comunicação entre o sistema de rede e o servidor de arquivos, de forma que cada solicitação que chega ao modelo é recebida pelo PFE. Como PFE é fullduplex, isto é, opera concorrentemente na transmissão e na recepção de mensagens, modelamse dois dispositivos de PFE: um para gerenciar a chegada de mensagens, dito PFE-In, e outro para a saida de mensagens, o PFE-Out (Oriandi, 1995).

Dessa forma, considerando o modelo III, as solicitações enviadas ao servidor de arquivos são primeiramente tratadas pelo PFE-In, que fica responsável por requisitar o processador. Caso o processador esteja ocupado, a solicitação deve ser inserida em sua fila de espera, caso contrário, a solicitação é imediatamente processada. Se durante o processamento for detectada a necessidade de operação com disco, o processador central bloqueia 0 processamento da solicitação, requisita o disco e inicia o processamento da solicitação seguinte. Ao chegar no disco, a solicitação é então inserida na fila de espera ou imediatamente atendida, e assim que a operação for concluida, o disco envia uma resposta ao processador, para que o mesmo possa, se necessário, finalizar o processamento da solicitação bloqueada. Finalizado o processamento da solicitação, o processador requisita o PFE-Out para que o mesmo possa enviar as respostas das solicitaçōes feitas ao servidor de arquivos (Orlandi, 1995).

O modelo III também possui uma chegada de clientes exponencialmente distribuída, disciplinas de fila do tipo FIFO, servidores de atendimento exponencial e classe única de clientes. A esse modelo serão aplicados os mesmo métodos utilizados para solucionar os modelos I e II. 
Para o modelo III, tem-se os seguintes parâmetros de entrada:

$$
\begin{aligned}
& \lambda=12 \\
& \mu_{1}=25 \rightarrow S_{1}=1 / \mu_{1}=0,04 \\
& \mu_{2}=25 \rightarrow S_{2}=1 / \mu_{2}=0,04 \\
& \mu_{3}=20 \rightarrow S_{3}=1 / \mu_{3}=0,05 \\
& \mu_{4}=18 \rightarrow S_{4}=1 / \mu_{4}=0,0556 \\
& p=60 \%=0,6
\end{aligned}
$$

\subsubsection{Análise do Valor Médio (AVM)}

Pode-se avaliar o desempenho do Modelo III por intermédio do Algoritmo 4.1, que se refere à. Análise de Valor Médio para modelos abertos. Par isso, faz-se necessário o cálculo da taxa de visita, $V_{f}$, para cada centro (Allen, 1991):

$$
V_{j}=\sum_{j=0}^{M} V_{i} p_{i j},
$$

Onde $M$ é número de centros e $V_{0}=1$ é a taxa de visita do lado de fora do modelo. A partir dessa expressão, calculam-se:

$$
\begin{aligned}
& V_{1}=\underbrace{V_{0}}_{i} \underbrace{p_{01}}+V_{1} \underbrace{p_{13}}_{0}+V_{2} \underbrace{p_{21}}_{0}+V_{3} \underbrace{p_{31}}_{0}+V_{4} \underbrace{p_{43}}_{0} \rightarrow V_{1}=1 \\
& V_{2}=\underbrace{V_{0}}_{0} \underbrace{p_{02}}_{02}+V_{1} \underbrace{p_{12}}_{1}+V_{2} \underbrace{p_{22}}_{0}+V_{3} \underbrace{p_{32}}_{1}+V_{4} \underbrace{p_{42}}_{0} \rightarrow V_{2}=V_{1}+V_{3} \\
& V_{3}=\underbrace{V_{0}}_{1} \underbrace{p_{03}}_{0}+V_{1} \underbrace{p_{13}}_{0}+V_{2} \underbrace{p_{23}}_{q}+V_{3} \underbrace{p_{33}}_{0}+V_{4} \underbrace{p_{43}}_{0} \rightarrow V_{3}=q V_{2} \\
& V_{4}=\underbrace{V_{0}}_{1} \underbrace{p_{04}}_{0}+V_{1} \underbrace{p_{14}}_{0}+V_{2} \underbrace{p_{24}}_{p}+V_{3} \underbrace{p_{34}}_{0}+V_{4} \underbrace{p_{44}}_{0} \rightarrow V_{4}=p V_{2}
\end{aligned}
$$

Assim,

$V_{1}=1$

$V_{2}=1+q V_{2}=\frac{1}{1-q}=\frac{1}{p}=1,6667$

$V_{3}=0,4 \times 1,6667=0,6667$

$V_{4}=0,6 \times 1,6667=1$

Considerando-se o Throughput do sistema igual à taxa de chegada de clientes ao sistema $(X=\lambda)$, aplica-se o Algoritmo 4.1 e obtêm-se os seguintes valores médios: 
- Demanda de Serviço do centro: $D_{i}=S_{i} V_{i}\left\{\begin{array}{l}D_{1}=0,04 \times 1=0,04 \\ D_{2}=0,04 \times 1,6667=0,0667 \\ D_{3}=0,05 \times 0,6667=0,0333 \\ D_{4}=0,056 \times 1=0,056\end{array}\right.$

-Utilização do centro: $\rho_{i}=X D_{i}\left\{\begin{array}{l}\rho_{1}=12 \times 0,04=0,48 \\ \rho_{2}=12 \times 0,0667=0,8004 \approx 0,80 \\ \rho_{3}=12 \times 0,0333=0,3996 \approx 0,40 \\ \rho_{4}=12 \times 0,056=0,672 \approx 0,67\end{array}\right.$

- Throughput do centro: $X_{i}=X V_{i}\left\{\begin{array}{l}X_{1}=12 \times 1=12 \\ X_{2}=12 \times 1,6667=20,0004 \\ X_{3}=12 \times 0,6667=8,0004 \\ X_{4}=12 \times 1=12\end{array}\right.$

- Tempo de Resposta do centro:

$$
R_{t}=S_{i} /\left(1-\rho_{i}\right)\left\{\begin{array}{l}
R_{1}=0,04 /(1-0,48)=0,0769 \\
R_{2}=0,04 /(1-0,8004)=0,2004 \\
R_{3}=0,05 /(1-0,3996)=0,0833 \\
R_{4}=0,056 /(1-0,672)=0,1707
\end{array}\right.
$$

- Número de clientes no centro:

$$
N_{i}=\rho_{i} /\left(1-\rho_{i}\right)\left\{\begin{array}{l}
N_{1}=0,48 /(1-0,48)=0,9231 \\
N_{2}=0,8004 /(1-0,8004)=4,01 \\
N_{3}=0,3996 /(1-0,3996)=0,6656 \\
N_{4}=0,672 /(1-0,672)=2,0488
\end{array}\right.
$$

- Tempo de Resposta do sistema: $R=\sum_{i=1}^{M} R_{i} V_{i}$

$$
R=(0,0769 \times 1)+(0,2004 \times 1,6667)+(0,0833 \times 0,6667)+(0,1707 \times 1)=0,6371
$$

- Número de clientes no sistema: $N=\sum_{i=1}^{M} N_{i}$

$$
N=0,9231+4,01+0,6656+2,0488=7,6475
$$

\subsubsection{Rede de Jackson}

$\mathrm{O}$ modelo III, também pode ser solucionado analiticamente usando-se o método de Rede de Jackson, já que o modelo é aberto e possui chegada e atendimento de clientes exponencialmente distribuídos. 
Considerando-se os parâmetros de entrada do modelo III, aplica-se o método de Rede de Jackson:

$$
\begin{aligned}
& \pi_{n_{1}, n_{2}, n_{3}, n_{4}}= p_{1}\left(n_{1}\right) \cdot p_{2}\left(n_{2}\right) \cdot p_{3}\left(n_{3}\right) \cdot p_{4}\left(n_{4}\right) \\
&=\left(1-\rho_{1}\right) \rho_{1}^{n_{1}} \cdot\left(1-\rho_{2}\right) \rho_{2}^{n_{2}} \cdot\left(1-\rho_{3}\right) \rho_{3}^{n_{3}} \cdot\left(1-\rho_{4}\right) \rho_{4}^{n_{4}} \\
& \quad \text { onde } \rho_{i}=\frac{\Lambda_{i}}{\mu_{i}} \text { e } \Lambda_{i}=\lambda_{i}+\sum_{j=1}^{M} p_{j i} \cdot \Lambda_{j}
\end{aligned}
$$

Dessa forma, têm-se:

$$
\begin{aligned}
& \Lambda_{1}=\underbrace{\lambda_{1}}_{\lambda}+\underbrace{p_{11}}_{0} \Lambda_{1}+\underbrace{p_{21}}_{0} \Lambda_{2}+\underbrace{p_{31}}_{0} \Lambda_{3}+\underbrace{p_{41}}_{0} \Lambda_{4} \rightarrow \Lambda_{1}=\lambda=12 \\
& \Lambda_{1}=\underbrace{\lambda_{1}}_{\lambda}+\underbrace{p_{11}}_{0} \Lambda_{1}+\underbrace{p_{21}}_{0} \Lambda_{2}+\underbrace{p_{31}}_{0} \Lambda_{3}+\underbrace{p_{41}}_{0} \Lambda_{4} \rightarrow \Lambda_{1}=1 \\
& \Lambda_{2}=\underbrace{\lambda_{2}}_{0}+\underbrace{p_{12}}_{1} \Lambda_{1}+\underbrace{p_{22}}_{0} \Lambda_{2}+\underbrace{p_{32}}_{1} \Lambda_{3}+\underbrace{p_{42}}_{0} \Lambda_{4} \rightarrow \Lambda_{2}=\Lambda_{1}+\Lambda_{3} \\
& \Lambda_{3}=\lambda_{3}+p_{13} \Lambda_{1}+p_{23} \Lambda_{2}+p_{33} \Lambda_{3}+p_{43} \Lambda_{4} \\
& \Lambda_{4}=\lambda_{4}+p_{14} \Lambda_{1}+p_{24} \Lambda_{2}+p_{34} \Lambda_{3}+p_{44} \Lambda_{4} \\
& \Lambda_{1}=\underbrace{\lambda_{1}}_{\lambda}+\underbrace{p_{11}}_{0} \Lambda_{1}+\underbrace{p_{21}}_{1} \Lambda_{2} \rightarrow \Lambda_{1}=\lambda+\Lambda_{2} \\
& \Lambda_{2}=\underbrace{\lambda_{2}}_{0}+\underbrace{p_{12}}_{q} \Lambda_{1}+\underbrace{p_{22}}_{0} \Lambda_{2} \rightarrow \Lambda_{2}=q \Lambda_{1}
\end{aligned}
$$

Assim, pode-se calcular as taxas de entrada para cada centro de serviço:

$$
\begin{aligned}
& \Lambda_{1}=12 \\
& \Lambda_{2}=\lambda+q \Lambda_{2}=\frac{\lambda}{1-q}=\frac{12}{0,6}=20 \\
& \Lambda_{3}=0,4 \times 20=8 \\
& \Lambda_{4}=0,6 \times 20=12
\end{aligned}
$$

Tendo-se os valores das taxas de entrada $\left(\Lambda_{l}\right)$, calcula-se a utilização de cada centro:

$$
\rho_{i}=\frac{\Lambda_{i}}{\mu_{i}}\left\{\begin{array}{l}
\rho_{1}=\frac{12}{25}=0,48 \\
\rho_{2}=\frac{20}{25}=0,80 \\
\rho_{3}=\frac{8}{20}=0,40 \\
\rho_{4}=\frac{12}{18}=0,6667 \approx 0,67
\end{array}\right.
$$


Dessa forma, tem-se que a distribuição de equilíbrio para o número de clienteș do modelo II é dada por:

$$
\pi_{n_{1}, n_{2}, n_{3}, n_{4}}=(1-0,48) 0,48^{n_{1}} \cdot(1-0,80) 0,80^{n_{2}} \cdot(1-0,40) 0,40^{n_{3}} \cdot(1-0,67) 0,67^{n_{4}}
$$

Como em uma rede de Jackson se considera cada nó do modelo como um modelo $\mathrm{M} / \mathrm{M} / \mathrm{l}$, outras medidas de desempenho podem ser calculadas para cada nó, por intermédio das equações mostradas na solução de Processo Nascimento-e-Morte do Modelo I, já que o mesmo é um modelo $\mathrm{M} / \mathrm{M} / 1$. Sendo assim, obtêm-se as seguintes medidas:

- Número médio de clientes

- no nó 1: $n_{1}=\frac{\rho_{1}}{\left(1-\rho_{1}\right)}=0,9231$

- no nó 2: $n_{2}=\frac{\rho_{2}}{\left(1-\rho_{2}\right)}=4,0$

- no nó 3: $n_{3}=\frac{\rho_{3}}{\left(1-\rho_{3}\right)}=0,6667$

- no nó 4: $n_{4}=\frac{\rho_{4}}{\left(1-\rho_{4}\right)}=2,0303$

- Número médio de clientes na fila

- do nó 1: $n q_{1}=\frac{\rho_{1}^{2}}{\left(1-\rho_{1}\right)}=0,4431$

- do nó 2: $n q_{2}=\frac{\rho_{2}{ }^{2}}{\left(1-\rho_{2}\right)}=3,2$

- do nó 3: $n q_{3}=\frac{\rho_{3}{ }^{2}}{\left(1-\rho_{3}\right)}=0,2667$

- do nó 4: $n q_{4}=\frac{\rho_{4}{ }^{2}}{\left(1-\rho_{4}\right)}=1,3603$

- Tempo médio de resposta

- no nó 1: $r_{1}=\frac{1 / \mu_{1}}{\left(1-\rho_{1}\right)}=0,0769$

- no nó 2: $r_{2}=\frac{1 / \mu_{2}}{\left(1-\rho_{2}\right)}=0,20$

- no nó 3: $r_{3}=\frac{1 / \mu_{3}}{\left(1-\rho_{3}\right)}=0,0833$

- no nó 4: $r_{4}=\frac{1 / \mu_{4}}{\left(1-\rho_{4}\right)}=0,1684$ 
- Tempo médio de fila

- do nó 1: $w_{1}=\rho_{1} \frac{1 / \mu_{1}}{\left(1-\rho_{1}\right)}=0,0369$

- do nó 2: $w_{2}=\rho_{2} \frac{1 / \mu_{2}}{\left(1-\rho_{2}\right)}=0,16$

- do nó 3: $w_{3}=\rho_{3} \frac{1 / \mu_{3}}{\left(1-\rho_{3}\right)}=0,0333$

- do nó 4: $w_{4}=\rho_{4} \frac{1 / \mu_{4}}{\left(1-\rho_{4}\right)}=0,1128$

\subsubsection{Limites de Desempenho}

O cálculo dos limites assintóticos do Modelo III será efetuado através do Algoritmo 4.7, considerando-se que o número de centros de serviço do modelo é igual a $4(k=4)$. Para a aplicação do algoritmo, necessita-se também da utilização de cada centro de serviço $\left(\rho_{k}\right)$, que, de acordo com as soluções analíticas anteriores, correspondem a $\rho_{1}=0,48, \rho_{2}=0,80$, $\rho_{3}=0,40$ e $\rho_{4}=0,6667$.

Além desses valores, deve-se saber que o valor do tempo de pensar, $Z$, eqüivale a zero quando o modelo é aberto. Assim, para o Modelo III, tem-se que $Z=0$.

Diante dessas informações, aplica-se o Algonitmo 4.7, obtendo-se os seguintes valores:

$$
\begin{aligned}
& D_{k}=\frac{\rho_{k}}{\lambda}\left\{\begin{array}{l}
D_{1}=0,040 \\
D_{2}=0,0667 \\
D_{3}=0,0333 \\
D_{4}=0,0556
\end{array}\right. \\
& D=\sum_{k=1}^{k} D_{k}=0,1956 \\
& D_{\max }=\max _{k} D_{k}=0,0667 \\
& N^{*}=\frac{D_{+} Z}{D_{\max }}=2,9325
\end{aligned}
$$

Ainda através do Algoritmo 4.7, obtêm-se os pontos que constituem os gráficos dos limites de assintóticos do throughput e do tempo de resposta do sistema. 
O gráfico dos limites do throughput do sistema é dado pelos pontos:

Limite Otimista:

$$
\begin{aligned}
& (0,0) \text { e }\left(1, \frac{1}{D+Z}\right) \text { para } N \leq N^{*} \rightarrow(0 ; 0) \text { e }(1 ; 5,1125) \\
& \left(0, \frac{1}{D_{\max }}\right) \text { e }\left(1, \frac{1}{D_{\max }}\right) \text { para } N \geq N^{*} \rightarrow(0 ; 14,9925) \text { e }(1 ; 14,9925)
\end{aligned}
$$

Limite Pessimista: Este limite não é linear em $N$.

O gráfico dos limites do tempo de resposta do sistema é dado pelos pontos:

Limite Otimista:

$$
\begin{aligned}
& (0, D) \text { e }(1, D) \text { para } N \leq N^{*} \rightarrow(0 ; 0,1956) \text { e }(1 ; 0,1956) \\
& (0,-Z) \text { e }\left(1, D_{\max }-Z\right) \text { para } N \geq N^{*} \rightarrow(0,0) \text { e }(1 ; 0,0667)
\end{aligned}
$$

Limite Pessimista: $(0,0)$ e $(1, D) \rightarrow(0 ; 0)$ e $(1 ; 0,5556)$

Possuindo os pontos, como na solução do Modelo II, os gráficos que definem os limites de assintóticos para o throughput e tempo de resposta do Modelo III são traçados. O Gráfico 5.5 representa limite assintótico do throughput, composto apenas pelo limite otimista, que delimita a área onde deve estar o valor do throughput do sistema. De acordo com as soluções analíticas anteriores, o throughput médio do sistema é igual a 12 quando existem em média 7,6475 clientes no sistema, encontrando-se na área abaixo do gráfico (ponto na cor vermelha), como era desejado.

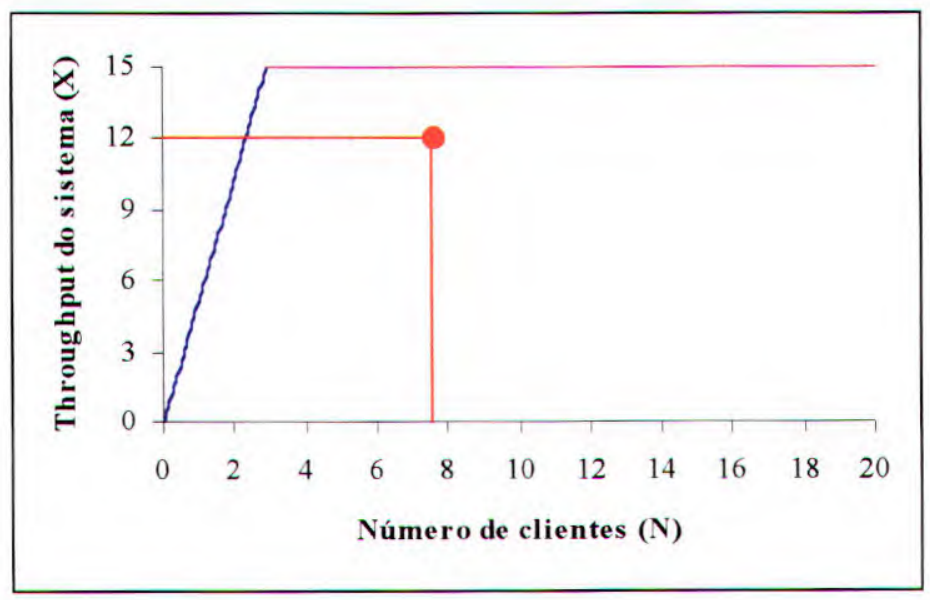

Gráfico 5.5 - Limite Otimista do Throughput do Modelo III

O limite assintótico do tempo de resposta está representado no Gráfico 5.6, composto tanto pelo limite otimista (retas nas cores azul e rosa), quanto pessimista (reta na cor verde), simbolizando que o valor do tempo de resposta do sistema deve estar na área delimitada por esses limites. No gráfico, mostra-se que o tempo de resposta do Modelo III se encontra dentro 
da área esperada (ponto na cor vermelha), já que, segundo as soluções analíticas anteriores, o valor do tempo de resposta é igual a 0,6371 quando o sistema possui uma média de 7,6475 clientes.

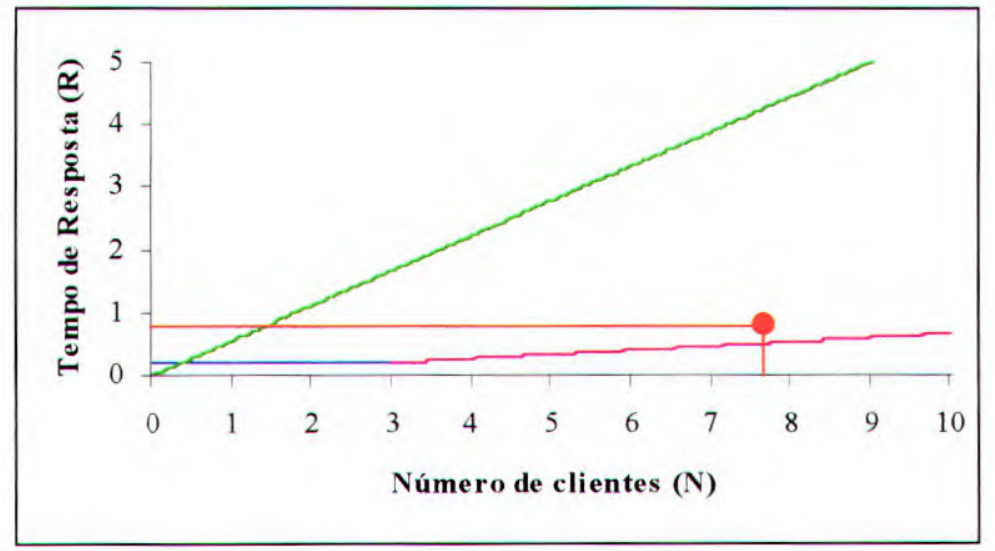

Gráfico 5.6 - Limites do Tempo de Resposta do Modelo III

\subsubsection{Simulação}

Para simular o Modelo III foi também utilizado o AsiA, considerando-se os seguintes parâmetros de entrada: $\tau=0,0833$ (tempo entre chegadas de clientes); $S_{1}=0,04$ (tempo de serviço do centro 1), $S_{2}=0,04$ (tempo de serviço do centro 2), $S_{3}=0,05$ (tempo de serviço do centro 3) e $S_{4}=0,0556$ (tempo de serviço do centro 4); te=1.000.000 (tempo de execução da simulação); e distribuições exponenciais para o tempo de serviço e para o tempo entre chegadas.

Para a simulação são consideradas 8 execuções (replicações), cada uma com um comprimento equivalente a 1.000 .000 ut e os resultados apresentados são valores médios, com o correspondente intervalos de confiança de 95\% (MacDougall,1989).

Simulando-se o Modelo III, para cada uma das execuções, obtêm-se como saída padrão um relatório contendo os resultados da simulação, dentre os quais destacam-se a utilização e o comprimento médio de fila. A Figura 5.9 apresenta o relatório correspondente à semente 0 (zero), uma das 8 sementes de números aleatórios.

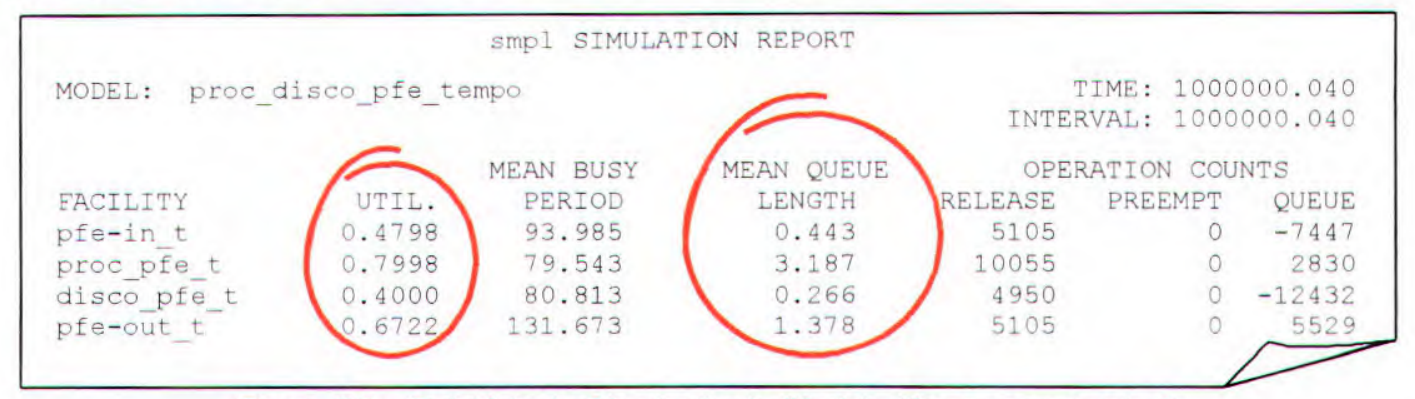

Figura 5.9 - Relatório de Simulação do Modelo III para a semente 0 
Da mesma forma que os casos anteriores, obtêm-se medidas de desempenho adicionais para o Modelo III . A Figura 5.10 apresenta as medidas de desempenho adicionais obtidas para a execução de semente 0 (zero) (MacDougall,1989):

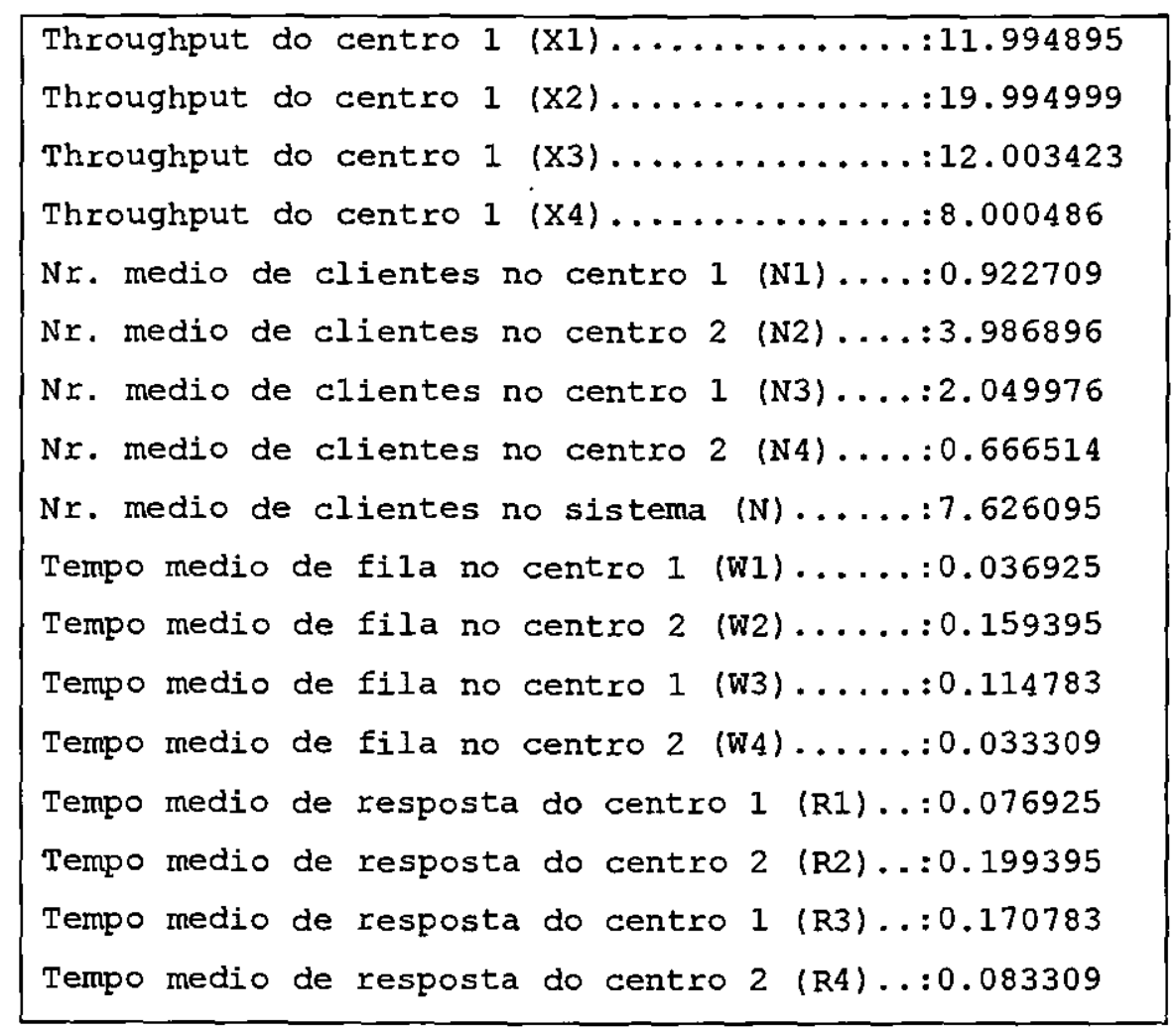

Figura 5.10 - Medidas de desempenho adicionais para o Modelo III - semente 0

Com os resultados obtidos a partir da simulação do Modelo III, que correspondem à média das 8 execuções (replicação), comparam-se seus resultados com os obtidos por intermédio das soluções analíticas, constatando a equivalência dos mesmos, como mostra a tabela a seguir.

\begin{tabular}{|c|c|c|c|c|}
\cline { 2 - 5 } \multicolumn{1}{c|}{} & \multicolumn{3}{c|}{ Soluçōes Analíticas } & \multicolumn{2}{c|}{ Simulaçäo } \\
\cline { 2 - 5 } & $\begin{array}{c}\text { Análise do } \\
\text { Valor Médio }\end{array}$ & $\begin{array}{c}\text { Rede de } \\
\text { Jackson }\end{array}$ & $\begin{array}{c}\text { Limites de } \\
\text { Desempenho }\end{array}$ & AsiA \\
\hline $\begin{array}{c}X \\
\text { (throughput do sistema) }\end{array}$ & 12 & 12 & OK & - \\
\hline$\rho_{1}$ & $0,48 \rightarrow 48 \%$ & $0,48 \rightarrow 48 \%$ & - & $0,47980338+0,00000752$ \\
\hline $\begin{array}{c}\text { (utilização do centro 1) } \\
\rho_{2}\end{array}$ & $0,8004 \rightarrow 80 \%$ & $0,80 \rightarrow 80 \%$ & - & $0,79979063 \pm 0,00001197$ \\
\hline $\begin{array}{c}\text { (utilização do centro 2) } \\
\rho_{3}\end{array}$ & $0,3996 \rightarrow 40 \%$ & $0,40 \rightarrow 40 \%$ & - & $0,40000638 \pm 0,00001165$ \\
\hline $\begin{array}{c}\text { (utilização do centro 3) } \\
\rho_{4}\end{array}$ & $0,672 \rightarrow 67 \%$ & $0,6667 \rightarrow 67 \%$ & - & $0,67217675 \pm 0,00001022$ \\
\hline
\end{tabular}




\begin{tabular}{|c|c|c|c|c|c|}
\hline $\begin{array}{c}X_{1} \\
\text { (throughput do centro 1) }\end{array}$ & 12 & - & - & & 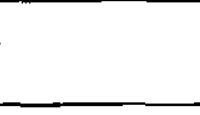 \\
\hline $\begin{array}{c}X_{2} \\
\text { (throughput do centro 2) }\end{array}$ & 20,0004 & - & - & 19,99476438 & $\pm 0,00029277$ \\
\hline $\begin{array}{c}\mathrm{X}_{3} \\
\text { (throughput do centro 3) }\end{array}$ & 8,0004 & - & - & 8,00014950 & $\pm 0,00023079$ \\
\hline $\begin{array}{c}X_{4} \\
\text { (throughput do centro 3) }\end{array}$ & 12 & - & - & 12,00031545 & $\pm 0,00017961$ \\
\hline $\begin{array}{c}R_{1} \\
\text { (tempo de resposta do centro } 1 \text { ) }\end{array}$ & 0,0769 & 0,0769 & - & 0,07692575 & $\pm 0,0000098$ \\
\hline $\begin{array}{c}\boldsymbol{R}_{\mathbf{2}} \\
\text { (tempo de resposta do centro 2) }\end{array}$ & 0,2004 & 0,20 & - & 0,19938588 & $\begin{array}{l}+ \\
-0,00001324 \\
\end{array}$ \\
\hline $\begin{array}{c}R_{3} \\
\text { (tempo de resposta do centro 3) }\end{array}$ & 0,0833 & 0,0833 & - & 0,08330688 & $\pm 0,00000138$ \\
\hline $\begin{array}{c}R_{4} \\
\text { (tempo de resposta do centro 4) }\end{array}$ & 0,1707 & 0,1684 & - & 0,17077804 & $\pm 0,00000524$ \\
\hline $\begin{array}{c}N_{1} \\
\text { (número de clientes no centro 1) }\end{array}$ & 0,9231 & 0,9231 & - & 0,92273150 & $\stackrel{+}{+} 0,00002101$ \\
\hline $\begin{array}{c}N_{2} \\
\text { (número de clientes no centro 2) }\end{array}$ & 4,01 & 4,0 & - & 3,98667263 & $\pm 0,00030976$ \\
\hline $\begin{array}{c}N_{3} \\
\text { (número de clientes no centro 3) }\end{array}$ & 0,6656 & 0,6667 & - & 0,66646913 & $\pm 0,00002840$ \\
\hline $\begin{array}{c}N_{4} \\
\text { (número de clientes no centro 4) }\end{array}$ & 2,0488 & 2,0303 & - & 2,04987158 & $\pm 0,00009338$ \\
\hline $\begin{array}{c}R \\
\text { (tempo de resposta do sistema) }\end{array}$ & 0,6371 & - & OK & & \\
\hline $\begin{array}{c}N \\
\text { (número de clientes no sistema) }\end{array}$ & 7,6475 & - & - & 7,62574193 & $\pm 0,00030875$ \\
\hline $\begin{array}{c}\qquad N q_{1} \\
\text { (nr. de clientes na fila do centro 1) }\end{array}$ & - & 0,4431 & - & 0,44292825 & $\pm 0,00001459$ \\
\hline $\begin{array}{c}\quad \mathrm{Nq}_{2} \\
\text { (nr. de clientes na fila do centro 2) }\end{array}$ & - & 3,2 & - & 3,18688163 & $\pm 0,0003009$ \\
\hline $\begin{array}{c}\qquad N q_{3} \\
\text { (nr. de clientes na fila do centro 3) }\end{array}$ & - & 0,2667 & - & 0,26646150 & $\pm 0,00001734$ \\
\hline $\begin{array}{c}N q_{4} \\
\text { (nr. de clientes na fila do centro 4) }\end{array}$ & - & 1,3603 & - & 1,37769200 & $\begin{array}{l}+0,00008161 \\
\end{array}$ \\
\hline $\begin{array}{c}W_{1} \\
\text { (tempo de fila do centro 1) }\end{array}$ & - & 0,0369 & - & 0,03692575 & $\begin{array}{l}+0,00000098 \\
\end{array}$ \\
\hline $\begin{array}{c}W_{2} \\
\text { (tempo de fila do centro 2) }\end{array}$ & - & 0,16 & - & 0,15938588 & $\pm 0,00001324$ \\
\hline $\begin{array}{c}W_{3} \\
\text { (tempo de fila do centro 3) }\end{array}$ & - & 0,0333 & - & 0,03330688 & $\pm 0,00000138$ \\
\hline $\begin{array}{c}W_{4} \\
\text { (tempo de fila do centro 4) }\end{array}$ & - & 0,128 & - & 0,11477750 & $\pm 0,00000545$ \\
\hline
\end{tabular}

Tabela 5.3 - Comparação entre os resultados das soluçöes do Modelo III 


\subsection{Modelo IV: Ambiente Distribuido}

Ao contrários dos anteriores, o modelo IV não considera apenas o servidor de arquivos, e sim um ambiente distribuído por completo (Figura 5.11), tendo a representação dos seguintes elementos: usuários, rede local e o servidor de arquivos. Representa-se o servidor de arquivos por um processador e um disco, da mesma forma que no modelo II. O usuário é representado pelo seu tempo de pensar, de forma que com um centro delay, nomeado de Centro de Pensar, representa-se o tempo de pensar de todos os usuários do sistema.

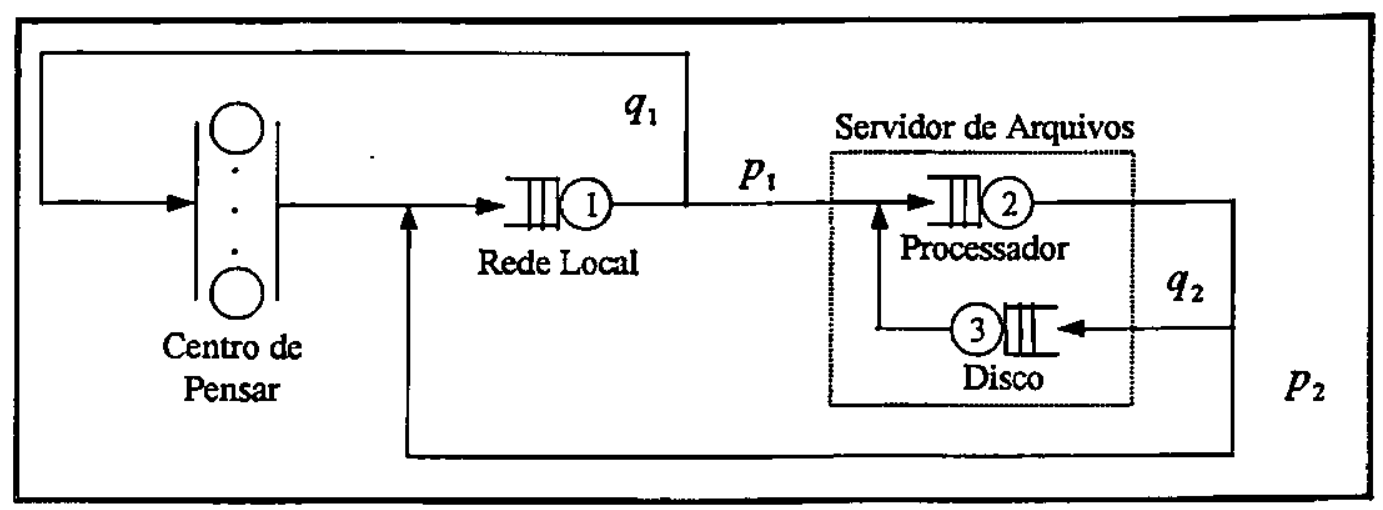

Figura 5.11 - Modelo IV: Ambsente Distribuido

Assim, os usuários fazem solicitações ao servidor de arquivos, que chegam até o mesmo por intermédio de uma rede local de comunicação. A rede local é responsável tanto por enviar as solicitação ao servidor de arquivos, quanto por retornar ao usuário a resposta de sua solicitação. Um usuário, ao receber a resposta de sua solicitação, passa um intervalo de tempo "pensando" e só então envia uma nova solicitação. Sabe-se que esse intervalo é chamado de tempo de pensar, dando origem ao centro de pensar, que é um centro delay, onde cada um de seus servidores representa apenas o tempo de pensar de um usuário. Em relação ao funcionamento do servidor de arquivos, continuam sendo válidas as considerações referentes ao modelo II.

Do mesmo modo que os outros, o modelo IV também possui uma chegada de clientes exponencialmente distribuída, disciplina de fila do tipo FIFO, servidores com atendimento exponencial e classe única de clientes. No entanto, por se tratar de um modelo fechado, não possui uma chegada externa de clientes. Seus parâmetros de entrada são:

$$
\begin{array}{ll}
\mu_{\mathrm{Rede}}=\mu_{1}=30 \rightarrow S_{1}=1 / \mu_{1}=0,0333 & \text { Número de Clientes no Sistema }: N=3 \\
\mu_{\mathrm{Pr} \text { ocessador }}=\mu_{2}=25 \rightarrow S_{2}=1 / \mu_{2}=0,04 & p_{1}=50 \%=0,5 \\
\mu_{\text {disco }}=\mu_{3}=20 \rightarrow S_{3}=1 / \mu_{3}=0,05 & p_{2}=60 \%=0,6
\end{array}
$$




\subsubsection{Análise do Valor Médio (AVM)}

Ao modelo IV, pode-se aplicar o Algoritmo 4.2, referente à Análise de Valor Médio para modelos fechados, também conhecido como Algoritmo AVM Exato. Entretanto, antes de aplicar a solução AVM, deve-se calcular a taxa de visita, $V_{j}$, para cada centro (Allen,1991):

$$
V_{j}=\sum_{i=0}^{M} V_{i} p_{i j},
$$

Onde $M$ é número de centros e $V_{0}$ é a taxa de visita do centro de pensar. A partir dessa expressão, calculam-se:

$$
\begin{aligned}
& V_{0}=V_{0} \underbrace{p_{00}}_{0}+V_{1} \underbrace{p_{10}}_{q_{1}}+V_{2} \underbrace{p_{20}}_{0}+V_{3} \underbrace{p_{30}}_{0} \rightarrow V_{0}=q_{1} V_{1} \\
& V_{1}=\underbrace{V_{0} \underbrace{p_{01}}_{1}}_{1}+V_{1} \underbrace{p_{11}}_{0}+V_{2} \underbrace{p_{21}}_{p_{2}}+V_{3} \underbrace{p_{31}}_{0} \rightarrow V_{1}=1+p_{2} V_{2} \\
& V_{2}=V_{0} \underbrace{p_{02}}_{0}+V_{1} \underbrace{p_{12}}_{p_{1}}+V_{2} \underbrace{p_{22}}_{0}+V_{3} \underbrace{p_{32}}_{1} \rightarrow V_{2}=p_{1} V_{1}+V_{3} \\
& V_{3}=V_{0} \underbrace{p_{03}}_{0}+V_{1} \underbrace{p_{13}}_{0}+V_{2} \underbrace{p_{23}}_{q_{2}}+V_{3} \underbrace{p_{33}}_{0} \rightarrow V_{3}=q_{2} V_{2}
\end{aligned}
$$

Assim,

$$
\begin{aligned}
& V_{0}=q_{1} V_{1}=1 \rightarrow V_{1}=\frac{1}{q_{1}}=2 \\
& V_{1}=1+p_{2} V_{2} \rightarrow V_{2}=\frac{1}{p_{2}}=1,6667 \\
& V_{3}=q_{2} V_{2}=0,6667
\end{aligned}
$$

Tendo-se as taxas de visita, pode-se então aplicar a solução AVM Exata. Para isso, implementou-se o Algoritmo 4.2 usando a linguagem de programação $\mathrm{C}+$, através do qual foram obtidas as seguintes medidas de desempenho:

Desempenho do Sistema:

- Throughput Médio do Sistema: 2,532662

- Tempo Médio de Resposta do Sistema: 0,184524

Desempenho de cada centro:

- Tempo de Resposta do centro 1 (rede): 0,03729

- Tempo de Resposta do centro 2 (processador): 0,044798

- Tempo de Resposta do Centro 3 (disco): 0,052918 
A esses valores, podem-se aplicar as seguintes expressões para obtenção das outras medidas de desempenho:

- Throughput dos centros: $X_{i}=X V_{i} \rightarrow\left\{\begin{array}{l}X_{1}=2,532662 \cdot 2=5,065 \\ X_{2}=2,532662 \cdot 1,6667=4,22 \\ X_{3}=2,532662 \cdot 0,6667=1,6885\end{array}\right.$

- Utilização dos centros: $\rho_{i}=X_{t} S_{i} \rightarrow\left\{\begin{array}{l}\rho_{1}=5,065 \cdot 0,0333=0,1687 \\ \rho_{2}=4,22 \cdot 0,04=0,1688 \\ \rho_{3}=1,6885 \cdot 0,05=0,0844\end{array}\right.$

Para o Centro de Pensar, no decorrer do Algoritmo 4.2, não são calculadas sequer uma medida de desempenho, já que esse centro se encontra representado pelo tempo de pensar, denotado como $Z$. Entretanto, finalizada a execução do referido algoritmo, podem-se aplicar ao centro de pensar as equações para o cálculo do throughput e da utilização:

- Medidas de Desempenho do Centro de Pensar:

- Thronghput: $X_{i}=X V_{i} \rightarrow X_{0}=X V_{0}=2,532662 \cdot 1=2,532662$

- Utilização: $\rho_{i}=X_{i} S_{i} \rightarrow \rho_{0}=X_{0} Z=2,532662 \cdot 1=2,532662$

\subsubsection{Decomposição Hierárquica}

A decomposição hierárquica é uma outra forma de se solucionar o Modelo IV, já que se trata de um modelo mais complexo, quando comparado com os demais deste capítulo. Podese então fazer uso do Algoritmo 4.6.

O algoritmo é composto por 5 passos, que serão descritos detalhadamente a seguir, considerando-se o Modelo IV e seus parâmetros de entrada.

\section{Aplicação do Algoritmo 4.6:}

- Passo 1: seleciona-se uma porção do sistema para ser o agregado. No caso do Modelo IV, escolhe-se arbitrariamente a porção que corresponde ao processador e disco para compor o agregado, denominando-se de complemento o restante do modelo. 


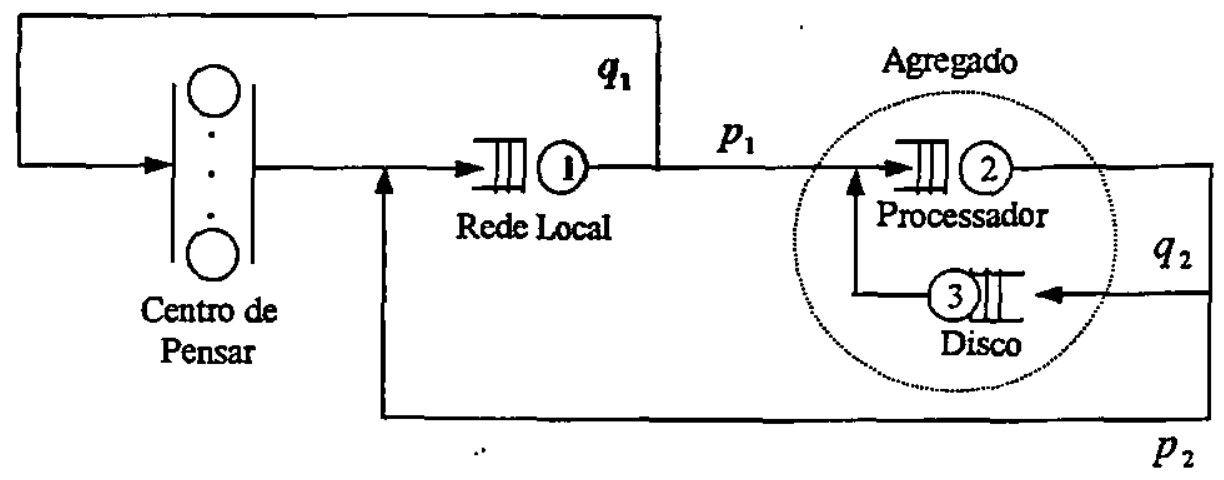

Figura 5.12 - Passo 1 da Decomposiçáo Hierárquica do modelo IV

- Passo 2: Cria-se um submodelo (nivel 1), no caso do desse modelo, atribuindo-se zero ao tempo de serviço do Centro de Pensar e do Centro 1 (rede), o que equivale a eriar um modelo com os centros que compōem o agregado.

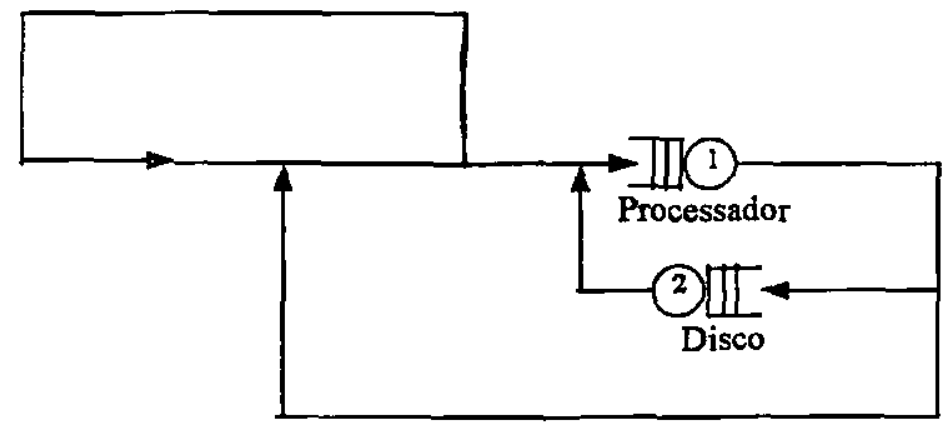

'Figura 5.13 - Passo 2 da Decomposiçäo Hierárquica do Modelo IV

- Passo 3: Soluciona-se o modelo criado no passo 2 (modelo do nível 1). Para esse caso, será usado o método de Gordon e Newell, utilizando-se probabilidade condicional para as medidas de desempenho dos centros de serviço desse modelo. A solução do modelo do nível 1 é dada por.

Consideram-se os seguintes parâmetros de entrada:

$N=3$ clientes

$\mu_{1}=25 \rightarrow S_{1}=0,04$

$\mu_{2}=20 \rightarrow S_{2}=0,05$

$V_{1}=1,6667$ e $V_{2}=0,6667$

Por intermédio de $D_{i}=S_{i} V_{i}$, calculam-se as demandas:

$D_{1}=0,0667$ e $D_{2}=0,0333$, 
Possuindo os valores de $D_{i}$, pode-se então aplicar o método de Gordon e Newell, obtendo-se os seguintes valores para o throughput.

- Throughput đo sistema quando há 1 cliente no sistema: $X(1)=9,995$

- Throughput đo sistema quanđo há 2 clientes no sistema: $X(2)=12,8507$

- Throughput do sistema quando há 3 clientes no sistema: $X(3)=13,993$

Ao final do Passo 5, serão calculadas as medidas de desempenho dos centros de serviço desse modelo do nível 1.

- Passo 4: Representa-se o agregado por um centro especial, denominado FESC, construindo assim um modelo equivalente ao modelo (modelo mostrado na Figura 5.12), que passa a compor o nível 0 (zero) da decomposição hierárquica. O FESC é um centro de serviço com taxa de serviço, para $n$ clientes, igual ao throughput do modelo criado no passo 2 (Figura 5.13), também para $n$ clientes. Ou seja, para o FESC, consideram-se: $\quad \mu_{2}(1)=X(1)=9,995 ; \quad \mu_{2}(2)=X(2)=12,8507 \quad \mathrm{e}$ $\mu_{2}(3)=X(3)=13,993$

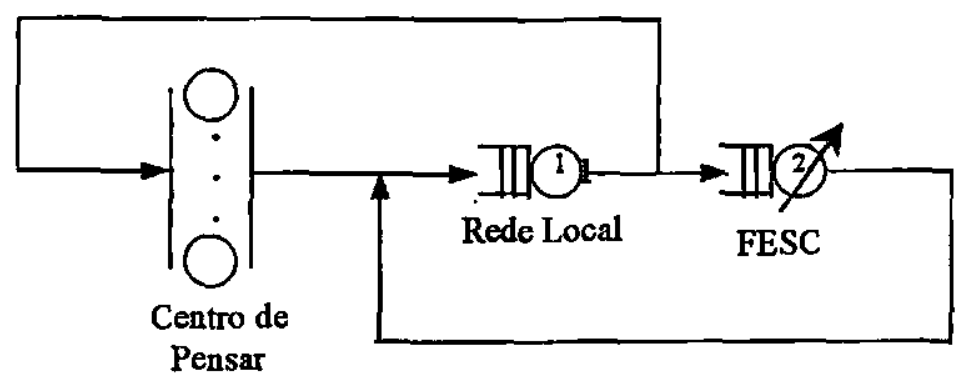

Figura 5.14 - Passo 4 da Decomposiçáo Hierárquica do Modelo IV - Modelo do NIvel $O$

- Passo 5: Soluciona-se o modelo equivalente (modelo do nível 0), usando o método de Análise de Valor Médio do Algoritmo 4.4, descrito no capítulo anterior, por se tratar de um método para avaliar centros de serviço dependentes de carga. Para essa solução, consideram-se como parâmetros de entrada:

$N=3$ clientes $; Z=l ; \quad V_{1}=2$ e $V_{2}=1$

$\mu_{1}=30 \rightarrow S_{1}=0,0333$

$\mu_{2} \rightarrow\left\{\begin{array}{l}\mu_{2}(1)=X(1)=9,995 \\ \mu_{2}(2)=X(2)=12,8507 \\ \mu_{2}(3)=X(3)=13,993\end{array}\right.$ 
Aplicando-se o Algoritmo 4.4, obtêm-se algumas medidas de desempenho para o modelo equivalente (Figura 5.14 - nivel 0), que correspondem à avaliação de desempenho do modelo original (Figura 5.12):

- Throughput do Sistema: $X(3)=2,5327$

- Tempo de Resposta do Sistema: $R(3)=0,1845$

- Tempo de Resposta do Centro 1 (Rede) : $R_{1}(3)=0,0373$

- Tempo de Resposta do Centro 2 (FESC): $R_{2}(3)=0,1099$

Medidas de desempenho adicionais podem ser calculadas, tanto para o modelo do nível 0 , quanto do nível 1 . De acordo com o exposto no capitulo anterior, na seção referente à Decomposição Hierárquica, tanto para modelo do nível 0 , quanto para o do nivel 1 , podem-se utilizar as seguintes expressões:

Centros do Modelo do Nivel 0:

- Throughput da Rede: $X_{R}=X V_{R}=2,5327 \cdot 2=5,0654$

- Throughput do FESC: $X_{\text {FESC }}=X V_{\text {FESC }}=2,5327 \cdot 1=2,5327$

- Throughput do Centro de Pensar. $X_{C P}=X V_{C P}=2,5327 \cdot 1=2,5327$

- Utilizaçāo da Rede: $\rho_{R}=X_{R} S_{R}=5,0654 \cdot 0,0333=0,1687$

- Utilizaçâo do FESC: $\rho_{\text {FESC }}=1-p(0 \mid N)=1-0,7561=0,2439$

- Utilização do Centro de Pensar : $\rho_{C P}=X_{C P} S_{C P}=2,5327 \cdot Z=2,5327$

Centros do Modelo do Nível 1 :

- Throughput do Processador: $X_{P}=X V_{P}=2,5327 \cdot 1,6667=4,2213$

- Throughput do Disco: $X_{D}=X V_{D}=2,5327 \cdot 0,6667=1,6886$

- Utilizaçăo do Processador: $\rho_{P}=X_{P} S_{P}=0,1689$

- Utilização do Disco: $\rho_{D}=X_{D} S_{D}=0,0844$

\subsubsection{Limites de Desempenho}

Para o cálculo dos limites de desempenho, em específico, dos limites assintóticos do quarto e último modelo, aplica-se o Algoritmo 4.7, sendo o número de centros de serviço do modelo é igual a $3(k=3)$. O algoritmo necessita também da utilização de cada centro de serviço $\left(\rho_{k}\right)$, que, de acordo com a solução AVM desse modelo, correspondem a $\rho_{1}=0,1687, \rho_{2}=0,1688$ e $\rho_{3}=0,0844$. 
Outra informação importante, também solicitada pelo Algoritmo 4.7, refere-se ao valor do tempo de pensar, $Z$, que nesse caso não eqüivale a zero, já que se trata de um modelo fechado. Esse valor deve ser conhecido e fornecido como parâmetro de entrada. Para o Modelo IV, considera-se $\mathrm{Z}=1$.

Tendo todas essas informações, aplica-se então o Algoritmo 4.7, para o cálculo dos limites assintóticos do modelo em referência, obtendo-se os seguintes valores:

$$
\begin{aligned}
& D_{k}=V_{k} \cdot S_{k} \rightarrow\left\{\begin{array}{l}
D_{1}=0,0666 \\
D_{2}=0,0667 \\
D_{3}=0,0333
\end{array}\right. \\
& D=\sum_{k=1}^{k} D_{k}=0,1666 \\
& D_{\max }=\max _{k} D_{k}=0,0667 \\
& N^{*}=\frac{D+Z}{D_{\max }}=17,4903
\end{aligned}
$$

Ainda por intermédio do Algoritmo 4.7, obtêm-se os pontos que compõem os gráficos dos limites de assintóticos do throughput e do tempo de resposta do sistema.

O gráfico dos limites do throughput do sistema é dado pelos pontos:

\section{Limite Otimista:}

$$
\begin{aligned}
& (0,0) \text { e }\left(1, \frac{1}{D+Z}\right) \text { para } N \leq N^{\star} \rightarrow(0 ; 0) \text { e }(1 ; 0,8572) \\
& \left(0, \frac{1}{D_{\max }}\right) \text { e }\left(1, \frac{1}{D_{\max }}\right) \text { para } N \geq N^{\star} \rightarrow(0 ; 14,9925) \text { e }(1 ; 14,9925)
\end{aligned}
$$

Limite Pessimista: Este limite não é linear em $N$.

O gráfico dos limites do tempo de resposta do sistema é dado pelos pontos:

\section{Limite Otimista:}

$$
\begin{gathered}
(0, D) \text { e }(1, D) \text { para } N \leq N^{*} \rightarrow(0 ; 0,1666) \text { e }(1 ; 0,1666) \\
(0,-Z) \text { e }\left(1, D_{\max }-Z\right) \text { para } N \geq N^{*} \rightarrow(0 ;-1) \text { e }(1 ;-0,9333) \\
\text { Limite Pessimista: }(0,0) \text { e }(1, D) \rightarrow(0 ; 0) \text { e }(1 ; 0,1666)
\end{gathered}
$$

Tendo-se esses pontos, os gráficos dos limites de assintóticos para o throughput e para o tempo de resposta do Modelo III são traçados, obtendo-se então o Gráfico 5.7. De acordo com a solução AVM do Modelo IV, o throughput médio do sistema é igual a 2,532662 quando existem 3 clientes no sistema. Esse throughput, como desejado, encontra-se na área que fica abaixo do gráfico (ponto na cor vermelha). 


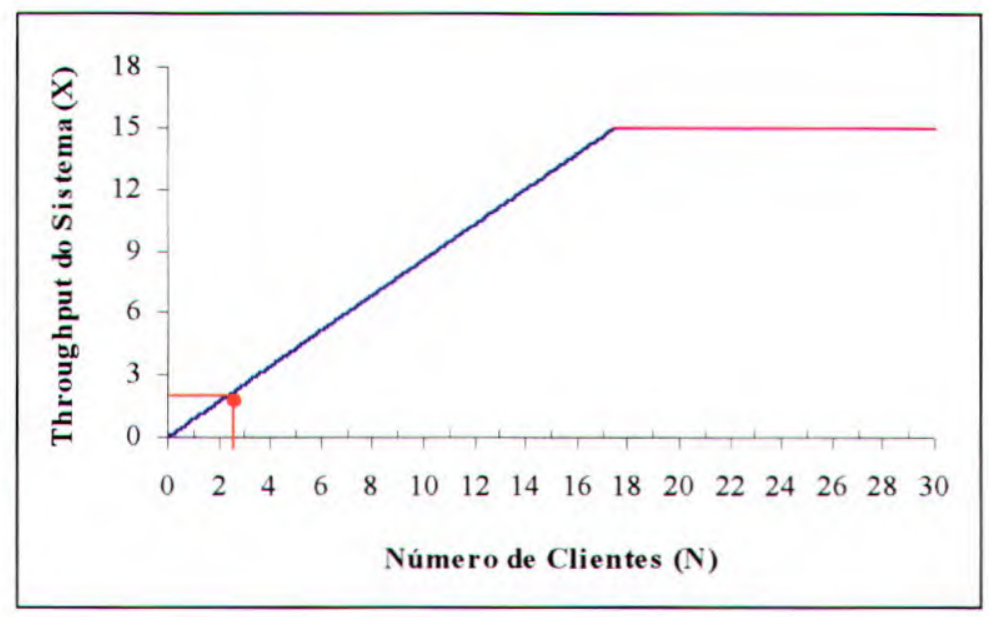

Gráfico 5.7 - Limite Otimista do Throughput do Modelo IV

Representando os limites assintóticos do tempo de resposta do sistema, tem-se o Gráfico 5.8 , composto tanto pelo limite otimista (retas nas cores azul e rosa), quanto pessimista (reta na cor verde), simbolizando que o valor do tempo de resposta do sistema deve estar na área delimitada por esses limites. Nesse gráfico, mostra-se que o tempo de resposta do Modelo IV se encontra dentro da área esperada (ponto na cor vermelha), já que, segundo a solução AVM, o valor do tempo de resposta do sistema é igual a 0,184524, quando existem 3 clientes presentes no sistema.

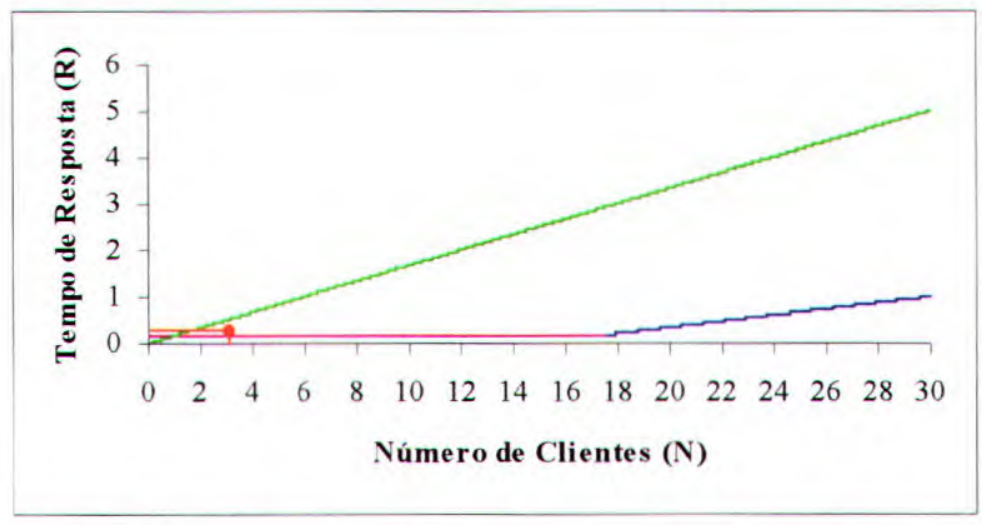

Gráfico 5.8 - Limites do Tempo de Resposta do Modelo IV

\subsubsection{Simulação}

Na simulação do Modelo IV também utilizando-se o AssiA, os seguintes parâmetros de entrada foram considerados: $S_{1}=0,0333$ (tempo de serviço do centro 1), $S_{2}=0,04$ (tempo de serviço do centro 2), $S_{3}=0,05$ (tempo de serviço do centro 3); $n=3$ (número de 
clientes no sistema), e distribuições exponenciais para o tempo de serviço e para o tempo entre chegadas.

Nota-se que, por se tratar de um modelo fechado, não mais é fornecido o tempo entre chegadas. Ao invés disso, informa-se o número de clientes que tiveram acesso ao sistema durante a simulação, simbolizado, no ASiA, pelo número de eventos. Além disso, também por ser um modelo fechado, não mais é fornecido o tempo de execução te, substituindo-se tal informação pelo que o ASiA conhece como número de ciclos, considerado no exemplo igual a 99.999.999.999.999 ciclos (Brushi, 1997).

Para a simulação são consideradas 8 execuçōes (replicaçōes), cada uma .com um comprimento equivalente a 99.999.999.999.999 ciclos e os resultados apresentados são valores médios, com o correspondente intervalos de confiança de 95\% (MacDougall, 1989).

Simulando-se o Modelo III, para cada uma das execuções, obtêm-se como saída padrão um relatório contendo os resultados da simulação, dentre os quais destacam-se a utilizaçä̃o e o comprimento médio de fila. A Figura 5.15 apresenta o relatório correspondente à semente 0 (zero), uma das 8 sementes de números aleatórios.

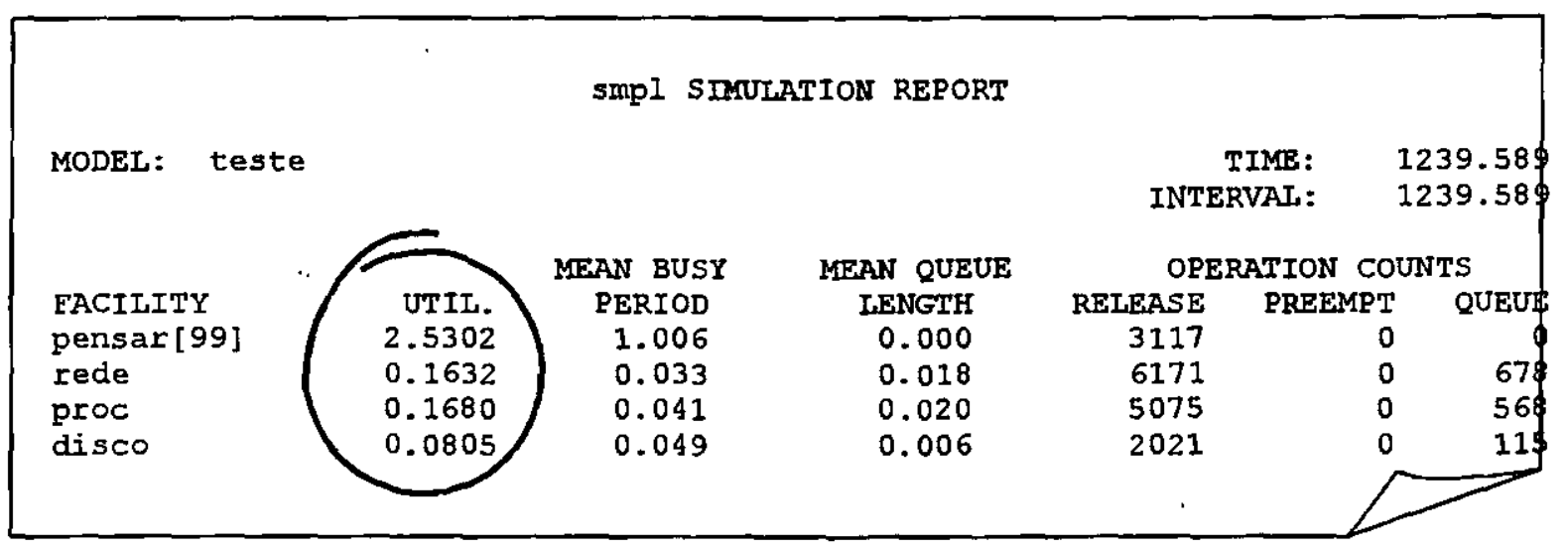

Figura 5.15 - Relatório de Simulação do Modelo IV para a semente 0

Assim como nas simulações dos modelos anteriores, medidas de desempenho adicionais foram obtidas para o Modelo IV. A Figura 5.16 apresenta as medidas de desempenho adicionais obtidas para a execuçāo de semente 0 (zero) (MacDougall, 1989):

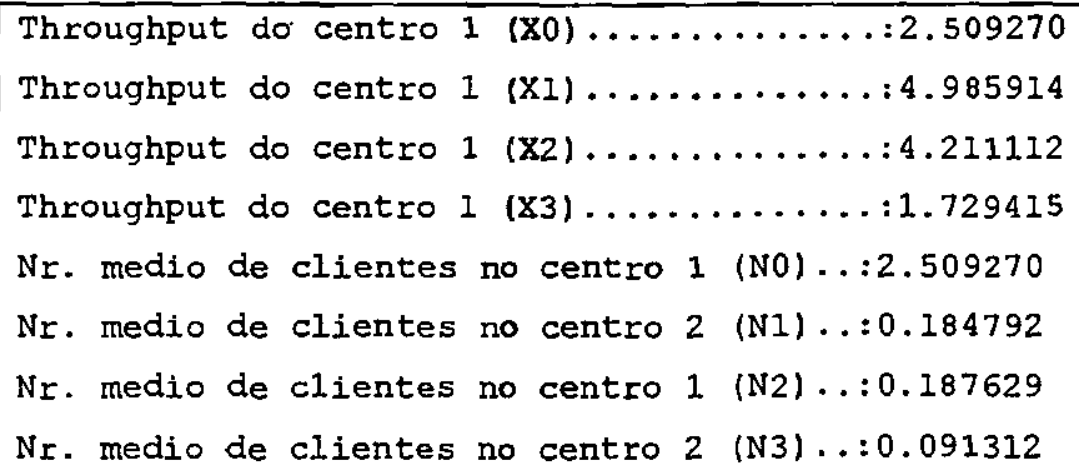




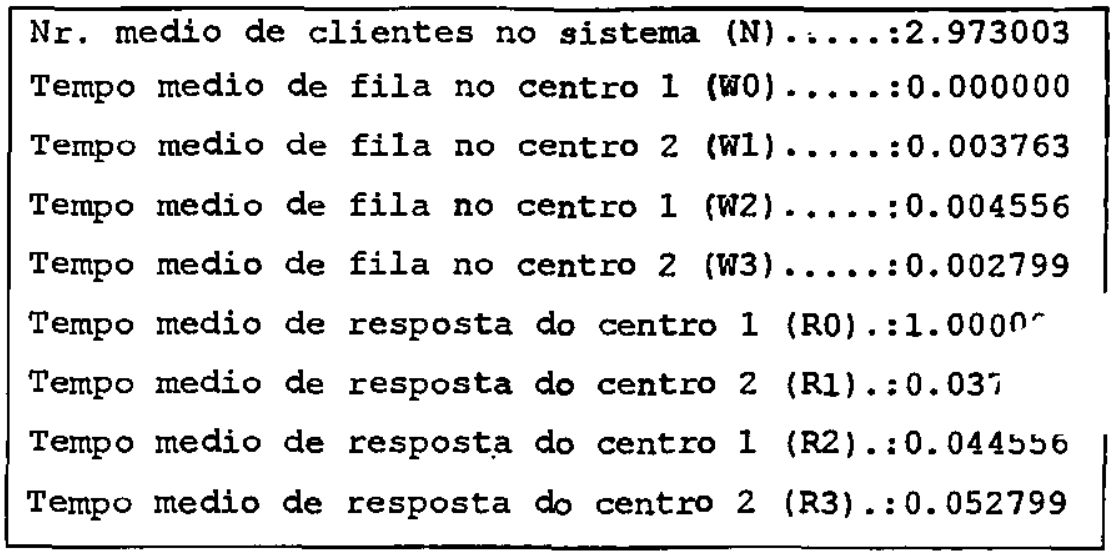

Figura 5.16 - Medidas de desempenho adicionais para o Modelo IV - semente 0

Com os resultados da simulação, que correspondem à média das 8 execuçōes (replicação), confrontam-se seus resultados com os obtidos nas soluções analíticas, sendo possivel constatar a equivalência dos mesmos, como mostra a tabela a seguir.

\begin{tabular}{|c|c|c|c|c|c|}
\hline & \multicolumn{3}{|c|}{ Soluç̄es Analiticas } & \multirow{2}{*}{\multicolumn{2}{|c|}{$\frac{\text { Simulaçẫo }}{\text { ASIA }}$}} \\
\hline & $\begin{array}{c}\text { Análise do } \\
\text { Valor Médio }\end{array}$ & $\begin{array}{l}\text { Decomposição } \\
\text { Hierárquaica }\end{array}$ & $\begin{array}{c}\text { Limites de } \\
\text { Desempenho }\end{array}$ & & \\
\hline $\begin{array}{c}X \\
\text { (throughput do sistema) }\end{array}$ & 2,532662 & 2,5327 & OK & & \\
\hline $\begin{array}{c}R \\
\text { (tempo de resposta do sistema) }\end{array}$ & 0,184524 & 0,1845 & OK & & \\
\hline $\begin{array}{c}R_{1} \\
\text { (tempo de resposta do rede) }\end{array}$ & 0,03729 & 0,0373 & - & 0,03718938 & + \\
\hline $\begin{array}{c}R_{2} \\
\text { (tempo de resposta do processador) }\end{array}$ & 0,044798 & - & - & 0,04480700 & $\pm 0,00022552$ \\
\hline $\begin{array}{c}R_{3} \\
\text { (tempo de resposta do disco) }\end{array}$ & 0,052918 & - & - & 0,05287325 & $\pm 0,00028714$ \\
\hline $\begin{array}{c}\rho_{0} \\
\text { (utilização do centro de pensar) } \\
\end{array}$ & $2,532662 \rightarrow 2,5 \%$ & $2,5327 \rightarrow 2,5 \%$ & - & 2,51654700 & $\pm 0,01406890$ \\
\hline $\begin{array}{c}\rho_{1} \\
\text { (utilização da rede) }\end{array}$ & $0,1687 \rightarrow 17 \%$ & $0,1687 \rightarrow 17 \%$ & - & 0,16699675 & $\pm 0,00253142$ \\
\hline $\begin{array}{c}\rho_{2} \\
\text { (utilização do processador) } \\
\end{array}$ & $0,1688 \rightarrow 17 \%$ & $1,1689 \rightarrow 17 \%$ & - & 0,16799775 & + 0,00194873 \\
\hline $\begin{array}{c}\rho_{3} \\
\text { (utilização do disco) }\end{array}$ & $0,0844 \rightarrow 8,4 \%$ & $0,0844 \rightarrow 8,4 \%$ & - & 0.08372075 & $\pm 0,00210247$ \\
\hline $\begin{array}{c}X_{0} \\
\text { (throughput do centro de pensar) }\end{array}$ & 2,532662 & 2,5327 & - & 2,51581813 & $\pm 0,01447169$ \\
\hline $\begin{array}{c}X_{1} \\
\text { (throughput da rede) }\end{array}$ & 5,065 & 5,0654 & - & 5,01491850 & $+0,07601287$ \\
\hline $\begin{array}{c}X_{2} \\
\text { (throughput do processador) }\end{array}$ & 4,22 & 4,2213 & - & 4,19994725 & $+0,04871661$ \\
\hline $\begin{array}{c}X_{3} \\
\text { (throughput do disco) }\end{array}$ & 1,6885 & 1,6886 & - & 1,67441513 & $+0,04204562$ \\
\hline
\end{tabular}




\subsection{Considerações Finais}

Ao longo deste capítulo alguns modelos foram solucionados por métodos analíticos e por simulação. Esses exemplos representam situações práticas o bastante, em particular, em ambientes computacionais distribuídos. Os resultados obtidos através das diversas soluções analíticas foram comparados aos obtidos nas simulações, sendo sempre equivalentes. Isso demonstra que o ferramental analítico pode, potencialmente, ser utilizado em diversas situações práticas, envolvendo elementos de um sistema computacional distribuído. As simulações serviram, de outra forma, como um parâmetro para validação dos resultados obtidos analiticamente. 


\section{Capítulo 6}

\section{Conclusão}

\section{1 Considerações Iniciais}

A solução de modelos de rede de filas para sistemas computacionais distribuidos, considerando métodos analíticos e simulação foi abordada como tema central desta dissertação.

Assim, os seguintes métodos analíticos foram discutidos: Análise de Valor Médio (AVM), Rede de Jackson, Método de Gordon e Newell, Redes BCMP, Decomposição Hierárquica, Limites de Desempenho e Processo Nascimento-e-Morte;

O método de Análise de Valor Médio é um dos mais simples, consistindo na aplicação de algoritmos de fácil entendimento, podendo ser aplicado a modelos abertos ou fechados com uma variedade de disciplinas de atendimento, de distribuições de tempo de serviço e com única ou múltipla classe de clientes. Além disso, no caso de modelos fechados, pode-se aplicar o método AVM também para modelos que possuem centros de serviço dependentes de carga.

A Rede de Jackson é também um método simples, porém aplicável somente a modelos abertos que obedecem a um certo conjunto de condições, como distribuições exponenciais para o tempo de chegada e de atendimento do modelo, o que restringe bastante o seu uso. Considerando-se esse mesmo grupo de condições, Gordon e Newell apresentam uma solução abrangendo modelos fechados, caracterizando-se como uma extensão da Rede de Jackson. O método de Gordon e Newell é também simples e de aplicação restrita.

O método de Redes BCMP corresponde a uma generalização de Redes de Jackson e do método de Gordon e Newell, por apresentar uma solução analítica para modelos tanto abertos, como fechados. Além disso, ao contrário dos outros dois métodos, um grupo de condições mais abrangente é aplicado aos modelos, o que torna sua utilização menos restrita.

A decomposição hierárquica é o método aconselhado para modelos com um grau de complexidade elevado, onde um modelo grande é dividido em submodelos menores, onde 
cada um desses submodelos são avaliados separadamente e suas soluções individuais são combinadas para obter a solução do modelo original. $\mathbf{O}$ método de decomposição hierárquica pode ser aplicado a modelos abertos ou fechados, com uma ou múltiplas classes de clientes e com uma variedade de disciplinas de atendimento e de distribuições de tempo de serviço. Esse não é um dos métodos analíticos mais simples, entretanto, possui a grande vantagem de poder ser aplicado a modelos complexos, caso em que geralmente se emprega a simulação.

O cálculo de limites de desempenho, além de simples, é um método rápido, podendo até ser feito manualmente, sendo aplicado a modelos abertos e fechados. Esse método consiste em calcular limites inferiores e superiores do througput do sistema e do tempo de resposta, como funções do número ou taxa de chegada dos clientes. $O$ cálculo de limites pode ser usado, por exemplo, para eliminar alternativas inadequadas.

Uma outra forma de solucionar um modelo aberto é descrevendo o seu comportamento como um processo nascimento-e-morte. Nesse método, considerando-se $n$ como o estado atual do modelo, a chegada de um novo cliente, representada por $\lambda$, muda o estado do sistema para $n+1$, sendo chamado de nascimento. Da mesma forma, a saida de um cliente, representada por $\mu$, muda o estado para $n-1$, sendo chamado de morte. Esse não é um dos métodos mais simples, exceto, por exemplo, para o caso do modelo $M / M / 1$, que já possui diversas equações previamente definidas.

Respeitando-se suas restrições e particularidades, cada um desses métodos analíticos foram aplicados a diversos modelos que representam elementos fundamentais de um sistema computacional distribuído, como servidor de arquivos, rede de comunicação, etc.

Além dos métodos de solução analítica, considerou-se também a solução por simulação, através do emprego do ASiA, possibilitando-se assim a discussão e comparação dos resultados obtidos tanto analiticamente, como por simulação, constatando-se uma equivalência, o que demonstra que os métodos analíticos abordados por esta dissertação, podem ser aplicados com êxito a modelos relevantes da área de sistemas computacionais distribuídos.

\subsection{Contribuições desta Dissertação}

Considerando o trabalho desenvolvido nesta dissertação, têm-se as seguintes contribuições:

Na revisão bibliográfica, nota-se que os diversos métodos de solução analitica são geralmente encontrados distribuídos em diversas referências bibliográficas inerente 
ao assunto. Assim, esta dissertação traz como contribuição o fato de reunir os estudos de diversos métodos analíticos, tendo ainda para cada método uma abordagem teórica e prática, apresentadas de forma adequada para a área de sistemas computacionais distribuidos;

Abstração dos pontos importantes do estudo teórico de diversos métodos analíticos, proporcionando ao leitor da dissertação o entendimento do método sem ser necessário discutir em detalhes deđuções matemáticas complexas, ao contrário de boa parte da literatura, fato que dificulta o estudo de métodos analíticos para os interessados em aplicações práticas na área de sistemas computacionais distribuídos;

Grande parte da literatura estudada apresenta a solução de modelos que representam elementos gerais da computação, não especificamente da área de sistemas computacionais distribuídos. Dessa forma, além da solução analítica de modelos relevantes à área de sistemas distribuídos, contribui-se também com o fato de se aplicar diversos métodos analíticos a cada um dos modelos;

A equivalência observada entre os valores obtidos com a simulação e com os métodos analíticos, serve como parâmetro para auxiliar um usuário da área de sistemas computacionais distribuídos interessado em analisar um dado elemento, na escolha do método mais adequado;

Os diversos exemplos estudados contribuem para o estabelecimento de diretrizes para auxiliar as decisões em estudos posteriores sobre sistemas computacionais distribuídos, resultando numa espécie de guia de solução analítica, já que nesta dissertação não se exige que o leitor possua conhecimentos profundos a respeito das abordagens analiticas.

\subsection{Dificuldades Encontradas}

Inúmeras foram as dificuldades encontradas no desenvolvimento deste trabalho, destacando-se:

Seleção adequada de diversos métodos analíticos que se encontram distribuídos em vários livros e artigos; 
Compreensão dos métodos analíticos para posteriormente formular uma redação que os apresente de forma simples e clara, objetivando-se que o leitor da área de sistemas computacionais distribuídos possa ler e entender facilmente cada método, mesmo sendo no campo analítico. Essa tarefa foi bastante dificultada pelo fato de haver poucas publicações da área de computação abordando os métodos analíticos, sendo grande parte da literatura puramente da área de processos estocásticos;

Além de explicar de forma clara, objetivou-se a aplicação de cada um dos métodos abordados, o que não é uma tarefa fácil, pois, se entender plenamente o mẹétodo é, muitas vezes, complicado, aplicá-lo a exemplos práticos, pode ser mais dificil ainda.

Foram encontradas poucas publicações abrangendo métodos analíticos mais recentes, como é o caso da Decomposição Hierárquica, havendo assim, poucos exemplos práticos de aplicações desse método.

\subsection{Trabalhos Futuros}

Aplicação dos métodos estudados nesta dissertação a outros modelos relevantes à área de sistemas distribuídos;

Ampliação do estudo desenvolvido neste trabalho, incluindo-se novos métodos analíticos, para que se possa assim estender o domínio de aplicação;

\subsection{Considerações Finais}

Diante dos objetivos e motivações inicialmente propostos para este trabalho de mestrado, constata-se que os resultados esperados foram plenamente alcançados, tendo-se como principal conquista um estudo abrangente de diversos métodos de solução analítica para modelos de rede de filas aplicados à área de sistemas computacionais distribuidos. Além dos métodos analíticos, considerou-se também a solução por simulação, que permitiu, dessa forma, a apresentação, discussão e comparação dos resultados obtidos tanto analiticamente como por simulação, constatando-se uma equivalência.

Acredita-se que, com base nos métodos e exemplos discutidos nesta dissertação, outros experimentos visando avaliar o desempenho em sistemas computacionais distribuídos, possam ser mais facilmente desenvolvidos. 


\section{Referências Bibliográficas}

(Allen, 1990)

ALLEN, Arnold O., Probability, Statistics, and Queueing Theory - With Computer Science Applications, $2^{\text {a }}$ Edição, Academic Press, 1990.

(Brushi,1997) BRUSHI, Sarita, Extensão de ASiA pra Simulação de Arquitetura de Computadores, Instituto de Ciências Matemáticas e de Computação-ICMC/USP, Setembro, 1997.

(Buzen,1973) BUZEN, J. P., Computational Algorithms for Closed Queueing Networks with Exponential Servers, Comunications ACM, 16(9), 527-531.

(Farias,1991) FARIAS, A. A., SOARES; J. F.; CESAR, C. C., Introdução à Estatística, Guanabara Koogan S.A., 1991.

(Fernandes,1992) FERNANDES, Márcio Nerino, Modelagem Analítica de Desempenho de Sistemas Multiprocessadores: Aplicação ao Multiprocessador CPER, Dezembro, 1992.

(Francês, 1998) FRANCÊS, Carlos Renato Lisboa; Stochastic Feature Charts Uma Extensão Estocástica para os State Charts, Instituto de Ciências Matemáticas e de Computação -ICMC/USP, Abril, 1998.

(Jain,1991) JAIN, Raj, The Art of Computer Systems Performance Analysis - Tecnichniques for Experimental Design, Measurement, Simulation e Modeling, John Wiley e Sons Inc, 1991.

(Kleinrock, 1975) KLEINROCK, Leonard, Queueing Systems - Volume I: Theory, John Wiley e Sons Inc, 1975. 
(Kleinrock,1976) KLEINROCK, Leonard, Queueing Systems - Volume II: Computer-Applications, John.Wiley.e-Sons Inc,-1976.

(Lazowska,1984) LAZOWSKA, Edward D.; ZAHORJAN, John; GRAHAM, G. Scott; SEVCIK, Kenneth C.; Quantitative System Performance: Computer System Analysis Using Queueing Network Models; Prentice-Hall, New Jersy, 1984.

(MacDougall,1989) MACDOUGALL, Myron H. Simulation Computer System Techniques and Tools, The MIT Press, 1989

(Maciel,1996) MACIEL, P. R. M., LINS, R. D., CUNHA, P. R. F., Introdução às Redes de Petri e Aplicações, $10^{a}$ Escola de Computação, Campinas, Julho, 1996.

(Menascé,1985) MENASCÉ, Daniel Na; AĩMEIDA, Virgílio Na F., Planejamento de Capacidade de Sistemas de Computação: análise operacional como ferramenta, Ed. Campus Ltda, Rio de Janeiro, 1985.

(Orlandi,1995) ORLANDI, Regina Célia G. S, Ferramentas para Análise de Sistemas Computacionais Distribuídos, Dissertação de Mestrado, Instituto de Ciências Matemáticas de Na Carlos ICMSC, Universidade de Na Paulo - USP, Março, 1995.

(Santana, 1990) SANTANA, Marcos José, Na Advanced Filestore Architeture for a Multiple - Lan Distributed Computing System, PHD Thesis, University of Southamptom, January, 1990.

(Santana,1990a) SANTANA, Regina Helena G., Performance Evalution of Lan-Based File Serves, PHD Thesis, University of Southamptom, January, 1990. 
(Santana,1997) SANTANA, Marcos José; SANTANA, Regina Helena C.; FRANCÊS; Garlos Renato Lisboa; ORLANDI, Regina Célia G. S, Tools and Methodologies For Performance Evalution Of Distributed Computing System - A Comparison Study in The Proceedings of the 1997, Porland, Oregon, USA, 1997.

(Soares, 1990) SOARES, . Luiz Fernando G., Modelagem e Simulação Discreta de Sistemas, IME-USP, 1990.

(Weicker, 1990) WEICKER, R., An Overview of Common Benchmarks, IEEE . Computer, 65-75, Dezembro, 1990.

(Westphall,1987) WESTPHALL, Carlos B.; TAROUCO, Liane Margarida R. Medidas Para Avaliar Desempenho Em Redes, XX Congresso Nacional de Informática, Vol.2, 722-726, São Paulo, 1987.

(Tanenbaum, 1995) TANENBAUM, Andrew S., Distributed Operating Systems, Prentice Hall International Inc., 1995. 